\title{
MEAN AND FLUCTUATING VELOCITY CONTOURS \\ AND ACOUSTIC CHARACTERISTICS OF SUBSONIC AND SUPERSONIC JETS
}

By H.T. Nagamatsu, R.E. Sheer, Jr., and E.C. Bıgelow

\author{
Prepared under Contract No. NASW-1784 by \\ GENERAI ELECTRIC RESEARCH AND DEVELOPMENT CENTER \\ Schenectady, New York
}

for NASA Headquarters, Office of Advanced

Research and Technology, Research Division

COLOR HLUSTRP III BEACK AND WHATE

September 15,1970
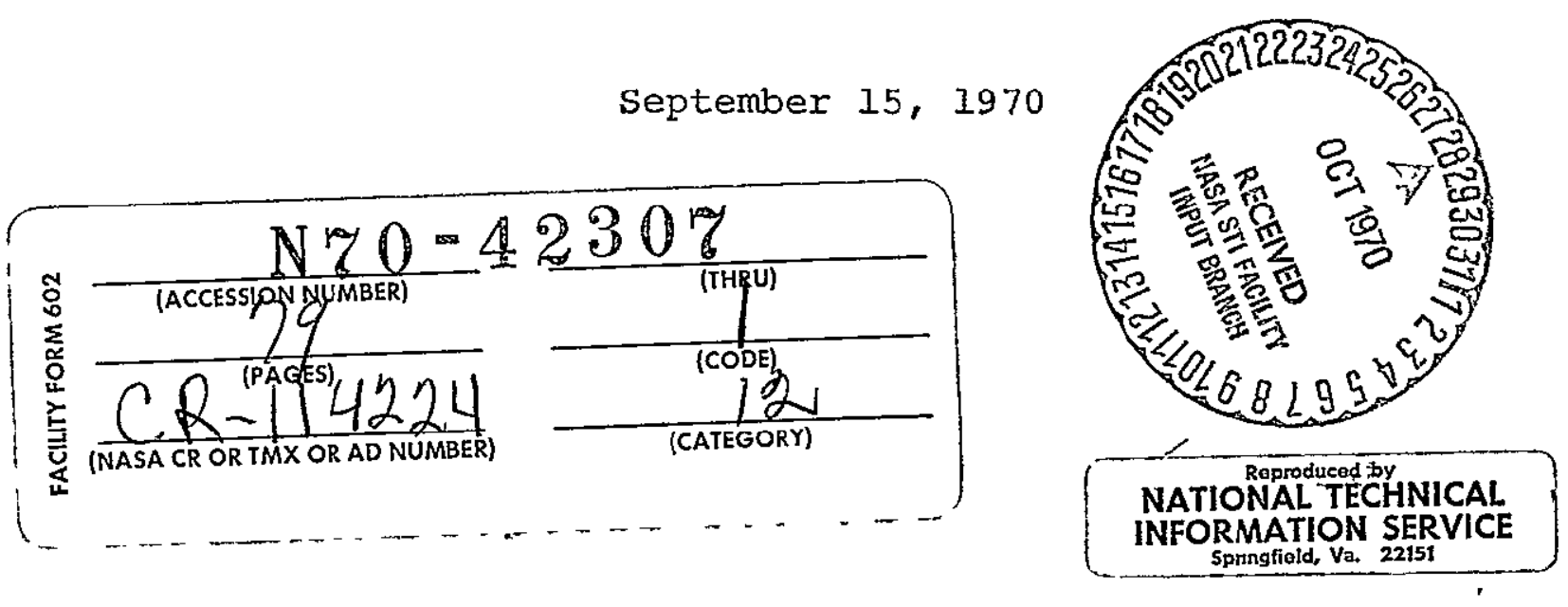


\section{FOREWORD}

This report was prepared under contract No. NASW-1784 for NASA Headquarters, Office of Advanced Research and Technology, Research Division, under the technical direction of Mr. I.R. Schwartz. The work was conducted at the Mechanical Englneering Iaboratory, General Electrıc Research and Development Center in Schenectady, New York. 
Spark shadowgraph photographs of the jet flow at Mach numbers of 0.6 to 1.4 were obtalned which indicated the presence of shock bottles for supersonic Mach numbers. Mean and fluctuating velocities contours were determined for a convergent nozzle from the surveys with impact pressure and piezoelectric pressure gage probes. The velocity and piezoelectric pressure fluctuation contours were similar for subsonic Mach numbers of 0.6 to 1.0 . But for supersonic Mach numbers of 1.2 and 1.4 the length of the supersonic region increased as the square of the Mach number and the peak pressure fluctuations occurred close to the sonzc velocity contour. For subsonic Mach numbers of 0.6 to 1.0 the peak pressure fluctuations occurred in a toroldal region located approximately 4 to 6 diameters from the nozzle. An analysis was made to show that the output of the piezoelectric pressure gage was proportional to the turbulent velocity fluctuations. Downstream of the core region for subsonic Mach numbers the velocity decay along the axis varied as $x^{-1}$ in the fully developed turbulent region and for supersonic Mach numbers of 1.2 and 1.4 the velocity decay downstream of the sonlc location was also $\mathrm{x}^{-1}$. The piezoelectric pressure fluctuations along the axis in fully developed turbulent subsonic flow varied as $\mathrm{x}^{-1.74}$ for both subsonic and supersonic jet Mach numbers.

The normalized overall sound pressure levels for subsonic jet Mach numbers of 0.6 to 1.0 were sumlar wj th the pressure level decreasing monotonically with angle from the axis. But for supersonic Mach numbers the overall sound pressure levels decreased initially and then increased with angle due to the existence of shock bottles. The normalized sound power spectra for subsonic Mach numbers were similar and for supersonic Mach numbers the power spectra shifted to the higher frequencies. overall sound power increased as $\mathrm{U}_{j}^{\&}$ for subsonlc Mach numbers as predicted by Lighthill but for supersonic Mach number range of 1.0 to 1.4 the sound power varied as U 12 because of the shock waves. Overall sound power levels for supersonlc jet Mach numbers at different total temperatures were correlated with the supersonic jet nolse theory of Nagamatsu and Horvay. 
TABLE OF CONTENTS IV

LIST OF FIGURES $\quad$ vi

IIST OF SYMBOIS $\quad$ IX

1.0 INTRODUCTION 1

2.0 EXPERIMENTAL FACILITIES AND PROCEDURES

2.1 Alr Supply and Gas Fired Heater 7

2.2 Nozzle and Test Facility 8

2.3 Instrumentation 8

2. 4 Procedure 9

3.0 MEAN AND FLUCTUATING VEIOCITY DISTRIBUTIONS FOR 11 SUBSONIC AND SUPERSONIC JETS

3.1 Shadowgraph Photographs of Subsonzc and 11 Supersonic jets

3.2 Mean Velocity Distributions 12

3.3 Piezoelectrıc Pressure Fluctuation 16 Distributions

4.0 PIEZOELECTRIC PRESSURE FLUCTUATIONS AND TURBULENT 20 VELOCITY FIUCTUATIONS

- 4.1 Hot-Wire and Plezoelectric Pressure 20

4.2 Analysis of Piezoelectric Pressure 21 Fluctuations at the stagnation Point of a Probe

5.0 ANALYSIS OF EXPERIMENTAI FLOW AND ACOUSTIC RESULTS 28

5.1 Flow and Acoustic Charactexıstics 28

5.1.1 Flow Characteristics for Subsonic and 28 Supersonic Jets

5.1.2 Acoustic Characteristics of Subsonıc and 29 Supersonic Jets 
TABLE OF CONTENTS (Continued)

Page Number

5.2 Correlation of Acoustic Data with Jet

31 Nozse Theorzes

6.0 CONCLUSIONS

REFERENCES

35

FIGURES

39 
Elgure 12 Inch and 6.15 Inch Diameter Flow and Acoustic Facılıtıes.

Figure 2 One Inch Diameter Flow and Optical Facility.

Figure $3 a$ Shadowgraph Photographs of a One Inch Convergent Nozzle at Jet Mach Numbers of 0.7 (Left) and 0.6 (RIght).

Figure $3 \mathrm{~b}$ Shadowgraph Photographs of a One Inch Convergent Nozzle at Jet Mach Numbers of 1.0 (Left) and 0.85 (RIght).

Figure 3c Shadowgraph Photographs of a one Inch Convergent Nozzle at Jet Mach Numbers of 1.4 (Left) and 1.2 (RIght).

Figure $4 a$ Constant Mach Number and Piezoelectric Pressure Fluctuation Contours in the Flow Field from a One Inch Convergent Nozzle, $\mathrm{M}_{J} \approx 0.6$.

Figure $4 b$ Mach Number Profiles Across the Exit of a one Inch Diameter Convergent Nozzle at Different Distances from the Nozzle Exit, $M_{J} \approx 0.6$.

Figure 4c Piezoelectric Pressure Fluctuation Profiles Across the Exit of a One Inch Diameter Convergent Nozzle at Different Distances from the Nozzle Exit, $M_{j} \approx$
0.6 .

Figure $5 a$ Constant Mach Number and Plezoelectric Pressure Fluctuation Contours in the Flow Field from a one Inch Convergent Nozzle, $\mathrm{M}_{J} \approx 0.7$.

Fl.gure 5b Mach Number Profiles Across the Exit of a one Inch Diameter Convergent Nozzle at Different Distances from the Nozzle Exit, $M_{J} \approx 0.7$.

Figure 5c Piezoelectric Pressure Fluctuation Profiles Across the Exit of a One Inch Diameter Convergent Nozzle at Different Distances from the Nozzle Exit, $M_{I} \approx$
0.7 .

Figure $6 \mathrm{a}$ Constant Mach Number and Piezoelectric Pressure Fluctuation Contours in the Flow Field from a one Inch Convergent Nozzle, $\mathrm{M}_{\mathrm{J}} \approx 0.85$.

Figure 6b Mach Number Profiles Across the Exit of a One Inch Diameter Convergent Nozzle at Different Distances from the Nozzle Exit, $M_{J} \approx 0.85$.

vi 
Figure 6c Piezoelectric Pressure Fluctuation Profiles Across the Exit of a One Inch Diameter Convergent Nozzle at Different Distances from the Nozzle Exit, $M_{J} \approx$ 0.85 .

Figure 7a Constant Mach Number and Plezoelectric Pressure Fluctuation Contours in the Flow Field from a one Inch Convergent Nozzle, $\mathrm{M}_{J} \approx 1.0$.

Figure 7b Mach Number Profiles Across the Exit of a one Inch Diameter Convergent Nozzle at Different Distances from the Nozzle Exit, $M_{J} \approx 1.0$.

Figure 7c Plezoelectric Pressure Fluctuation Profiles Across the Exit of a One Inch Diameter Convergent Nozzle at Different Distances from the Nozzle Exit, $M_{J} \approx$ 1.0 .

Figure 8a Constant Mach Number and Plezoelectric Pressure Fluctuation Contours in the Flow Field from a one Inch Convergent Nozzle, $\mathrm{M}_{\mathrm{J}} \approx 1.2$.

Figure 8b Mach Number Profiles Across the Exit of a One Inch Diameter Convergent Nozzle at Different Distances from the Nozzle Exit, $\mathrm{M}_{j} \approx 1.2$.

Figure 8c Plezoelectric Pressure Fluctuation Profiles Across the Exit of a One Inch Diameter Convergent Nozzle at Different Distances from the Nozzle Exit, $\mathrm{M}_{\mathrm{J}} \approx$ 1.2 .

Figure $9 \mathrm{a}$ Constant Mach Number and Piezoelectric Pressure Fluctuation Contours in the Flow Field from a one Inch Convergent Nozzle, $\mathrm{M}_{J} \approx 1.4$.

Figure 9b Mach Number Proflies Across the Exlt of a One Inch Diameter Convergent Nozzle at Different Distances from the Nozzle Exit, $\mathrm{M}_{\mathrm{J}} \approx 1.4$.

Figure 9c Piezoelectric Pressure Fluctuation Profiles Across the Exit of a one Inch Diameter Convergent Nozzle at Different Distances from the Nozzle Exıt, $\mathrm{M}_{\mathrm{J}} \approx$

Figure 10 Variation of Normalized Hot-Wire and Piezoelectric Pressure Fluctuations Along the Jet Axıs for Subsonic Jet.

Figure lla Flow Mach Number Ratio on Jet Axis for one Inch Diameter Convergent Nozzle. 


\section{LIST OF FIGURES (Continued)}

Figure Ilb Velocity Ratio on Jet Axis for Two Inch Diameter Convergent Nozzle.

Figure 12a Variation of Piezoelectric Pressure Fluctuations on Jet Axis with Distance from Jet Exit for one Inch Diameter Convergent Nozzle.

Figure 12b Variation of Impact Pressure Fluctuations on Jet Axis with Distance from Jet Exit for Two Inch Dzameter Convergent Nozzle.

Figure 13 Normalized Overall sound Pressure Level as a Function of Angular Position from Jet Axis for Two Inch Diameter Convergent Nozzle.

Figure 14 Ratıo of Third-Octave Band Sound Power Level to Peak Sound Power Level for Two Inch Dlameter Convergent Nozzle.

Figure 15 Overall Sound Power Level in Watts for Constant Mass flow as Function of Jet Velocity.

Figure 16 Overall Sound Power Level in db Per Unit Slug Mass as Function of Jet Velocity. 
c

ca

c

D

$\ell_{S}$

m

M

$\mathrm{M}_{3}$

pa

$p_{0}$

p'

$\overrightarrow{\mathrm{p}}$

$\left\langle\mathrm{p}^{\prime}\right\rangle$

$\tilde{\mathrm{p}}$

$\mathrm{p}_{\mathrm{T}}$

$\mathrm{P}_{\mathrm{I}}^{\mathrm{I}}$

q

$q^{\prime}$

r

ro

$T_{t}$

$\mathrm{U}_{j}$

w

w

$u$
$\mathrm{v}$
$\mathrm{w}$

velocity of sound

velocity of sound in ambient air

velocity of sound in jet

nozzle exit diameter

supersonic length

mass flux

Mach number

jet Mach number

ambient pressure

total pressure

Impact pressure after normal shock

mean statıc pressure

pressure fluctuation caused by turbulence

pressure fluctuation due to sound field

total pressure along a streamline

total pressure fluctuation

mean vector velocity

vector turbulent velocity

radius from jet centerline

radius of nozzle exıt

jet total temperature

jet exit velocity

sound power per unit length

overal1 sound power

velocity components 


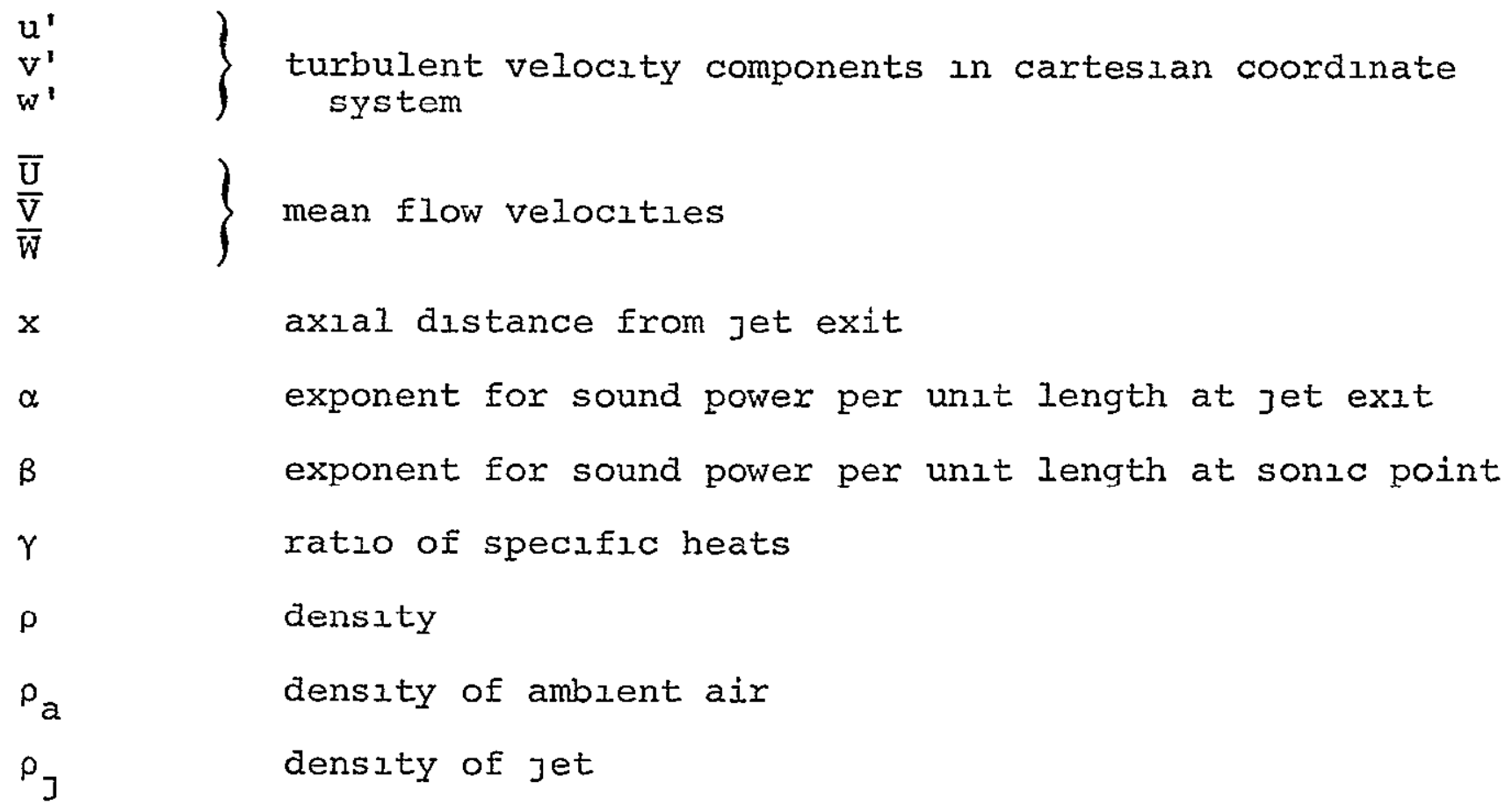




\subsection{INTRODUCTION}

The noise emitted by the jet engines is a critical problem around metropolitan airports because of the large number of commercial jet aircrafts on scheduled flights and the long range jet aircraft with long take-off distances. For the supersonic transport airplanes, the jet engines have large thrust with supersonic jet exhaust velocities and thus, the jet exhaust noise during take-offs is critical without a suppression device. To reduce this exhaust noise by suppressors it is necessary to obtain some knowledge regarding the noise generation mechanism and suppression phenomenon for supersonic jets. Even for subsonic jets the actual location of the noise sources within the jet from the turbulent fluctuations has not been well defined. But for supersonic jets the available flow and acoustic experimental data is very meager and the relationship between the noise generation in the supersonic region and the radiation to the far field is not too well defined. The present investigation is a continuation of the research undertaken to gain fundamental flow and acoustic knowledge for subsonic and supersonic jets and some of the previous results are presented in Refs. 1 - 3. With better information regarding the sources of acoustic radiation from supersonic jets it should be possible to develop an efficient suppressor for reducing the supersonic jet exhaust noise.

In Ref. 3 the mean velocity and piezoelectric pressure fluctuation distributions were determined along the axis over a jet Mach number range of 0.6 to 1.4 for a 2 in. diameter convergent jet. Also, the corresponding sound pressure level variations with angular position from the jet exhaust on a $10-\mathrm{ft}$. radius and the sound power spectra were determined for the various jet Mach numbers. The primary objectives of the investigation were to determine similarities and differences between subsonic and supersonic jets and to attempt to determine the relationship between the flow and acoustic phenomena in the jet exhaust. The present study was conducted to obtain the mean velocity and piezoelectric pressure distributions in the jet flow for subsonic and supersonic jets. Since the acoustic radiation is dependent upon the fluctuating turbulent stress tensor in the flow field as postulated by Lighthill in Refs. 4 and 5 for subsonic jets, it is necessary to determine the mean velocity distributions in subsonic and supersonic jets and the corresponding fluctuating velocity and pressure fluctuations due to turbulence in the jet. The available literature on these jet flow phenomena is still too limited to resolve the question of actual noise generation mechanisms in the jet flow region for both subsonic and supersonic exiraust velocities.

The variation of the mean velocity along the axis for subsonic jets has been determined by impact pressure or by hot-wire in Refs. 3, $6-9$. All of these references have indicated that 


\section{if)}

the uniform core region extends over 4 to 5 diameters from the jet exit, and the core length is dependent upon the initial. turbulence level in the reservolr. In Ref. 3 the core region extended over approximately 5 diameters for jet exhaust Mach numbers of 0.60 to 1.0. At supersonic Mach numbers the jet flow depends upon the type of nozzle, convergent or convergentdivergent, and the pressure ratio to produce the supersonic velocities. Iove et allo have correlated the calculated supersonlc flow fleld with the experimental data for botn convergent and convergent-divergent nozzles at varıous pressure ratıos. For convergent nozzles at pressure ratios greater than the critical value to produce sonıc velocity at the exit, the jet flow will always contain shock bottles because of the inertia effects as observed In Refs. 3, 10 - 13 with the length of the first shock bottle dependent upon the supersonic jet Mach number or the pressure ratio. Similar shock bottles are formed when the contoured convergent-divergent nozzle is operated at pressure ratios greater or less than the design value for a given supersonic exhaust Mach number. The fllow fields for supexsonic jet exhaust velocitıes from convergent-civergent nozzles designed for uniform parallel flow at the nozzle exit have been investigated in Ref́s. 9, 14 - 16 for various supersonic velocities. Under ldeal pressure ratios for these nozzles the supersonic flow at the nozzle exit does not contain shock waves like the convergent nozzle, but great care must be taken to achleve uniform supersonlc flow without shock waves as discussed in Ref. 16. From these experimental observations for supersonic jets, the supersonic core region and the supersonic region were determined and the experimental results are summarized in Refs. 17 - 19.

Llghthil14,5 showed that a fluctuating flow of gas in a turbulent jet generates in the surrounding atmosphere the same fluctuations of density as would be producea in a classical stationary acoustic medium by a system of external applied stresses. And the radiated sound is due to the turoulent flow which does not react significantly upon it for subsonic flow velocities. Thus, to apply IIghthili's concept of noise radiation It is necessary to know the distribution of the fluctuation stress tensor in the flow field.

Hot-wires have been used by various investıgators $6-8,20-23$ to investigate the turbulent velocity Fluctuations in the subsonic jet flow field. Corrsin and Uberol 6 Investigated mean and fluctuating. velocity and temperature distributions for a one Inch dlameter jet ac a velocity range of 65 to 110 It/sec. and a jet temperature range of $20^{\circ}$ to $385^{\circ} \mathrm{C}$. Comparison of the relative magnitudes of turbulence level, temperature fluctuation level, and temperature-velocity correlation were made from the experimental data. The purpose of this investigation was to determine the flow characteristics of a heated subsonic jet. But the later studies with hot-wires by other investigators $20-23$ 
were directed toward obtaining the turbulent fluctuations for the purpose of determining the nolse generation mechanism for subsonic jets as well as to attempt to evaluate the fluctuating stress tensor or the quadrupole 1,2 strength and distribution in subsonic jet flows. By the use of two hotwires in a subsonic jet. Davies and colleagues 22 obtained the radial distribution of the turbulence level and the corresponding pressure fluctuations due to turbulence at a few fixed axial distances from the jet exit. Their results indicated that the maximum pressure fluctuations in the jet were not located at the maximum turbulent velocity fluctuations. This is a rather interesting and significant data for relating the pressure fluctuations associated with turbulence level and additıonal investigatıons should be conducted to substantiate this result for a subsonic jet.

For supersonic turbulent flows the avallable literature on the turbulence measurements with hot-wires is still very limited. Kovasnay 24 investigated the turbulence level in a supersonic free stream and in the turbulent boundary layer with a hot-wire to show that it is feasible for determining the turbulent fluctuations. Iaufer 25,26 obtalned not-wire measurements in the free stream of a supersonic wind tunnel over a Mach number range of 1.6 to 5.0 and showed that the turbulent boundary layer along the nozzle walls is responsible for the sound field. At present no hot-wire data is avallable for supersonic jet velocities because of the difficulties in maintaining a small diameter hot-wire with high frequency response in the jet stream without fallure. At supersonic flow velocities it is necessary to use small diameter hotwires for the high Irequency range needed for measuring tie supersonic turbulence level. To overcome the limitation off the hot-wire for supersonic jet flow, Fisher and Joinston $2 \frac{7}{7}$ used an optical "crossed-beam" method to measure turbulence properties of two supersonic alr jets at Mach numbers of 2.46 and 3.34. With ultraviolet light sources the distributions of turbulent convection speeds, length scales, and spectra were obtalned for the supersonic Mach numbers. Pettit28 as used the laser doppler velocimeter technique for measuring the turbulence level in a subsonic jet and has obtained good correlation with the hot-wire measurements 7,8 at a jet Macn number of 0.3 . A more powerful laser has been obtained for extending the turbulence measurements to supersonic jet velocities, and the electronic systems associated with this laser technique are being improved for use at higher jet velocicies. To resolve the nolse generation sources from supersonic jet velocities, It is imperative that the turbulence level and the corresponding pressure fluctuations must be decerminea in the supersonic flow fields.

Since It is nearly impossible to obtain hot-wire measurerents of the turbulence level in supersonic jet flows, a Eew Investigators in the past several years have used the microphone and 
plezoelectrıc pressure transducers to measure the fluctuating pressures for impact and static pressure probe conditions in subsonic $29-34$ and supersonic 2,3 jet flows. Siddon 29 developed a minlature condenser microphone of nominal 0.100 in. diameter and housed this microphone in a static pressure probe with an outside diameter of $1 / 8 \mathrm{In}$. With this probe the reasurements were conducted in a number of contrived unsteady subsonic flows, including turbulent flow, to determine error between the measured and true static pressure existing without the probe. These results indicated that the correction to root-mean-square pressure fluctuation level in turbulent flow was small for subsonic flow.

Nakamura and colleagues 30 used a microphone with Impact and statıc pressure probe configurations to measure the turbulence level in a low speed plpe flow with a diameter of $37 \mathrm{~cm}$. They found that the sound pressure-levels in decibels re $0.0002 \mu$ bar for the impact pressure and static pressure probe configurations differed by approximately $24 \mathrm{db}$ with a $1 / 3$ octave band fllter over the fllow velocity range of 3 to $10 \mathrm{~m} / \mathrm{sec}$. These results indicated that the pressure filuctuations measured with the impact pressure probe configuration was a function of the turbulent velocity fluctuations, and the static pressure fluctuations measured with the static pressure probe was a function of the pressure fluctuations due to turbulence. Fuchs analyzed the fluctuations in a subsonic uniform moving medium orlginating from convected sources 31,32 and conducted with microphone probes of various configurations to measure the static pressure fluctuations in a subsonic jet flow 33 . The radial statıc pressure distrıbution at an axial distance of 5 diameters from the jet exit for a velocity of $30 \mathrm{~m} / \mathrm{sec}$. was quite different from that deduced by Davies and colleagues 22 by means of two hot-wires. Lau, Fuchs, and Fisher 34 used a microphone static pressure probe and hot-wire simultaneously with the hot wire placed at various axial positions from the static pressure orifices to measure the pressure and velocity fluctuations in the core and entrainment regions of a room temperature subsonic jet. Correlation technlques were used to determine the phase relationship between tne pressure fluctuations, and the axial and radial velocity fluctuations in each of the two regions.

Maestrello and McDard ${ }^{35}$ measured the pressure fluctuations on a plate placed close to the edge of a subsonic jet for the purpose of attempting to determine the strength and location of nolse sources in a high velocity subsonic jet. The acoustic sources were traced to the perıphery of the jet by means of wave-vector decomposition of the space-time correlation of the pressure field on a plane of rigid surface located in the vicinity of the jet. Unfortunately, this method does not glve detalis of the acoustic generation within the jet flow due to the turbulence. 
To obtain information of the turbulence level for subsonic and supersonic jet flows, Nagamatsu and colleagues ${ }^{2}, 3$ measured the plezoelectric impact pressure probe fluctuations along the axis for a jet Mach number range of 0.60 to 1.4. For subsonic jet Mach numbers of 0.6 to 1.0 , the peak pressure fluctuations occurred at an axial position of approximately 9 diameters from the exit of the convergent nozzle. But for supersonic Mach numbers of 1.2 and 1.4 the peak pressure fluctuations occurred Just ahead of the sonjc velocity location on the axis. A lasex doppler technique 28 is being developed for use at supersonic velocities to determine the correlation between the plezoelectric and laser measurements at supersonic jet velocitıes.

The nolse generation from subsonic jets has been analyzed by Lighthili 4,5 , Ribner ${ }^{36}$ and others and a rather complete review of the existing literature on the jet nolse generation phenomena Is presented in Ref. 36. Phillips 37 considered the generation of sound from supersonic turbulent shear layer and Wllilams 38 extended the analysis to the generation of sound from turbulience convected at hIgh speeds Recently, Ollerhead $^{9}$, plumblee ${ }^{39}$, and Nagamatsu and Horvay ${ }^{17}$ have consıdered the acoustıc radıation from supersonlc jet exhaust velocities, and the later reference considered the flow and acoistic characteristics of supersonic jets in deriving the acoustic radiation from supersonic jets.

Experimental data for the acoustic radiation from subsonic jets have been obtained by various investigators $40-44$ at various subsonic exhaust velocities. For supersonıc exhaust velocities the avallable literature $2,3,16,45-47^{\prime}$ on the acoustic and flow phenomena is still limited. Potter and Jones ${ }^{16}$ were able to determine the distribution of the acoustic radiation as a function of jet length from a small Mach 2.49 nitrogen jet. Their results indicated that the maximum acoustic radiation occurred just ahead of the sonic velocity on the jet axis, which was nearly 20 diameters from the jet exit. Nagamatsu and colleagues 3 by means of the piezoelectric pressure fluctuatıons and near field microphone measurements also found that the peak acoustic radiation occurred in the vicinity of the sonic velocity on the axis for a Mach 1.4 convergent jet, which was approximately 12 diameters from the jet exit.

The present investigation was the continuation of the previous study for the purpose of determining the mean velocity and turbulent fluctuation distributions in the jet flow field for a jet exhaust Mach number range of 0.60 to 1.4 from a convergent nozzle. In Ref. 3 the mean velocity and piezoelectrıc pressure fluctuations were determined along the axis for subsonic and supersonic jet velocities. For the purpose of determining the location and strength of acoustic sources in the jet flow, it is necessary to know the mean velocity and fluctuating quantities in the flow field. Also, for supersonic exhaust velocities, the location of the sonic contour is necessary to define the 
supersonlc and subsonlc mixing regions. An analysis was made to show that the piezoelectric impact pressure probe fluctuations were related to the turbulent velocity fluctuations and the experimental correlation with hot-wire and laser results is discussed. The experimental flow measurements for subsonic and supersonlc jet velocities are analyzed and the acoustic data are correlated with subsonic jet nolse theory of IIghthil14,5 and supersonıc theory of Nagamatsu and Horvay ${ }^{17}$. 


\subsection{EXPERIMENTAL FACILITIES AND PROCEDURES}

\subsection{Alr Supply and Gas Fired Heater}

For the flow and acoustic investigations of subsonic and supersonlc jets exhausting to the atmosphere from 2 and $6.15 \mathrm{In}$. diameter convergent nozzles, shown in Fig. 1, the compressed alr is supplied by two $800 \mathrm{hp}$ three-stage compressors and a two-stage $200 \mathrm{hp}$ compressor. For supersonic jet exhaust operation with the $t^{2}$ in. nozzle both $800 \mathrm{hp}$ compressors were required for Mach numbers greater than 1.4. With all three compressors in parallel it was possible to operate the 6.15 in. diameter nozzle at $850 \mathrm{ft} / \mathrm{sec}$. at a flow rate of approximately $12 \mathrm{lbs} / \mathrm{sec}$. After the compressors the arr was passed through after-coolers, large oll separators and settling tanks. A photograph of the jet exhaust test faclilty, consisting of the 2 in. and 6.15 in. diameter nozzles, Is shown in FIg. I with the bullding housing the compressors and a cooling tower on top of the building. From the bullding the alr supply is passed through 8 in. diameter pipe with insulation so that heated air can be used to investigate the jet temperature upon the flow and acoustic characteristics for subsonic and supersonzc jets. Just inside the bullding the alr supply is diverted into two $4 \mathrm{ln}$. diameter pupes connected to the main 8 in. pipe, and on one $4 \mathrm{In}$. pipe a Fisher pressure control system is installed for regulating the nozzle reservolr pressure. With this automatic alr flow control system it is possible to maintain the pressure at the preselected constant operating value in the 12 in. and 24 in. diameter reservolr chambers located at the end of the $4 \mathrm{ln}$. and $8 \mathrm{ln}$. dia. pipes for the $2 \mathrm{In}$. and $6.15 \mathrm{ln}$. diameter nozzles respectively as shown in Fig. I. A large gas fired alr heater is avallable to heat the air to $1260^{\circ} \mathrm{R}$ at $500 \mathrm{psig}$ for hot jet experiments. The initial 4 in. diameter pipe used for the $2 \mathrm{ln}$. nozzle has been replaced by the 8 In. diameter Insulated pipe for the purpose of operating a 6.15 In. nozzle as well as to be able to use the heated arr supply.

A 1 in. diameter convergent nozzle attached to a reservolr section of 6 In. diameter, cf. FIg. 2, was used inside the Fuller compressor room to obtain the mean velocity and piezoelectric impact pressure probe fluctuation distributions for jet Mach numbers of 0.6 to 1.4 . The compressed alr to this nozzle was supplied by the $200 \mathrm{hp}$ compressor from the adjacent Combustion BuIlding. With this nozzle inside the building it was possible to make detalled radial surveys of the impact pressure and plezoelectric pressure probe fluctuations over a large distance from the nozzle exit. These radial surveys at various distances from the nozzle exit are difflcult to conduct outdoors with the $2 \mathrm{In}$. and $6.15 \mathrm{In}$. nozzles, Fig. 1, because of the wind conditions. Also, with the indoor nozzle lt was easier to obtain optical photographs of the jet flow fleld with a short duration spark source. 


\subsection{Nozzle and Test Faclinty}

A convergent nozzle and a contoured parallel flow nozzle for an exit Mach number of 1.5 with throat diameter of 2 in. have been used to obtain the flow and acoustic characteristics and the previous results are presented in Refs. 1 - 3. The 1 in. diameter convergent nozzle has exactly the same geometrical shape as the $2 \mathrm{in}$. diameter convergent nozzle used for the flow and acoustic studies with the outdoor faclinty, Fig. 1. The geometry for the $6.15 \mathrm{In}$. diameter nozzle for subsonic jet flow velocity range of 100 to $850 \mathrm{ft} / \mathrm{sec}$. Was also the same as the $2 \mathrm{In}$. convergent nozzle. With these convergent nozzles it is posisble to investigate the effects of nozzle diameter upon the acoustic and flow characteristics of subsonic and supersonlc jets. For these different size nozzles, both the static pressure and total temperature of the compressed air were measured in the plenum chamber, which contained screens to break large scale turbulent eddies into smaller eddies.

For both the $2 \mathrm{ln}$. and $6.15 \mathrm{ln}$. dlameter nozzles trolley systems, as shown in Fig. I, were used to conduct axial surveys of the jets with impact pressure, total temperature, and piezoelectric pressure probes. Similar axial surveys in the vertical direction from the 1 in. diameter jet exit were conducted with the movable probe holder shown in Fig. 2 .

\subsection{Instrumentation}

Reservoly pressures in the settling chambers for the different diameter nozzles were measured with a Helse gage. High impact pressures in the jet flow for the higher velocities were measured with pressure gages and as the impact pressure decreased downstream of the jet exit a mercury manometer was used. For each test the amblent pressure and temperature were observed. All static and impact pressures were read after the flow and pressures were stabilized. Also, different diameter impact pressure and static pressure probes are used depenaing upon the diameter of the jet nozzie. The axial and radial impact pressure surveys conducted for the 1 in. nozzle, were made with a $1 / 16$ in. diameter probe.

A 1/4 In. diameter Klstler quartz plezoelectric pressure transducer was used as the impact pressure fluctuation probe. The pressure gage was mounted whth the gage face exposed perpendicular to the free stream. The output from the pressure transducer was read with a Ballantine rms meter and the response time of the gage was less than $20 \mu$ sec. An analysis of the plezoelectric pressure gage output will be presented in this report indicating that the rms output is a linear function of the turbulent velocity fluctuations for subsonic jet velocities. A smaller lead-zirconate-tıtanate plezoeleccrlc pressure trarsducer with an outside diameter of $3 / 32$ in. has also been usec 
to survey the turbulent fluctuations in the jet flows and the results were similar to that obtained with the larger diameter Kistler gage.

The total temperature in the plenum chambers was determined by elther a chromel-alumel thermocouple or an Ashcroft dial

thermometer. A chromel-alumel thermocouple was used in the total temperature probe for the axlal surveys along the jet axis. The outputs from the total temperature thermocouples in the plenum chamber and in the jet flow were recorded simultaneously on a Minneapolils-Honeywell visicorder. These thermocouples were calibrated over the range of total temperature encountered in the flow for subsonic and supersonic jet velocities.

Instrumentation for obtaining acoustic information consisted of a $B \& K I / 2$ In. free field response condenser microphone with a cathode follower for a frequency response of $20 \mathrm{~Hz}$ to $40 \mathrm{kHz}$. Before each run the microphone was callbrated with a B\&K plston phone calibrator which produced an osclllating dynamic pressure of $124 \mathrm{db}$ re $0.0002 \mu$ bar at $250 \mathrm{~Hz}$. Far fleld acoustic measurements were made with the microphone placed in the plane of the jet axis at 8 angular positions on a 10-ft. radius for the 2 In. diameter nozzles. The output of the microphone was connected to a Ballantine true rms voltmeter, $B \& K$ sound level meter, and General Radio tape recorder which had a frequency response of $15 \mathrm{~Hz}$ to $16 \mathrm{kHz}$. To obtain sound power levels at high frequencies a Norelco elght channel tape recorder with a response of $15 \mathrm{~Hz}$ to $100 \mathrm{kHz}$ was purchased. The Ballantine true rms voltmeter had a flat frequency response better than $200 \mathrm{kHz}$. The tape recordings were analyzed using a B\&K I/3 octave-band analyzer coupled to a Hall squaring circuit and a digital integrating voltmeter. With this procedure mean square pressure determinations over 5-second perıods for each analyzer band were made as discussed in Ref. 1.

With the avallable optical instrumentation it is possible to obtain schlieren, shadowgraph, and interferometer photograpns of the jet flow. Also, laser equipment is avallable to determine the mean and fluctuating velocities in the jet flow as discussed in Ref. 28. For the schlieren and shadowgraph photographs of the jet flow, the duration of the spark light source Is 0.4 mlcroseconds and some of the shadowgraph photographs of subsonic and supersonic flows from a one in. diameter convergent nozzle are presented in Figs. $3 a-c$. With this short duration spark source, it is possible to observe the eddies present a the outer boundary of the jet as well as the Mach waves for supersonic jet velocities. The field of view for the portable interferometer is 2 in. diameter with elther green or white light sources.

\subsection{Procedure}

With the 2 in. diameter nozzle located outside the bullding, 
Fig. 1, for flow and acoustic investigations two separate runs were made at each selected reservour pressure for jet flow Mach numbers of 0.60 to 1.4 to obtain the acoustic and flow data. After the jet flow had attained equilibrium condition the nozzle and reservolr pressures and the total temperature in the reservolr were recorded. For the $2 \mathrm{in}$. nozzle the total pressure and total temperature surveys were made along the jet axis from the nozzle exit to 40 nozzle diameters. With the 1 in. convergent nozzle, FIg. 2, the total pressure and Kistler plezoelectric impact pressure fluctuation surveys were conducted at a large number of radial and axial positions for jet Mach numbers of 0.60 to 1.4 in order to obtain the constant Mach number and piezoelectric pressure fluctuation contours. This information is necessary for understanding the noise generation mechanisms from subsonic and supersonic jets. The one in. dlameter nozzle was selected to conduct the detalled flow field surveys because the nozzle was located inside the bullding which eliminated the outdoor wind conditions present with the 2 in. nozzle.

Both near fleld and far fleld acoustic measurements were made with the $2 \mathrm{ln}$. nozzle located outdoors. The far fleld microphone measurements were made on a 10-ft. radius from the jet exit and the output tape recorded. But for the near field microphone positions the output was connected to the Ballantine rms voltmeter to obtain the sound pressure level at each location in $\mathrm{db}$ re .0002 microbar as discussed in Ref. 3. 
3.0 MEAN AND FLUCTUATING VEIOCITY DISTRIBUTIONS FOR SUBSONIC AND SUPERSONIC JETS

\subsection{Shadowgraph Photographs of Subsonıc and Supersonıc Jets}

To obtain flow features of subsonic and supersonic jets, both surveys with impact pressure and plezoelectric pressure probes and optical photographs of the jets were obtalned with the one in. diameter convergent nozzle, and the shadowgraph photographs are presented in Figs. 3a - c for jet Mach numbers of 0.6 to 1.4. Since the field of view using a parallel light system is Ilmited to the size of the $4 \mathrm{x} 5$ film sheets, $a 12$ in. dlameter mirror was used and the camera was moved relative to the jet exhaust to obtain the shadowgraph photographs over the initial $8 \mathrm{ln}$. from the jet exıt. It was necessary to obtain two photographs of the jet which ere superimposed for these photographs. WIth a spark light source duration of 0.4 $\mu$ sec. It was possible to observe the eddies at the jet boundary as well as the turbulence in the jet. For a jet Mach number of $0.6, F I g$. 3a, the vortex formation close to the jet exit is quite evident and the outer edge of the jet boundary is very Irregular. It is interesting to note that the flows for jet Mach numbers of 0.6 to 1.0, Figs. $3 a$ and $b$, are quite similar. For these exhaust Mach numbers the jet emerging from the convergent nozzle seems to have a laminar layer around the periphery before breaking down into a turbulent region as observed previously by other investigators with small jets. The transition to a turbulent type of layer takes place in a short distance for these subsonlc Mach numbers. These shadowgraph photographs indicate that the flow for a sonic jet velocity is similar to those for subsonic velocities, and the impact pressure and total temperature surveys along the jet axis at Mach numbers of 0.6 to 1.0 in Ref. 3 showed the same result.

There is a drastic change in the flow phenomenon as the jet velocity increases from sonic to supersonic as indicated in Figs. $3 b$ and $3 c$. As soon as the pressure ratio for the convergent nozzle exceeded the sonlc value, the shock bottles $10,11,13$ were formed due to the inertia effect of the alr emerging from the convergent nozzle as discussed in Ref. 10. At the lower supersonic Mach number of $1.2, F I g .3 c$, the spacing between the shock bottles Is smaller than for the higher Mach number of 1.4 and the region of shock bottles or the supersonic region increases with the increasing supersonic Mach number. By comparing the shadowgraph photographs of the sonic and supersonic jet the spreading of the supersonic jet over the initial region from the jet exit is less than for the sonic and subsonic jets. At a jet Mach number of I. 4, Fig. 3c, the diameter of the shock diamonds decrease slowly with distance. Approximately seven shock bottles are evident in the jet exhaust, which indicate the extent of the supersonic region. As the diameter of the supersonic region decreases with distance from the jet exit, the region of subsonic turbulent mixing increases rapidly with 
distance. Dosanjh and $\mathrm{Iu}^{13}$ have shown that the shock bottles in the supersonic jets are sources of acoustic radiation.

Nagamatsu and colleagues ${ }^{2}$ have compared the directivity, power spectra, and overall sound power level for contoured parallel flow and convergent nozzles with a throat diameter of 2 in. and a pressure ratio for a Mach number of 1.5 . Due to the existence of shock bottles with the convergent nozzle, the overall sound pressure level did not decrease as much with angular position from the jet axis as the parallel flow nozzle and the overall sound power level was 3 ab higher for the convergent nozzle.

Since the shadowgraph photographs indicate only the supersonic region and the outer boundaries of the subsonic and supersonic jets, axial surveys with impact pressure and Kistler pressure fluctuation probes were conducted to determine the flow characteristics within the jet flow and the results are presented In the next section of the report. With hot-wire and laser techniques it is possible to obtain the fluctuating and mean velocity distributions within the jet flow for subsonic jets. But for supersonic exhaust velocities a laser technique is being developed to measure the flow conditions within the jet. By combining the shadowgraph photographs, Flgs. $3 a-c$, with the radial surveys within the jet flow, It should furnish additional information regarding the mixing phenomena of subsonic and supersonic jets.

\subsection{Mean Velocity Distributions}

Impact pressure surveys for jet Mach numbers of 0.60 to 1.4 were conducted at varıous axial and radial locations from the one in. drameter convergent nozzle, Fig. 2, with a $1 / 16$ in. diameter Impact probe, and the results are presented in Figs. $4 a$ and $b$ through $9 a$ and $b$. To determine the Mach number from the impact pressure probe data, the static pressure in the jet was assumed to be equal to the amblent pressure. This assumption is reasonable for subsonic jet exhaust velocities, but for supersonic velocities the assumption is not valid close to the jet exit but becomes more reasonable further downstream as the jet velocity decreased and becomes subsonic. For subsonic jets the local flow Mach numbers were determined from the equation

$$
\frac{p_{a}}{p_{0}}=\left(1+\frac{\gamma-1}{2} M^{2}\right)^{-\frac{\gamma}{\gamma-1}}
$$

At supersonlc jet velocities the Mach number at the exit of a convergent nozzle is sonic and the static pressure is greater than the ambient pressure. Thus, in the immediate vicinity of the convergent nozzle exit the Mach numbers were determined from the equation 


$$
\frac{p_{0}^{\prime}}{p_{0}}=\left(\frac{(\gamma+1) M^{2}}{(\gamma-1) M^{2}+2}\right)^{\frac{\gamma}{\gamma-1}}\left(\frac{\gamma+1}{2 \gamma M^{2}-(\gamma-1)}\right)^{\frac{1}{\gamma-1}}
$$

And farther downstream from the jet exit where the static pressure is close to the amblent pressure the Mach numbers were determined from the Raylejgh formula

$$
\frac{\mathrm{p}_{\mathrm{a}}}{\mathrm{p}_{0}^{l}}=\left(\frac{2 \gamma}{\gamma+1} \mathrm{M}^{2}-\frac{\gamma-1}{\gamma+1}\right)^{\frac{1}{\gamma-1}}\left(\frac{\gamma+1}{2} \mathrm{M}^{2}\right)^{-\frac{\gamma}{\gamma-1}}
$$

It was shown in Ref. 3, with a 2 in. diameter convergent nozzle, that the difference in the Mach numbers determined by these equations became smaller as the jet Mach number approached unity.

The contours of constant Mach number for subsonic jet Mach numbers of $0.6,0.7,0.85$, and 1.0 are presented in Figs. $4 a$ 7a. And the radial flow Mach number distrıbutions for varıous axial positıons from the nozzle exit are presented in Figs. $4 \mathrm{~b}-7 \mathrm{~b}$. With the existing survey device it was possible to survey the flow field from the jet exit to 18 in. downstream, and the radial surveys were conducted at given axial locations. To regulate the reservoir pressure in the 6 in. diameter plenum chamber, FIg. 2, a valve was installed in the 2 in. diameter pipe upstream of the chamber. Within the plenum chamber flow stralghteners and screens were installed to break up the eddies and decrease the turbulence level. At the end of the plenum chamber a one in. diameter convergent nozzle was attached with an area contraction ratio of reservoir to nozzle area of 36 . Even with this arrangement for the one in. diameter nozzle, the uniform core region for the subsonic jet Mach numbers was slightly less than 4 diameters while for the 2 in. convergent nozzle In Ref. 3 the region extended to approximately 5 diameters.

The contours of constant Mach numbers for subsonic jet Mach numbers of 0.60 to 1.0 , Figs. $4 a-7 a$, are quite simllar. As the jet Mach number increased the intersection of the contour of constant flow Mach number of 0.2 with the jet axis moved farther downstream. And the contours of higher constant Mach number also extended farther downstream with increasing jet exit Mach number. For these subsonic Mach numbers the outer edge of the jet boundaries are indicated by dashed lines in these figures, and the boundarles were not sharply defined by the Impact pressure probes because of the turbulent eddies as shown by the shadowgraph photographs, Figs. $3 a-c$. Also, near the jet exit the probe diameter is $1 / 16$ in. so that the dimension is relatively large for a one in. diameter nozzle to obtain local flow conditions where gradients are large. For a sonic jet exhaust Mach number, Fig. 7a, the sonlc Mach number extends to nearly 3 diameters from the jet exit and the flow is mixing rapidly with the ambient air so that the sonic region 
Is relatively small downstream of the nozzle exit. Consequently, the sonic jet has flow characteristics similar to the subsonic jets where the subsonic mixing region is dominant and no Mach waves are present like the supersonic jets.

By plotting the radial Mach number distributions at various axial distances from the jet exit for subsonic Mach numbers of 0.6 to 1.0 , Figs. $4 b-7 b$, the change in the large velocity gradient existing at the nozzle exit with distance becomes more evident. For all of these subsonic Mach numbers the flow Mach number decreases very rapidly at the nozzle exit as a function of the radial distance from the axis. As the axial distance increases from the nozzle exit, the velocity in the central region of the jet decreases and the jet spreads out with the mixing of the primary jet with the ambient alr. For all of these subsonic Mach numbers the radial velocity distributions at the 18 diameter location from the nozzle were rather gradual as indicated in Figs. 4b - 7b. The transitions in the radial velocity distributions with axial distance for these subsonic Mach numbers were also rather gradual as indicated by these flgures. At a greater distance than 18 diameters from the nozzle exit the velocity in the jet becomes smaller as found in Ref. 3 from the axial velocity measurements over 40 diameters from a 2 in. diameter nozzle. For a sonic jet Mach number the radial distribution across the nozzle exit was nearly uniform as shown in Fig. $7 b$ and the velocity on the axis was sonic at the $3 \mathrm{in}$. location. But at the $5 \mathrm{in}$. location the flow Mach number had decreased to 0.93 on the jet axıs.

In Figs. $8 a$ and 9 a the contours of constant flow Mach number are presented for supersonic jet Mach numbers of 1.2 and 1.4 , and the corresponding radial distributions of the Mach number for various distances from the convergent nozzle exit are presented in Figs. $8 \mathrm{~b}$ and $9 \mathrm{~b}$. By comparing the Mach $I$ contours for jet Mach numbers of $1.0,1.2$, and 1.4 , the supersonic mixing region increases very rapidly with the jet Mach number as found previously in Refs. 3 and 18. The intersection of the sonic contour with the jet axis increased from approximately 2.75 to 10.7 diameters from the nozale exit for jet Mach numbers of 1.0 and 1.4 respectively as indicated in Figs. $7 a-9 a$. The increase in the supersonic region varies approximately as the square of the jet Mach number as observed previously in Refs. 3 and 18. This rather rapld increase in the supersonic region with Mach number was also indicated by the shadowgraph photographs of the sonic and supersonic jet flows in Figs. $3 \mathrm{~b}$ and $c$. The shock bottles in the shadowgraph photographs gave the approximate extent of the supersonic region of the jet flow, but impact pressure, hot-wire, or laser radial and axial surveys are necessary to locate the boundary of the supersonic and subsonic turbulent mixing regions for sonic and supersonic jets. Even at the jet Mach number of 1.2 the supersonic region extended to approximately 7.4 diameters from the nozzle exit, FIg. 8a, which is nearly twlce the length compared to the sonic 
Jet, Fig. $7 \mathrm{a}$.

With convergent nozzles operated at pressure ratios greater than the value to produce sonic exhaust velocity, the shock bottles are produced in the supersonic region $2,3,10,13$ so that the flow Mach number varies along the jet axis depending upon the location relative to the shock waves, Fig. 3c. For these radial and axial surveys for supersonic jet Mach numbers the axial and radial spacings were too large to observe the detalled flow Mach number variation along the jet axis as indicated by the shadowgraph photographs, Fig. 3c, for Jet Mach numbers of 1.2 and 1.4. At these Mach numbers the region of subsonic turbulent mixing close to the nozzle exit is rather small as indicated by the velocity contours in Figs. $8 \mathrm{a}$ and $9 \mathrm{a}$ and shadowgraph photographs in Fig. 3c. But this subsonic mixing region for the supersonic jets increases rapidly with axial distance. Thus, for supersonic jet Mach numbers the nolse generated in the supersonic turbulent mixing region must propagate through the supersonic and subsonic region before the acoustic radiation emits to the surrounding quiescent atmosphere. It is not clear at present what type of norse generation, monopole, dipole, quadrupole, or osclllating shock waves is the dominant acoustic source in the supersonlc core and turbulent mixing regions. These velocity contours for supersonic jets do define the region of supersonic and subsonic flows.

In the subsonic turbulent mixing region surrounding the sonic and supersonic regions, Flgs. 7a - 9a for Mach 1.0, 1.2, and 1.4 Jets, nolse will be generated due to turbulent velocity fluctuations and this acoustic radiation will propagate through the subsonic turbulent mixing region to the outside. The acoustic radiation will have to propagate through a region of large velocity gradient as shown by the velocity contours for subsonic and supersonic jets. The generation and transmission of the acoustic radiation in the subsonic turbulent mixing region with large velocity gradients from sonic to zero velocity in the subsonic mixing region are still not too well understood except for Idealized cases $4,36-\overline{3} 9$. Once the jet flow becomes completely subsonic across the jet, from initial supersonic jet Mach numbers, the subsonic turbulent mixing regions are similar as observed previously in Ref. 3 and will be discussed in more detall in the latter part of this report.

The radial flow Mach number distributions for jet Mach numbers of $1.0,1.2$, and 1.4, Figs. $7 b-9 b$, Indicate that large veloclty gradients exist in the vicinity of the nozzle exit, which were evident in the shadowgraph photographs, Figs. $3 \mathrm{~b}$ and $3 \mathrm{c}$. This large velocity gradient at the jet periphery exists over greater distances from the nozzle exit with increasing supersonic Mach numbers. Also, from the radial velocity distributions it is evident that the region of supersonic flow increases rapidly with the jet Mach number. Because of the presence of the shock bottles in the supersonic jet Mach numbers 
of 1.2 and 1.4 the flow Mach number distributions across the jet at a fixed axial location close to the nozzle exit are not constant, Figs. $8 \mathrm{~b}$ and $9 \mathrm{~b}$, as would be observed for a contoured nozzle for parallel flow at the exit as observed in Refs. 9, 10, 15, 16. Once the flow in the jet becomes subsonic for these supersonic Mach numbers the variations of the Mach number across the jet are quite similar for initial jet Mach numbers of 1.0 , 1.2 , and 1.4. This jet mixing phenomena for supersonic jets were observed by other investigators $9,10,15$.

\subsection{Piezoelectric Pressure Fluctuation Distributions}

Since hot-wires with high frequency response, which is necessary for supersonic velocities, are too fraglle to use in high velocity alr streams, a Kistler quartz plezoelectric pressure transducer with a response time of less than $20 \mu$ sec. was used to measure the pressure fluctuations. These gages have been used extensively for measuring static and impact pressures in the hypersonic shock tunnel 48 where the hypersonic flow duration time in the test section is approximately 3 milliseconds. For the present investigation of the flow field with the piezoelectrıc pressure transducer, the alameter of the Kistler gage was $1 / 4 \mathrm{In}$. and It was used with the gage surface exposed as an impact pressure probe. Some preliminary results were obtained with a smaller lead-zirconate-titanate gage with an outside diameter of $3 / 32 \mathrm{ln}$. and the shape of the pressure fluctuation distributions were very close to that observed with the larger Kistler gage. Recent results $3,29-34$ with microphone and plezoelectric pressure gages in subsonic turbulent flows and jets have indicated chat the output of the piezoelectric impact pressure probe is a function of the turbulent velocity fluctuations. In the next section of this report an analysis of the piezoelectric pressure filuctuations and correlation with hot-wire data for subsonic jets will be presented.

The radial distributions of the piezoelectric pressure fiuctuations are presented in Figs. 4c - 7c for subsonic jet Mach numbers of 0.6 to 1.0 . In these figures the output of the Kistler gage from the pressure fluctuations was measurea with a Ballantine voltmeter and given in terms of rms in mv. For all of these subsonic jet Mach numbers the magnitude of the piezoelectric pressure fluctuations at the exit plane of the convergent jet was nearly constant across the nozzle and the magnitude was quite low. This may be due to the fact that the one in. diameter convergent nozzle was attached to a 6 in. diameter plenum chamber for large area contraction ratio in order to dampen the disturbances in the flow. At the one in. axial location from the nozzle exit the amplitude of the plezoelectric pressure fluctuations increased compared to the nozzle exit for these subsonic Mach numbers. At this axial station the peak pressure fluctuations occurred at approximately $r / r_{0}=1.1$ for 
jet Mach numbers of 0.6 and 0.7 , FIgs. $4 \mathrm{c}$ and $5 \mathrm{c}$, whlle the peaks were sharper and were located at $r / r_{0}=1.0$ for jet Mach numbers of 0.85 and 1.0, FIgs. $6 \mathrm{c}$ and $7 \mathrm{c}$. These pressure fluctuations results agree with the jet flow boundary indicated In the shadowgraph photographs, FIg. $3 a$ and b. For an axial distance of 3 diameters from the nozzle exit the maximum magnitude of the piezoelectric pressure fluctuations occurred at approximately the $x / r_{0}=0.75$ location for jet Mach numbers of 0.6 to 1.0, Figs. 4c-7c. And for these subsonic jet Mach numbers the magnitude of the peak pressure fluctuations was nearly five times that existing at the jet exit plane. The highest plezoelectric pressure fluctuations occurred at approximately $r / r_{0}=0.5$ at an axial location of 5 diameters for these Mach numbers and the magnitude of the peak pressure fluctuations was approximately 6 times the pressure fluctuations existing at the jet exit.

For axial distances greater than 5 diameters from the jet exit, the magnitude of the plezoelectric pressure fluctuations decreased and the peak fluctuations occurred on the jet axis as Indlcated in Figs. 4c - 7c. At a distance of 18 diameters the variations of the piezoelectric pressure fluctuations across the jet flow were quite simllar for jet Mach numbers of 0.6 to 1.0. The magnitude of the pressure fluctuations on the axis of the jet decreased to the value existing at the jet exit for an axlal distance of approximately 18 diameters for jet Mach numbers of 0.6 to 1.0 as indicated in Figs. $4 \mathrm{c}-7 \mathrm{c}$.

The radial distributions of the plezoelectric pressure fluctuations for supersonic jet Mach numbers of 1.2 and 1.4 are presented in Figs. 8c and 9c. For these Mach numbers the piezoelectric pressure fluctuations are nearly constant across the nozzle exit, but at an axial location of one diameter downstream the piezoelectric pressure fluctuations are lower over most of the central portion of the jet than at the nozzle exit. But at a sonlc jet Mach number the plezoelectric pressure fluctuations are about the same on the axis for both the nozzle exit and one diameter downstream as indicated in Fig. 7c. The radial location of peak pressure fluctuations for Mach numbers of 1.2 and 1.4 moved from $r / r_{0}=1.0$ at an axial distance of one diameter to the $r / r_{0}=0.25$ location for an axial position of 7 diameters at a Mach number of 1.2 and to $\mathrm{r} / \mathrm{r}_{0}=$ 0.25 at an axial position of 9 diameters for a Mach number of 1.4. Downstream of the position for peak pressure fluctuations the radial variations of the pressure fluctuations for these supersonic Mach numbers were simllar to those observed with sonlc and subsonic jets with the peak occurring on the jet axis and decreasing away from the axis. The ratios of the peak pressure fluctuations occurring in the jet flow to that at the nozzle exit were approximately 7.5 and 9 for jet Mach numbers of 1.2 and 1.4 respectively as indicated In Figs. $8 \mathrm{c}$ and $9 \mathrm{c}$. These ratios are higher than those observed for sonic and subsonic jets. 
In FIg. 4a - 9a the contours of constant plezoelectric pressure fluctuations are presented for jet Mach numbers $0 \equiv 0.6$ to 1.4 . For subsonic jet Mach numbers of 0.6 to 1.0, Figs. $4 a-7 a$, the contours of constant amplitude of the piezoelectric pressure fluctuations are quite similar like the contours of constant flow Mach number in the flow. The region of peak pressure fluctuations for these subsonic Mach numbers occurred not on the jet axis but off the axis in a toroldal region. And the peak toroldal pressure fluctuations were located over an axial distance of 4 to 6 diameters as Indicated in these figures. The centers of these toroldal regions were located at approximately 50 percent of the nozzle radius from the jet axis. For these subsonic jet Mach numbers the toroldal region of peak pressure fluctuations occurred downstream of the core region In the flow adjustment region before the fully developed turbulent flow was established. The shadowgrapn photographs, Figs. $3 a$ and $3 b$, for these subsonic Mach numbers seem to indicate the existence of a high turbulence region as observed with piezoelectric pressure fluctuations. Downstream of the location for the peak pressure fluctuations the contours of constant pressure fluctuations indicate that the amplitude of pressure fluctuations for a given axial location was not highest on the jet axis but was located approximately 50 percent of the nozzle radıus from the axis. Even. for the $18 \mathrm{in}$. location from the nozzle exit the amplitude of pressure fluctuations was not the greatest on the jet axis. Evidently it requires a greater distance from the nozzle exit for the jet to become fully turbulent with peak pressure fluctuations occurring on the axis. Additional investigations will be conducted with the plezoelectric pressure gage to determine the radial distributions of the pressure fluctuations for axial distance of 18 to 40 diameters from the nozzle exit.

For supersonic Mach numbers of 1.2 and 1.4, Figs. $8 \mathrm{a}$ and $9 \mathrm{a}$, the peak pressure fluctuations were located in a toroldal region as for subsonlc jets, but these toroldal regions were locatea farther downstream from the nozzle exıt. At a jet Mach number of 1.2 the toroldal region for the peak amplitude of pressure fluctuation was located over an axial distance of approximately 5 to 8 diameters from the nozzle exit, and the toroldal region was located at approximately 40 percent of the nozzle radius from the jet axis. Also, it is interesting to note that the peak pressure fluctuations occurred close co the sonic velocity at all axial locations as shown in Fig. 8a. At any given axial location in the supersonic region there is a very large increase In the pressure fluctuations with distance from the axis anc they attain a peak value at the sonic line before decreasing rapidly outside the sonic velocity region. Downstream of the supersonic region, the contours of the piezoelectric pressure fluctuations are similar to those observed for subsonic jets.

As the jet Mach number was increased to 1.4, the coroldal region of the peak pressure fluctuations moved farther downstream 
and occurred over an axial distance of approximately 7 to 9 diameters as shown in FIg. 9 a. Also, this toroldal region was located closer to the axis than for the Mach 1.2 jet. Again the amplitude of the peak pressure fluctuations occurred close to the sonic velocity location in the jet. The shadowgraph photograph, Fig. 3c, of the jet flow at a Mach number of 1.4 indicates the approximate location of the sonic veloclty from the shock bottles. Sonic velocicy must be close to the outer edge of each shock bottle. The radial dimension of the shock bottles decreases with the axial distance from the nozzle exit. On the axis of the jet the flow became sonic at approximately 10.7 diameters from the nozzle exit. Again for this supersonic Mach number the peak pressure fluctuations increased with radial distance from the jet axis for a given axıal distance in the supersonic region to the peak value in the vicinity of the sonic velocity before decreasing towards the outer edge of jet in the subsonzc mixing region as shown in Fig. 9a. Downstream of the supersonic region the contours of constant pressure fluctuations were similar to those existing at sonıc and subsonic Mach numbers, Figs. 4a - 7a. 
4.0 PIEZOELECTRIC PRESSURE FLUCTUATIONS AND TURBULENT VELOCITY FLUCTUATIONS

\subsection{Hot-Wire and Piezoelectric Pressure Fluctuations}

The nolse produced by a subsonic jet exhausting into ambient alr is due primarily to the turbulence in the highly sheared mixing region as shown by IIghthill in Refs. 4 and 5 on sound generated aerodynamically. He derıved the exact equations of motion in a compressible fluid and compared these with the equations of sound propagation in a medium at rest with the introduction of the stress tensor $T$ as the forcing function. To solve the exact equation for the dcoustic propagation from subsonic jets, it is necessary to know the strength and distributzons of the stress tensor in the flow field.

Since the appearance of IIghthl 1 l's papers on aerodynamic nolse, different investigators $7,8,20-2 \frac{3}{3}$ have investigated the distribution of the turbulence levels for subsonic and supersonic jets. The majority of the avallable references for the turbulence level in subsonic jets were obtalned with the use of hotwire, but for high subsonic and supersonlc jet velocities the environment in the jet flow is too severe for the hot-wire to survive. Thus, in the past few years other investigators $27,2 \delta$ have investigated the use of optical methods to determine the turbulence levels in hlgh subsonlc and supersonlc jets. In principle the optical technique is not limited by the jet velocity and it is possible to determine the turbulent velocity fluctuations without disturbing the flow. Besides the optical techniques to determine the turbulence level in the high veloclty jets, piezoelectric pressure transducers have been investigated in subsonic flows 29,30 and jets $31-34$ and in supersonlc jet flows ${ }^{2}, 3$. The plezoelectric pressure gages have been used as impact and static pressure probe configurations. In this Section the piezoelectric pressure gage results will be correlated with the hot-wire measurements and an analysis will be presented to show relationship between the plezoelectric pressure fluctuations and the local turbulent velocity fluctuations.

Laurence ${ }^{7}$ surveyed a room temperature subsonic jet with a hotwire and obtalned the velocity proflles, turbulence intensities and spectra for a $3.5 \mathrm{ln}$. diameter jet at Mach numbers of 0.3 and 0.7. In FIg. 10 the hot-wire data along the axis for a Mach number of 0.3 Is presented. Laurence's results for the level of the axial velocity fluctuations was normalized with respect to the peak value located at approximately 9 diameters downstream of the nozzle exit. Bradshaw and colleagues investrgated the turbulence in a circular jet with a hot-wire at a Mach number of 0.3 . A 2 in. diameter nozzle was used in their study and great care was exercised in minlmizing the turbulence level and disturbances in the reservolr section before the room 
temperature alr was accelerated through a contraction region of $36: 1$. For this nozzle arrangement the boundary layer at the exit was found to be laminar at a Mach number of 0.3 , and the normalized velocity fluctuations along the axis are presented in Fig. 10. Pettıt 28 conducted an experimental program to test the validity of the laser Doppler velocimeter for measuring the turbulence against the not-wire measurements in a subsonic air jet at a Mach number of 0.3. For this purpose a small 1/2 In. diameter jet was constructea and attached to a $4 \mathrm{In}$. drameter plenum chamber with screens and honeycomb. The hot-wire data for the velocity fluctuations along the axis are presented in FIg. 10 and the results agreed well with the data of Laurence and Bradshaw for slightly larger diameter jets at Mach 0.3 .

The plezoelectric pressure fluctuations with an impact pressure probe configuration were obtained in Ref. 3 for a convergent nozzle with a diameter of 2 in. From the impact and total temperature probe surveys along the axis, the variations of the velocity and Mach number were determined over a jet Mach number range of 0.6 to 1.4. Over the subsonic jet Mach numbers of 0.6 to 1.0 the uniform velocity core region extended to approximately 5 diameters downstream of the nozzle exit. Also, the peak pıezoelectrıc pressure fluctuations occurred at approximately 9 diameters for these subsonlc Mach numbers. The piezoelectric pressure fluctuations along the axis were normalized with the peak value occurring at the 9 diameter location for a jet Mach number of 0.6 and the results are presented In FIg. 10. It is interesting to observe the excellent agreement between the hot-wire data $7,8,28$ for the velocity fluctuations and the piezoelectric pressure data from the nozzle exit to the peak velocity fluctuation location. Downstream of the peak fluctuations the normalized plezoelectric pressure values are less than the normalized hot-wire results ard this difference will be discussed in the next part of this section.

\subsection{Analysis of Piezoelectric Pressure Fluctuations at the Stagnation Point of a Probe}

The analysis of the measurements of the total and static pressures in an incompressible turbulent flow with pitot and static pressure probes was made by Goldsteın 49 and experiments were conducted by Fage 50 to determine the effects of fully developed turbulence on the reading of the static pressure probes in subsonic Incompressible flows. An extensive siudy of the effects that fluctuating flows have upon the statıc pressure measurements ${ }^{\prime} n$ a turbulent flow and in a subsonic jet was made by Sidon ${ }^{29}$, and he found that the correction to the root-meansquare pressure level was small in a fully curbulent flow. Nakamura and assoclates 30 and Fuchs and asscciates 31,34 conducted investigations with total and static pressure probes with microphones as the sensing units to measure the pressure 
fluctuations in fully developed subsonic turbulent pipe flow and in the mixing region of a subsonic jet.

In a fully developed turbulent flow at low subsonic velocities with no appreciable shear gradient, the turbulent flow can be considered as roughly isotropic, so that

$$
\overline{\mathrm{u}^{12}}=\overline{\mathrm{v}^{12}}=\overline{\mathrm{w}^{\prime 2}}=\frac{1}{3} \overline{\mathrm{q}^{\prime 2}}
$$

where $u^{\prime}, v^{\prime}$, and $w^{\prime}$ are the turbulent veloclty components in the cartesian coordinate system. For a flow with uniform mean velocity in the $x$-durection, the velocity componerts can be expressed as

$$
\begin{aligned}
& \mathrm{u}=\overline{\mathrm{U}}+\mathrm{u}^{\prime} \\
& \mathrm{v}=\mathrm{v}^{\prime} \\
& \mathrm{w}=\mathrm{w}^{\prime}
\end{aligned}
$$

since $\bar{V}$ and $\bar{W}$ vanish in the assumed axial symmetric turbulent flow. For this assumed low speed homogeneous lsotroplc turbulent flow there will be a mean static pressure $\bar{p}$. Besides this mean pressure there wlll be pressure fluctuations assoclated with the turbulent flow Itself and the mean-square pressure fluctuation was derived by Kraıchnan 51 as

$$
\left\langle\overline{\mathrm{p}^{\prime 2}}\right\rangle=\overline{\mathrm{p}}^{2} \mathrm{u}^{14} \mathrm{c}^{-4}
$$

where $c$ is the velocity of sound. And the ratio of the turbulence velocity in the flow direction to the local velocity of sound can be considered as the local turbulence Mach number

$$
\mathrm{M}^{\prime}=\frac{\mathrm{u}^{\prime}}{\mathrm{C}}
$$

Since at low flow Mach number $\frac{\overline{\mathrm{U}}}{\mathrm{C}} \ll I$, the turbulent velocity u' is usually much smaller than the mean flow velocity $\bar{\sigma}$ so that the magnitude of the pressure fluctuations assoclated with the turbulent flow Itself is small as given by Eq. (6). And only at higher subsonic velocities does the turbulent pressure fluctuations become appreciable to produce acoustic radiation. Besides the turbulent pressure fluctuations there will be a pressure fluctuation in low speed flows due to a sound field being superimposed from outside the flow or generated aerodynamically in the flow and this pressure fluctuation wil be denoted by $\tilde{p}$. Thus, in a low speed homogeneous ısotropic turbulent flow there will be a pressure in the flow given by

$$
\mathrm{p}=\overline{\mathrm{p}}+\left\langle\mathrm{p}^{\prime}\right\rangle+\tilde{\mathrm{p}}
$$

The pressure fluctuations caused by turbulence, $\left\langle p^{\prime}\right\rangle$, wII be assumed to propagate close to the velocity of the arrflow, while 
the pressure fluctuations due to acoustic field will propagate with the velocity of sound for low subsonic flow velocity.

When a probe with a plezoelectric pressure gage is inserted into the turbulent flow, there will be pressure fluctuations generated by the Interaction between the probe and the turbulent flow adjacent to 2t. These pressure fluctuations appear as a self-generated noise and must be considered as an interference factor for pressure measurements in a moving medium. sidon 29 investigated an error-compensating scheme for correcting the unsteady pressure measurements for low speed turbulent flow. For an impact pressure probe configuration with a piezoelectric pressure gage, the self-generated nolse effects are small, but this is not the case for the static pressure probe.

At the stagnation point of the $1 / 4$ In. diameter plezoelectric pressure gage with the pressure sensing surface exposed normal to the flow direction, the turbulent flow is forced to come to a rest, and in this region there are strong gradients of the flow properties. For a low subsonic flow the density can be considered to be constant so at the stagnation region there will be large velocity and pressure gradients as the flow is decelerated to zero velocity at the stagnation point. Thus, in this region the spatial changes will exceed any temporal ones. Under these circumstances the total pressure along a streamline in turbulent flow from Bernoulli's equation is given by

$$
\mathrm{p}_{\mathrm{T}}=\mathrm{p}+\frac{1}{2} \rho \mathrm{q}^{2}
$$

where $q$ is the vector velocity consisting of a mean vector velocity and a vector turbulent velocity. By substituting Eqs. (5) and (8) into Eq. (9) and neglecting higher order terms of the turbulent velocity fluctuations, Eq. (9) can be split into mean and fluctuating parts respectively:

$$
\begin{aligned}
& \overline{\mathrm{p}}_{\mathrm{T}}=\overline{\mathrm{p}}+\frac{\mathrm{l}}{2} \rho \overline{\mathrm{U}}^{2} \\
& \mathrm{p}_{\mathrm{T}}^{\prime}=\left\langle\mathrm{p}^{\prime}\right\rangle+\tilde{\mathrm{p}}+\rho \overline{\mathrm{U}} \mathrm{u}^{\prime}
\end{aligned}
$$

It Is Implied in this IInearization that the following velocity conditions are satisfied

$$
\begin{aligned}
& u^{\prime}, \dot{v}^{\prime}, w^{\prime} \ll \bar{U} \\
& u^{\prime 2}, v^{\prime 2}, w^{\prime 2} \ll u^{\prime} \bar{U}
\end{aligned}
$$

and the flow velocity is low so that turbulent flow can be considered as being incompressible with constant density. The contribution of the pressure fluctuations due to turbulence 
$\left\langle p^{\prime}\right\rangle$ given by Eq. (6) for low speed isotropic turbulent flow should be small and Nakamura et al 30 have obtained experimental data in low speed turbulent pipe flow which confirms the low level of pressure fluctuations due to turbulence. Fuchs 32 in his analysis of the pressure fluctuations at the stagnation pount for low speed turbulent flow showed that the static pressure fluctuation was an order of magnitude smaller than the total head fluctuations.

When the acoustic field from outside the flow field and the aerodynamic noise produced by the turbulence is negligible, the acoustic pressure fluctuation $\tilde{p}$ in $\mathrm{Eq}$. (11) can also be neglected. Thus, the plezoelectric pressure fluctuation with a total pressure probe configuration in a low speed turbulent flow with negligible acoustic field is given by

$$
\mathrm{p}_{\mathrm{T}}^{\prime} \cong \rho \overline{\mathrm{U}} \mathrm{u}^{\prime}
$$

whIch is dependent on the axial veloclty fluctuations and the local mean velocity. Thus, a plezoelectric pressure gage in an Impact probe configuration can be used in place of hot-wire method to investigate the fluctuations in unsteady flows as discussed by Siddon 29 and Fuchs 31 , and the correlation of the hot-wire and plezoelectric pressure probe data in Fig. 10 confirms this hypothesis for low speed turbulent flow encountered in the mixing region of subsonic jets.

The application of Eq. (IIa) to determine the velocity fluctuations for higher subsonic and supersonic unsteady flows mus be used with caution because the flow can no longer be considered as being incompressible with constant density. Also, in deriving this equation it was assumed that the pressure fluctuations cue to turbulence and the sound field generated aerodynamically are negligible for low speed unsteady flows. At higher velocities where compressible effects and pressure fluctuations due to turbulence and aerodynamically generated sound fields are not small in Eq. (8), they must be considered in the piezoelectric pressure fluctuations. For supersonic flows there will be a detached shock ahead of the lmpact pressure probe so that the pressure fluctuations assoclated with the shock waves must be considered. Iaser technıque ${ }^{28}$ and addıtional stagnation and static pressure fluctuations $w 111$ be obtalned for subsonic and supersonic jet velocities to develop a relationship between the piezoelectric pressure fluctuations at the stagnation point iith the turbulent velocity fluctuations.

The plezoelectric pressure fluctuations with the impact pressure probe can be normalized with respect to the jet exit velocit:- $\bar{U}_{J}$ to obtain

$$
\frac{p_{T}^{\prime}}{\rho \bar{U}_{J}^{2}}=\frac{\bar{U}}{\bar{U}_{J}} \frac{\underline{u}^{\prime}}{\overline{\mathrm{U}}_{J}}
$$


And the axial velocity fluctuations can be expressed as

$$
\frac{u^{\prime}}{\overline{\mathrm{U}}_{J}}=\frac{\mathrm{p}_{\mathrm{T}}^{\prime}}{\rho \overline{\mathrm{U}}_{J}^{2}} \cdot \frac{1}{\frac{\overline{\mathrm{U}}}{\overline{\mathrm{U}}_{J}}}
$$

In Figs. Ila and Ilb the variations of the mean velocity along the jet axis are presented for convergent nozzles with an exit dlameter of 1 and 2 in. respectively for jet Mach numbers of 0.6 to 1.4. For both nozzles the velocity decay along the axis with distance for subsonic Mach numbers of 0.6 to 1.0 downstream of the initial core mixing region when the fully turbulent flow is established in the jet is given by

$$
\frac{\overrightarrow{\mathrm{U}}}{\overrightarrow{\mathrm{U}}_{J}} \propto(x / D)^{-I}
$$

For supersonic jet Mach numbers of 1.2 and 1.4 , the sonic locations for these Mach numbers are shown in FIgs. $11 \mathrm{a}$ and $11 \mathrm{~b}$, and downstream of the sonic locations in the fully developed subsonic turbulent flow the mean velocity decay for these supersonic jet Mach numbers Is given by Eq. (15). As the supersonlc jet Mach number increases the sonic location moves downstream as the square of the Mach number as discussed in Refs. 3, 17 and 18 . Thus, for supersonic jets with ambient reservolr temperature, the velocity in the fully developed turbulent subsonic flow decays like that for subsonic jets.

By comparing the core lengths, in terms of nozzle diameters, for subsonic Mach numbers of 0.6 to 1.0 for these two nozzles In Figs. $11 \mathrm{a}$ and $1 \mathrm{lb}$, the core length is shorter for the 1 in. nozzle than for the 2 in. nozzle. This difference is probably caused primarily by the higher initial turbulence level in the reservoir for the smallex dlameter nozzle. Also, the core length for the $2 \mathrm{In}$. diameter was approxlmately 5 dlameters from the nozzle exit, which is higher than most published data and implies that the initial turbulence level was quite low. But It is interesting to note that in spite of the difference in core lengths for these two nozzles the velocity decay in the fully established turbulent flow regions for these nozzles was the same. Evidently the initial turbulence level in the jet flow does not influence the velocity decay in the fully turbulent flow region. Similar flow phenomena were observed at the supersonic jet Mach numbers of 1.2 and 1.4 for these two nozzles as Indicated in Figs. Ila and lib.

The velocity decay along the axis for a heated jet will be more rapid than that for a room temperature jet because of the heat 
transfer to the amblent air as discussed in Refs. 9, 10 and 15. But, the sonlc location for supersonic jets is mainly governed by the jet Mach number and not influenced appreclably by the temperature as discussed in Refs. 3, 17 and 18. The avallable data on the velocity decay with heated jets are still limited because of the difflculties of measuring flow properties at hıgh temperatures.

The variations of the plezoelectric pressure fluctuations on the axis with distance from the nozzle exit are presented in Figs. $12 \mathrm{a}$ and $12 \mathrm{~b}$ for 1 and 2 in. dlameter nozzles, respectively. These fluctuating pressure data were obtained with the quartz plezoelectric pressure gage used as an impact probe and the results for the 2 in. nozzle were obtained previously ${ }^{3}$. The pressure fluctuations determined for the 1 in. diameter nozzle are not as reliable close to the nozzle exit locations as for the 2 in. diameter nozzle because the outslde diameter of the Kistler probe was $1 / 4$ In. As the jet spreads out with distance due to mixing with the ambient arr the ratio of the probe diameter to the jet diameter becomes smaller so that the plezoelectric pressure fluctuations data should be more representative of the local. flow conditions.

By comparing the variations of the pressure fluctuations along the jet axis for both nozzles, Figs. $12 \mathrm{a}$ and $12 \mathrm{~b}$, It 1 s seen that the peak pressure fluctuations occurred at approximately 6 and 7 diameters from the $1 \mathrm{ln}$. diameter nozzle exit for jet Mach numbers of 0.6 and 1.0 respectively. While for the 2 in. nozzle the location of the peak pressure fluctuations occurred at approximately 9 diameters for these subsonic Mach numbers. Similar differences in the lengths of the unlform velocity core were observed with these nozzles at subsonic jet velocities, Figs. Ila and Ilb. But the magnitude of the peak pressure fluctuations for these nozzles was about the same for the subsonic Mach numbers. Also, the variations of the pressure fluctuations with distance downstream of the peak location for both nozzles at subsonic jet velocities were the same within the experimental accuracy, and this variation can be expressed as

$$
\mathrm{p}_{\mathrm{T}}^{\prime} \propto(\mathrm{x} / \mathrm{D})^{-1.74}
$$

For supersonic jet Mach numbers of 1.2 and 1.4 the location of the peak pressure fluctuations on the axis occurred in the vicinity of the sonic velocity or near the end of the supersonlc region for both nozzles as indicated in Figs. 12a and $12 \mathrm{~b}$. With the 1 In. nozzle the locations of the peak pressure fluctuations were 8 and 9 diameters for Mach numbers of 1.2 and 1.4 respectively. While the locations of the peak pressure fluctuations were 8.5 and 11.5 diameters for the corresponding supersonic Mach numbers with the $2 \mathrm{In}$. nozzle. The magnitude of the peak pressure fluctuations was about the same for these supersonlc Mach numbers for both nozzles. Downstream of the peak 
pressure fluctuations in the subsonic turbulent flow, the variations of the pressure fluctuations with distance were the same as observed for subsonic jet Mach numbers with these two nozzles as indicated in Figs. $12 \mathrm{a}$ and $12 \mathrm{~b}$. Similar results were observed with the velocity decay, Eq. (15), in the subsonic fully developed turbulent flows for both subsonlc and supersonic jets, Flgs. Ila and $11 \mathrm{~b}$.

It was shown in the analysis for a low speed turbulent flow that the piezoelectric pressure fluctuation for an impact probe configuration is related to the local density, mean velocity, and fluctuating velocity as given by Eq. (11a). In FIg. 10 the normalized hot-wire and plezoelectric pressure data correlated well from the nozzle exit to the location of peak fluctuations for subsonic jet Mach numbers, but downstream of this location the normalized pressure fluctuations were lower than that observed with the hot-wire data. The velocity fluctuations for the hot-wire data were normalized with respect to the InItial jet velocity while the magnitude of the plezoelectric pressure -fluctuations is dependent upon the local mean velocity, which Is decreasing along the axis, Eq. (15). Thus, the plezoelectric pressure data must be correlated to determine the axial velocity fluctuations in terms of the initial jet velocity by substituting Eqs. (15) and (16) into Eq. (14) to obtain

$$
\frac{\mathrm{u}^{\prime}}{\overline{\mathrm{U}}_{\mathrm{J}}} \propto(\mathrm{x} / \mathrm{D})^{-.74}
$$

By correcting the plezoelectric pressure data downstream of the location for the peak velocity fluctuations by this equation, the corrected normalized plezoelectric pressure data correlates reasonably well with the hot-wire results. Further investigations will be conducted with laser technique and piezoelectric pressure gage to determine the turbulent velocity fluctuations in high subsonic and supersonic jets. 


\subsection{ANALYSIS OF EXPERIMENTAI FLOW AND ACOUSTIC RESULTS}

\section{I Flow and Acoustic Characteristics}

\subsubsection{Flow Characteristics for subsonic and supersonic Jets}

The shadowgraphs, Figs. $3 a-c$, of the subsonic and supersonic jet velocities from a 1 in. diameter convergent nozzle were taken with a $0.4 \mu$ sec spark light source. These photographs indicated that the flow structures for subsonic Mach numbers of 0.6 to 1.0 were quite similar, but as soon as the flow became supersonic jet Mach numbers of 1.2 and 1.4 the flow structure changed with the appearance of shock bottles in the flow. In Ref. 3 the flow phenomena for subsonic and supersonic jets were observed with interferometer, schlieren, and shadowgraph photographs. All of these optical photographs have indicated the similarities and differences in the flow structure for subsonic and supersonic jets.

Besıdes the optical studies of the jet flow phenomena axial surveys were conducted In Ref. 3 with Impact pressure, total temperature, and plezoelectrıc probes over a Mach number range of 0.6 to 1.4. These results indicated that the axial velocity distributions were similar for the subsonic Mach numbers of 0.6 to 1.0 and for supersonic Mach numbers of 1.2 and 1.4 the supersonic region increased as the square of the jet Mach number. In the present investigation with the 1 in. diameter convergent nozzle, extensive axial and radial surveys were conducted with both impact pressure and plezoelectrıc pressure probes to determine the mean velocity and plezoelectric pressure fluctuations In subsonic and supersonic jets, and the results are presented in Figs. 4-12. Along the axis the velocity and plezoelectric pressure variations with distance from the nozzle exit were simllar for both 1 and 2 In. diameter nozzles over a Mach number range of 0.6 to 1.4 .

From the radial and axial surveys in the present investigation the contours of constant Mach number and plezoelectrlc pressure fluctuation were determined for Mach numbers of 0.6 to 1.4 . These results indicated again the similar flow field for subsonlc Mach numbers of 0.6 to 1.0 and the rapld increase in the supersonic region with Mach number. From these contours for supersonic jet Mach numbers it is possible to determine the supersonic and subsonic mixing regions. At all axial locations where the velocity is supersonic the supersonic core region is surrounded by a subsonic mixing region. The contours of constant magnitude of the piezoelectric pressure fluctuations have indicated that for subsonic Mach numbers of 0.6 to 1.0 the pressure fluctuating fields are similar with the peak fluctuations occurring in a toroidal region at 4 to 6 diameters fror the nozzle exit. But for supersonic Mach numbers of 1.2 and 1.4 the peak pressure fluctuations occurred in the vicinity of the contour for the sonic velociry. 


\subsubsection{Acoustic Characteristics of Subsonic and Supersonic Jets}

The acoustıc data presented in Ref. 3 for a 2 in. diameter convergent nozzle operated over a Mach number range of 0.6 to 1.4 was analyzed to determine the acoustic characteristics of subsonic and supersonic jets. For this range of jet Mach numbers the peak overall sound pressure level occurred at the $19.1^{\circ}$ location from the jet axis. The variations of the overall sound pressure level as a function of the angular position from the jet axis on a lo-ft. radius were normalized with respect to the peak value for a given Mach number and the results are presented in FIg. 13. As the Jet Mach number is increased from 0.6 to 1.0 the normalized overall sound pressure levels vary more over the angular position of $19.1^{\circ}$ to $146.4^{\circ}$ with increase In the subsonic Mach number. For the sonic Mach number the ratio of the normalized overall sound pressure varies continuously from 1.0 to .884 for angular positions of $19.1^{\circ}$ and $146.4^{\circ}$ respectively. But as the jet Mach number increased to 1.2 and 1.4 the variations of the normalized sound pressure level were drastically different than those observed with subsonic jets as Indicated in Fig. 13. The normalized sound pressure level does not monotonically decrease with angle from the jet axis but reaches a minimum value and starts to increase. And for the Mach 1.4 jet the normalized overall sound pressure levels are much greater than for subsonic Mach numbers. These changes in the angular distribution of the normalized overall sound pressure level for the supersonic jets compared to subsonic jets are due primarily to the existence of the shock bottles, Figs. 3b $c$, for supersonic Mach numbers from a convergent nozzle. Dosanjh and colleagues 13 observed simllar effects of the shock bottles on the overall sound pressure level distribution. For sonic and subsonıc jets there are no shock waves so that the overall sound pressure level distributions are similar for subsonic jets with a continuous decrease in the pressure level with increasing angular position from the jet axis.

The sound power spectra for the $2 \mathrm{ln}$. diameter convergent nozzle ${ }^{3}$ at Mach numbers of 0.6 to 1.4 were normalized with respect to the peak thrrd-octave band sound power level for each Mach number and the results are presented in FIg. 14. Since the acoustic measurements were made with the microphone placed on a radius lo-ft. from the nozzle exit, the sound power spectra below $100 \mathrm{~Hz}$, which corresponds to a wave length of approximately $10 \mathrm{ft}$, is in the near field so that scatter in the acoustic data are evident. But for Erequencies higher than $100 \mathrm{~Hz}$ the microphone is in the far field with the wave lengths less than the 10-ft. radius for the microphone measurements. The normalized sound power level spectra for subsonlc jet Mach numbers of 0.6 to 1.0 are practically Identical over the frequency range of $150 \mathrm{~Hz}$ to $16 \mathrm{kHz}$. These results are consistent with the flow observations for these subsonic Mach numbers because the flow characteristics were very similar as determined from the radial and axial surveys. As soon as the jet Mach number increased to 1.2 and 1.4 the 
normalized sound power levels departed from the subsonic power spectra as Indicated in FIg. 14. The frequency for the peak sound power level increased with the supersonic Mach number and there was more acoustic energy in the higher frequencles than for the subsonic jets. This sudden change in the shape of the normalized sound power levels for the supersonic Mach numbers from that of the sonlc and subsonic jets is probably caused primarily by the appearance of the shock bottles in the supersonlc jets. Thus, the normalized overall sound pressure level distribution around the jet and the normalized sound power spectra indlcate the change in the acoustic radiation for supersonıc jets compared to that existing for subsonic jets.

In Ref. 3 the overall sound power levels were determined for the 2 in. diameter convergent nozzle operatea over a Mach number range of 0.6 to 1.4 with a room stagnation temperature for the jet. Since the mass flow of the nozzle decreased for lower Mach numbers from that existing at a Mach number of 1.4, the overall sound power levels were corrected to the Mach 1.4 mass flow of $0.1036 \mathrm{slugs} / \mathrm{sec}$. This was the procedure used to obtain the variation of the overall acoustic power with jet velocity for a constant mass flow. Over the subsonzc velocity range of 672 to $1038 \mathrm{ft} / \mathrm{sec}$., which correspond to jet Mach numbers of 0.6 to 1.0 respectively, the overall acoustic power increased approximately as U ${ }^{8}$. And for the higher velocity range of 1038 to $1346 \mathrm{ft} / \mathrm{sec}$, Mach number of 1.0 to 1.4 respectively, the overall acoustic power level increased approximately as u $\frac{1}{j}$, Flg. 15. There is a discontinuity in the slope of the overall acoustic power variation with velocity for subsonic and supersonic jet velocities. This variation in the overall acoustic power with velocity is different than that predicted by IIghthli1, 5 and others 36,38 in which these authors predicted a decrease in the slope of the overall acoustic power with velocity. In the next section, a discussion on the correlation of the experimental acoustic data with subsonlc jet nolse theory of LIghthili and supersonic theory of Nagamatsu and Horvay 17 will be presented to show the effects of jet temperature, Mach number, and velocity.

The Increase in the slope of the overall sound power with veloclty for the supersonic Mach numbers is caused primarily by the presence of shock bottles wath the convergent nozzles. Dosanjh and colleagues 13 have shown the acoustic radiations from the shock waves at supersonic Mach numbers. Existing jet nolse theories of Iighthili4,5 and Ribner 36 were derived on the acoustic radiation from turbulence but the noise generation from shock waves was not considered in these theories. But the supersonic jet nolse theory of Nagamatsu and Horvay $7^{\circ}$ was based upon the flow and acoustic characteristics of supersonic jets. The effects of the Mach number and shock waves were Included in the theory by the introduction of the parameters $\alpha$ and $\beta$, and these values for convergent and parallel flow nozzles were determined for room temperature jets as functions of jet Mach 
number in Ref. 18.

\subsection{Correlation of Acoustic Data with Jet Noise Theories}

IIghthil1 5 derived an equation for the overall sound power for subsonıc jets by using avallable experimental data and dımensional analysis as

$$
\mathrm{W}=10^{-4} \frac{1}{2} \rho_{\mathrm{a}} \frac{\mathrm{U}_{\mathrm{J}}^{8} \mathrm{~A}}{c_{\mathrm{a}}^{5}}
$$

where It was assumed that the jet density $\rho$ was equal to the amblent density $\rho_{a}$. This equation can also Jbe expressed as

$$
W=10^{-4} \frac{m}{2} \frac{\rho_{J}}{\rho_{a}}\left(\frac{c_{J}}{c_{a}}\right)^{5} c_{J}^{2} M_{J}^{7}
$$

where $m$ Is the mass flow of the jet. In the derivation of this subsonic equation there was no provision for the nolse generation from shock waves for supersonic jets. This equation was used to calculate the overall sound power level for unit slug mass as a function of the jet velocity in Fig. 16. As can be seen in this figure the overall acoustic power levels for a room temperature jet at supersonic Mach numbers are higher than that given by lighthili's theory. At subsonic Mach numbers, 0.85 and 1.0 which are the initial two points respectively in Fig. 16, the correlation between the theory and experiment is quite good, but for the later two points in this figure which are Mach numbers of 1.2 and 1.4 , the experimental sound power level is much higher than predicted by the theory due to the presence of shock bottles.

Nagamatsu and Horvay 17 derıved an equation for the overall acoustic power output for supersonic jets by considering the experimentally observed relationship for the supersonic length, the linear variation of acoustic radiation in the supersonic region, and the subsonic turbulent decay of $x^{-6}$. The overall sound power output from a supersonlc jet can be broken down into the contribution from the supersonic region, $0 \leq \mathrm{x} \leq l_{\mathrm{s}}$ ' and from the subsonic region, $l_{\mathrm{s}} \leq \mathrm{x}<\infty$, by

$$
W=\int_{0}^{\ell_{S}} w d x+\int_{l_{S}}^{\infty} w d x
$$

where $w$ Is the acoustic power output of a jet slice of unit length and is a function of $x$ for a given jet and ambient conditions. Thus, the overall acoustıc power output from a supersonic jet is given by 


$$
w=\frac{10^{-4}}{9.6} m \frac{\rho_{J}}{\rho_{a}}\left(\frac{C_{J}}{C_{a}}\right)\left(c_{J}^{2} M_{J}^{2}\right)\left(5 M_{J}^{2}+0.8\right)\left(\frac{M_{J}^{-\alpha}+M^{-\beta}}{2}+\frac{M_{J}^{-\beta}}{5}\right)
$$

where $\alpha$ and $\beta$ are exponents which have been evaluated in Ref. 18 from experimental acoustic data. This equation was solved In Ref. 17 by using the $\alpha$ and $\beta$ determined from the potter and Jones 16 acoustic data for a parallel flow Mach 2.5 jet for various jet temperatures and Mach numbers and one of the calculated curves are shown in F1g. 16. These calculated results Indicate that the jet temperature and Mach number are important in the overall acoustic power output from supersonic jets. IIghthlll and others had compared the theory with the overall acoustic power output from subsonlc and some supersonic jets as function of jet velocity in which the total temperature and the jet Mach number were varying.

In FIg. 16 the overall acoustic power output for unlt slug mass flow in the jet at various temperatures was calculated from Eq. (18) with $\alpha$ and $\beta$ determined from Potter and Jones data at Mach number of 2.5. The jet total temperature was taken over the range of $520^{\circ}$ to $3500^{\circ} \mathrm{R}$ and for each temperature the subsonic region is given by the dashed line. These acoustic curves indicate the importance of the jet total temperature upon the overall sound power level for varlous jet exhaust velocities. The acoustıc power output for room temperature jets for a jet Mach number range of 0.85 to 1.4 are presented from Ref. 3 . And the acoustic data for a total temperature of approximately $2000^{\circ} \mathrm{R}$ in Ref. 46 were obtalned over a Mach number range of 0.87 to 1.46 , which are close to the range of Ref. 3 for a room temperature jet, but there is a large change in the acoustic power output with velocity, similar to that calculated from Eq. (18). These results indicate the importance of using the correct jet and amblent conditions in the theoretical acoustic correlation with the experimental data. Further acoustic measurements should be obtained for various jet total temperatures over subsonıc to supersonıc jet exhaust velocities. 


\subsection{CONCLUSIONS}

Radial and axial surveys were conducted with impact pressure and piezoelectric pressure transducer probes for a convergent nozzle with an exit diameter of 1 in. over a Mach number range of 0.60 to 1.4. Flow and acoustic results for a 2 in. diameter nozzle were analyzed for subsonic and supersonic jet velocities.

Shadowgraph photographs with a $0.4 \mu$ sec light source were taken of the flow from the convergent nozzle, and for subsonic Mach numbers of 0.6 to 1.0 the flow phenomena were simllar. For supersonjc jet Mach numbers of 1.2 and 1.4 shock bottles were present in the flow with the number of bottles increasing with Mach number. The mixing of the supersonlc jets with the ambient air was slower in the supersonic region than for subsonic jets.

The velocity contours for subsonic jet Mach numbers of 0.6 to 1.0 were quite similar with the core extending to approximately 4 diameters on the axis for the 1 in. nozzle. For these subsonic jet Mach numbers the outer edge of the jet was not too well defined because of the turbulent eddies. At supersonic jet Mach numbers of 1.2 and 1.4 the distance from the nozzle exit to the sonic location on the axis increased as the square of the Mach number.

Contours of the plezoelectric pressure fluctuations for subsonlc Mach numbers of 0.6 to 1.0 were simllar with the peak fluctuations occurring in a torordal region located approximately 4 to 6 diameters from the nozzle. For supersonic Mach numbers of 1.2 to 1.4 the peak plezoelectric pressure fluctuations occurred close to the sonic velocity contour in the supersonic region of the jet. And the peak pressure fluctuations occurred in a toroldal region towards the end of the supersonic region.

An analysis was made to show that the output of a plezoelectric pressure gage as an impact probe is related to the turbulent velocity fluctuations in an isotropic incompressible turbulent flow. The turbulent velocity fluctuations in low speed jets determined with hot-wires were correlated with the plezoelectric pressure gage data and excellent agreement was obtained.

Downstream of the core region for the subsonic jet Mach numbers of 0.6 to 1.0 the velocity decay along the axis in the fully developed turbulent region varied as $\mathrm{x}^{-1}$, and for supersonic jet Mach numbers of 1.2 and 1.4 the velocity decay downstream of the sonic point was also $x^{-1}$. These results for the velocity decay were observed for both $I$ and $2 \mathrm{In}$. dzameter convergent nozzles.

For subsonic jets the piezoelectric pressure fluctuations decayed as $x^{-1.74}$ in the fully developed turbulent flow region. At supersonic Mach numbers the peak pressure fluctuations 
occurred in the vicinity of the sonic velocity contour, and in the subsonic region the pressure fluctuations along the axis decayed as $x^{-1.94}$. These results were also observed for both nozzle diameters used in the present investigation.

The normalized overall sound pressure levels for subsonic jet Mach numbers of 0.6 to 1.0 decreased monotonically with the Increase in the angular position from the jet axis with the peak value occurring at the $19.1^{\circ}$ location. But for supersonic jet Mach numbers of 1.2 and 1.4 the overall sound pressure level decreased" initially with angular position and then started to increase. This difference in the variation of the overall sound pressure level with angular position is caused primarlly by the existence of shock bottles for supersonic jet Mach numbers from a convergent nozzle.

The normalized power spectra for subsonic jet Mach numbers of 0.6 to 1.0 were quite similar with the peak occurring at approximately $2.5 \mathrm{kHz}$. But for supersonic jet Mach numbers the normalized power spectra shifted to higher frequencles with more acoustic energy in the higher frequencies compared to the subsonıc power spectra. .

Oyerall sound power for Mach numbers of 0.6 to 1.0 varled as $U^{8}$ as predicted by Ilghthill theory, but for supersonic jet Mach numbers of 1.0 to 1.4 the sound power varled approximately as $U^{12}$ because of the presence of shock bottles with acoustic radiation from the shock waves for a convergent nozzle.

The overall sound power levels for supersonic jet Mach numbers at different total temperatures were correlated with the supersonlc jet nolse theory of Nagamatsu and Horvay. The observed experimental effects of jet total temperature upon the acoustic radiation from subsonic and supersonic jets are large and agree with the calculated values from the supersonic jet noise theory. 
1. Nagamatsu, H.T., Sheer, R.E., Jr., and Wells, R.J., "Supersonic Jet Exhaust Nolse Reduction with Rods, Shroud, and Induced Flow, " Proc. AFOSR-UTIAS Symposium on Aerodynamic Nolse, Toronto, May 1968.

2. Nagamatsu, H.T., Pettıt, W.T., and Sheer, R.E., Jr., "Some Flow and Acoustic Characteristics of a Shrouded Supersonic Jet," General Electric Res. and Dev. Ctr. Rept. 68-C-302 (1968).

3. Nagamatsu, H.T., Sheer, R.E., Jr., and Glll, M.S., "Flow and Acoustic Characteristics of Subsonic and supersonic Jets from Convergent Nozzle," AIAA Paper No. 70-802 (1969).

4. LIghthı11, M.J., "On Sound Generated Aerodynamically," Proc. Roy. Soc. A211, 564-587 (1952).

5. IIghthill, M.J., "Jet Nolse," AIAA Jour, Vol. I, No. 7, 1507-1517 (1963).

6. Corrsin, S. and Uberol, M., "Further Experiments on the Flow and Heat Transfer in a Heated Turbulent Alr Jet," NACA Rept. 998 (1948).

7. Laurence, J.C., "Intensity, Scale, and Spectra of Turbulence in Mixing Region of Free Subsonic Jet," NACA Rept. 1292 $(1956)$.

8. Bradshaw, P., Ferrıss, D.H., and Johnson, R.F., "rurbulence In the Noise Producing Region of a Circular Jet," J. Fluid Mech., Vol. 19, Part 4, 591-624 (1964).

9. Warren, W.R., "An Analytical and Experımental study of Compressible Free Jets," Doctoral Dissertation Princeton Univ. (1957).

10. Love, E.S., Grigsby, C.E., Lee, I.P., and WoodIIng, M., "Experimental and Theoretical Studies of Axısymmetric Free Jets," J. A. Sc1., 25, p. 791-799 (1958).

11. Powell, A., "The Nolse of Choked Jets," JASA, Vol. 25, p. 385-389 (1953).

12. Gibbings, J.C., Ingham, J., and Johnson, D., "Flow in a Supersonic Jet Expanding from a Convergent Nozzle," Aero. Res. Councll, ARC FM 3968 (1968).

13. Dosanjh, D.S. and Monteganı, F.J., "Underexpanded Jet Nolse Reduction Using Radial Flow Impingement," AIAA Jour., Vol. 7, No. 3, p. 458-464 (1969). 
14. Johannesen, N.H., "Further Results on the Mixing of Free Axially-Symmetrical Jets of Mach Number 1.40," Aero. Res. Council, ARC R\&M No. 3292 (1959).

15. Eggers, J.M., "Velocity Proflles and Eddy Viscosity Distributions Downstream of a Mach 2.22 Nozzle Exhausting to Quiescent AIr," NASA TN D-3601 (1966).

16. Potter, R.C. and Jones, J.H., "An Experiment to Iocate the Acoustic Sources in a High Speed Jet Exhaust Stream," Wyle Lab. Rept. (1967).

17. Nagamatsu, H.T. and Horvay, G., "Supersonıc Jet Norse," AIAA Paper No. 70-237 (1970).

18. Nagamatsu, H.T., Sheer, R.E., Jr., and Horvay, G., "Supersonic Jet Nolse Theory and Experiments," Basic Aerodynamic Nolse Research Conf., NASA SP-207 (1969).

19. Ollerhead, J.B., "On the Prediction of the Near Field Nozse of Supersonlc Jets," NASA CR-857 (1967).

20. Davıes, O.A.L., Fısher, M.J., and Barratt, M.J., "The Characteristics of the Turbulence in the Mixing Region of a Round Jet," J. Fluld Mech., Vol. 15, Part 2, 337-366 (1963).

21. Chu, W.T., "Turbulence Measurements Relevant to Jet No1se," Unıv. of Toronto UTIA Rept. 119 (1966).

22. Davies, P.O.A.I., Ko, N.W.M., and Bose, B., "The Local Pressure Field of Turbulent Jets," ARC CP 989 (1967).

23. Nayar, B.M., Siddon, T.E., and Chu, W.T., "Propertıes of the Turbulence in the Transition Region of a Round Jet," UnIV. of Toronto UTIA Rept. 131 (1969).

24. Kovasznay, L.S.G., "Turbulence in Supersonic Flows," J. Aero. ScI., Vol. 25, No. 10, 657-682 (1953).

25. Laufer, J., "Aerodynamic Nolse in Supersonıc Wind Tunnels," J. Aero. Scl., Vol. 28, No. 9, 685-692 (1961).

26. Laufer, J., "Sound Radıation from a Turbulent Boundary Layer," CaIıf. Inst. of Tech. Jet Prop. Lab. Rept. 32-119 (1961).

27. Fisher, M.J., "Turbulence Measurements in Supersonic, ShockFree Jets by the Optical Cross-Beam Method," NASA TN D-5206 (1970).

28. Pettıt, W.T., III, "The Laser Doppler Velocimeter for Measurıng Turbulence in Gas Flows," Polytechnic Inst. of Brooklyn, M.S. Thesis (1970). 
29. Siddon, T.E., "On the Response of Pressure Measuring Instrumentation in Unsteady FIov," UnIV. of Toronto, UTIAS Rept. 136 (1969).

30. Nakamura, A., Matsumoto, R., Sugıyama, A., and Tanaka, T., "Some Investigations on Output Level of Microphones in AIr Streams," JASA, Vol. 46, No. 6, 1391-1396 (1969).

31. Fuchs, H.V., "Fluctuatıons in a Unıform Moving Medium OrIginating from Convected Sources," Unıv. of Southampton, Inst. of Sound and Vib., Memo. 280 (1969).

32. Fuchs, H.V., "Energy-Balance for small Fluctuations in a Moving Medıum," UnIV. of Southampton, Inst. oI Sound and VIb., Rept. 18 (1969).

33. Fuchs, H.V., "Measurements of Pressure Fluctuations with Microphones in an AIr Stream," UnIV. of Southampton, Inst. of Sound and VIb., Memo. 281 (1969).

34. Iau, J.C., Fuchs, H.V., and Fisher, M.J., "A Study of Pressure and Velocity Fluctuations Associated with Jet Flows," UnIV. of Southampton, Inst. of Sound and Vıb., Rept. 28 (1970).

35. Maestrello, I. and McDald, E., "Acoustıc Characteristıcs of a High-Subsonlc Jet," AIAA Paper No. 70-238 (1970).

36. Ribner, H.S., The Generation of Sound by Turbulent Jets, Adv. Appl. Mech., Vol. 8, Academic Press, Inc., N.Y. $(1964)$.

37. Phlllups, O.M., "On the Generation of Sound by Supersonıc Turbulent Shear Layers," J. Fluzd Mech., Vol. 9, Part 1, $1-28(1960)$.

38. Wrlliams, J.E.F., "The Nolse from Turbulence Convected at High Speed," Phil. Trans. Roy. Soc. London, Serles A225, $479-503$ (1963).

39. Plumblee, H.E., Jr., "The Effect of Exhaust Temperature on the Nolse Generation," Lockheed-Georgia Co. Rept. (1967).

40. Lassiter, L.W. and Hubbard, H.H., "Experimental Studies of Nolse from Subsonic Jets in Still AIr," NACA TN 2757 (1952).

41. Lassiter, I.W. and Hubbard, H.H., "The Near FIeld Nolse of Static Jets and Some Model Studies of Devices For Nolse Reduction," NACA Rept. 1261 (1954).

42. Mollo-Chrıstensen, E. and Narasımha, R., "Sound Emıssion from Jets at High Subsonic Velocity," J. Fluid Mech., Vol. $8,49-60$ (1960). 
43. Mollo-Christensen, E., "Jet Nolse and Shear Flow Instability Seen from an Experimenter's Viewpoint," Trans. of ASME, Paper No. 67, APM-C (1966).

44. Gerrard, J.H., "An Investigation of the Nolse Produced by Subsonlc Alr Jet," J. Aero. SC1., Vol. 23, 855-866 (1956).

45. Mayes, W.H., Lanford, W.E., and Hubbard, H.H., "Near Fleld and Far Field Noise Surveys of Solid Fuel Rocket Engınes for a Range of Nozzle Exit Pressures," NASA TN D-2I (1959).

46. Tatge, R.B. and Wells, R.J., "Model Jet Nolse study at Alplaus Facilıty," General Electrıc Engineerıng Laboratory Rept. 6IGL25 (196I).

47. Smlth, E.B. and Brown, W.L., "Acoustıc Scale-Model Tests of High-Speed Flows," Martin-Marietta Corp. Rept. CR-66-75 (1966).

48. Nagamatsu, H.T., Gelger, R.E., and Sheer, R.E., Jr., "HypersonIC Shock Tunnel," Jour. ARS, Vol. 29, 332-340 (1959).

49. Goldstein, S., "A Note on the Measurement of Total Head and Static Pressure in a Turbulent Stream," Proc. Roy. Soc. Al55, 570-575 (1936).

50. Fage, A., "On the Static Pressure in Fully-Developed Turbulent Flow," Proc. Roy. Soc. Al55, 576-596 (1936).

51. Kralchnan, R.H., "Pressure Fleld Within Homogeneous Anısotropic Turbulence," JASA, Vol. 28, 64-72 (1956). 


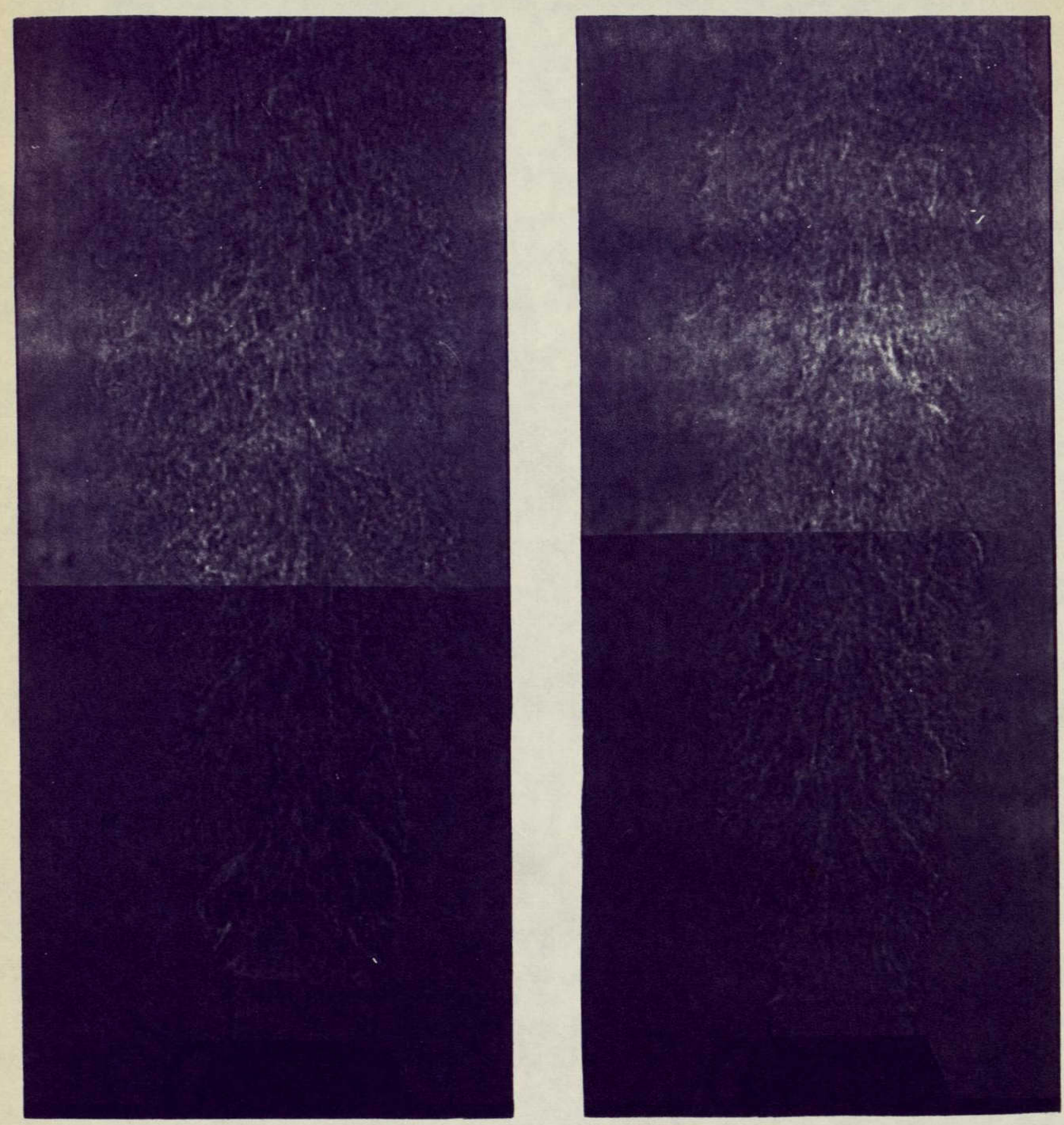

FIG.3a SHADOWGRAPH PHOTOGRAPHS OF AONE INCH CONVERGENT NOZZLE AT JET MACH NUMBERS OF 0.7 (LEFT) AND 0.6 (RIGHT) 

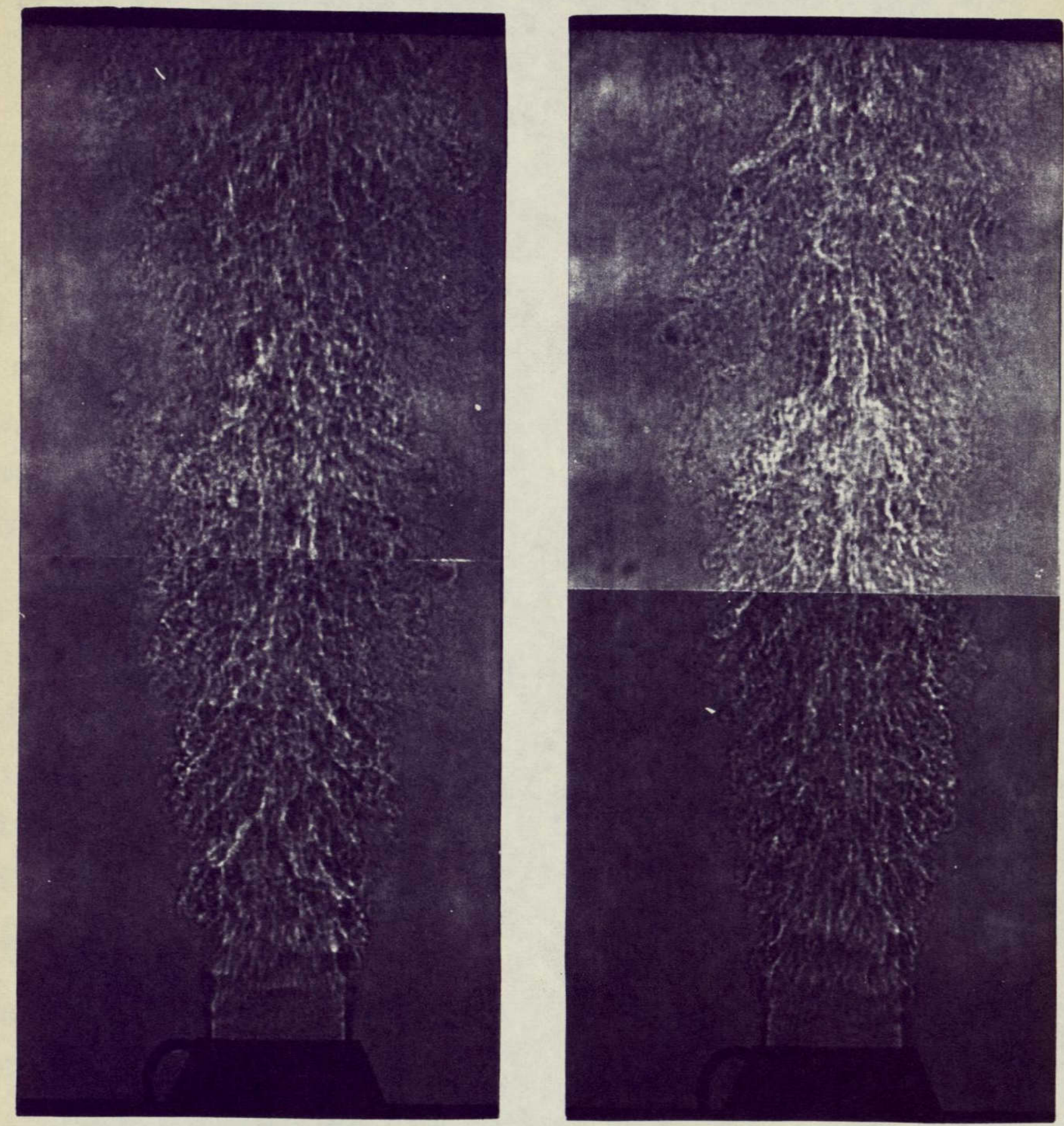

FIG3bSHADOWGRAPH PHOTOGRAPHS OF A ONE INCH CONVERGENT NOZZLE AT JET MACH NUMBERS OF I.O (LEFT) AND 0.85 (RIGHT) 

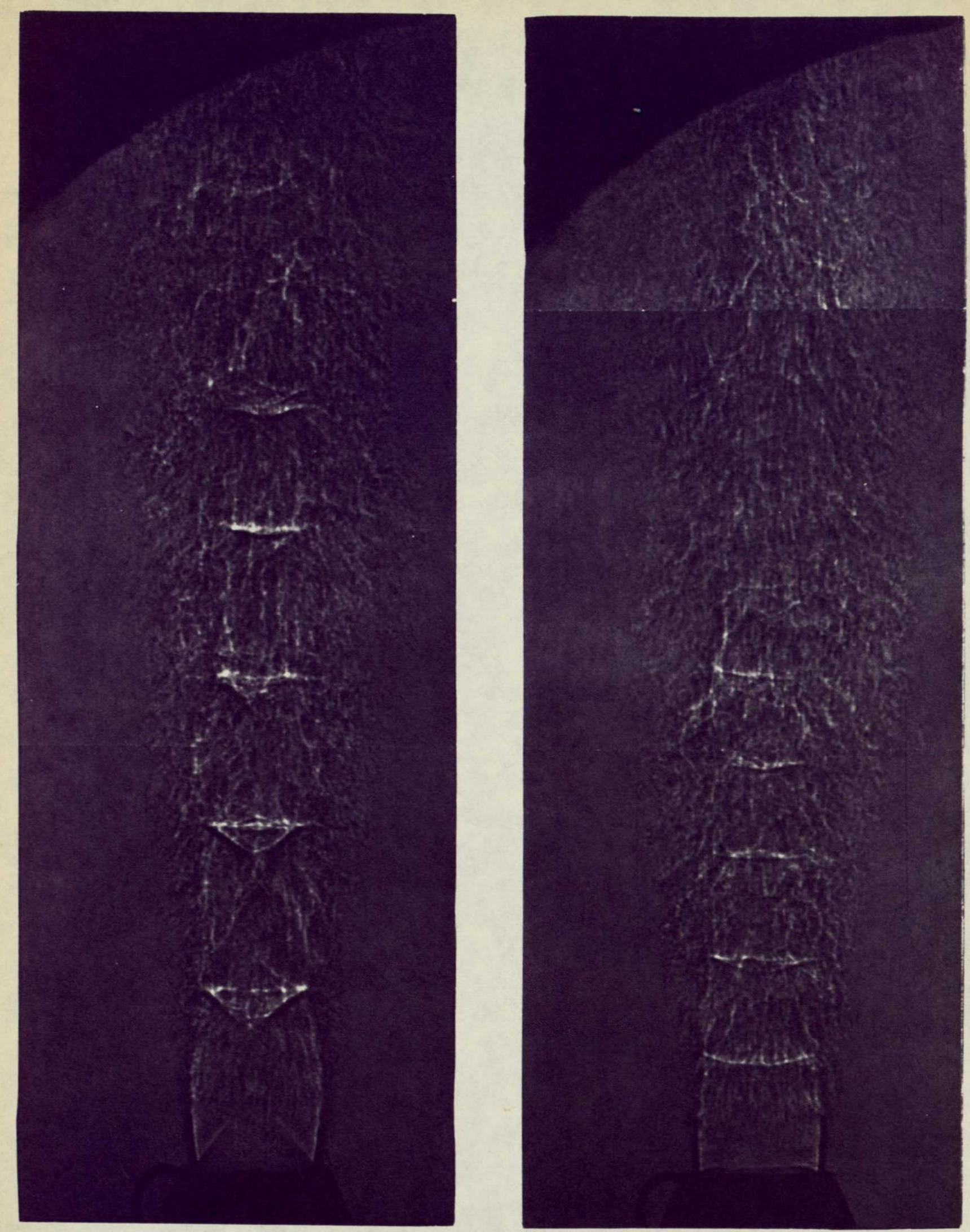

FIG.3CSHADOWGRAPH PHOTOGRAPHS OF A ONE INCH CONVERGENT NOZZLE AT JET MACH NUMBERS OF 1.4 (LEFT) AND I.2 (RIGHT) 


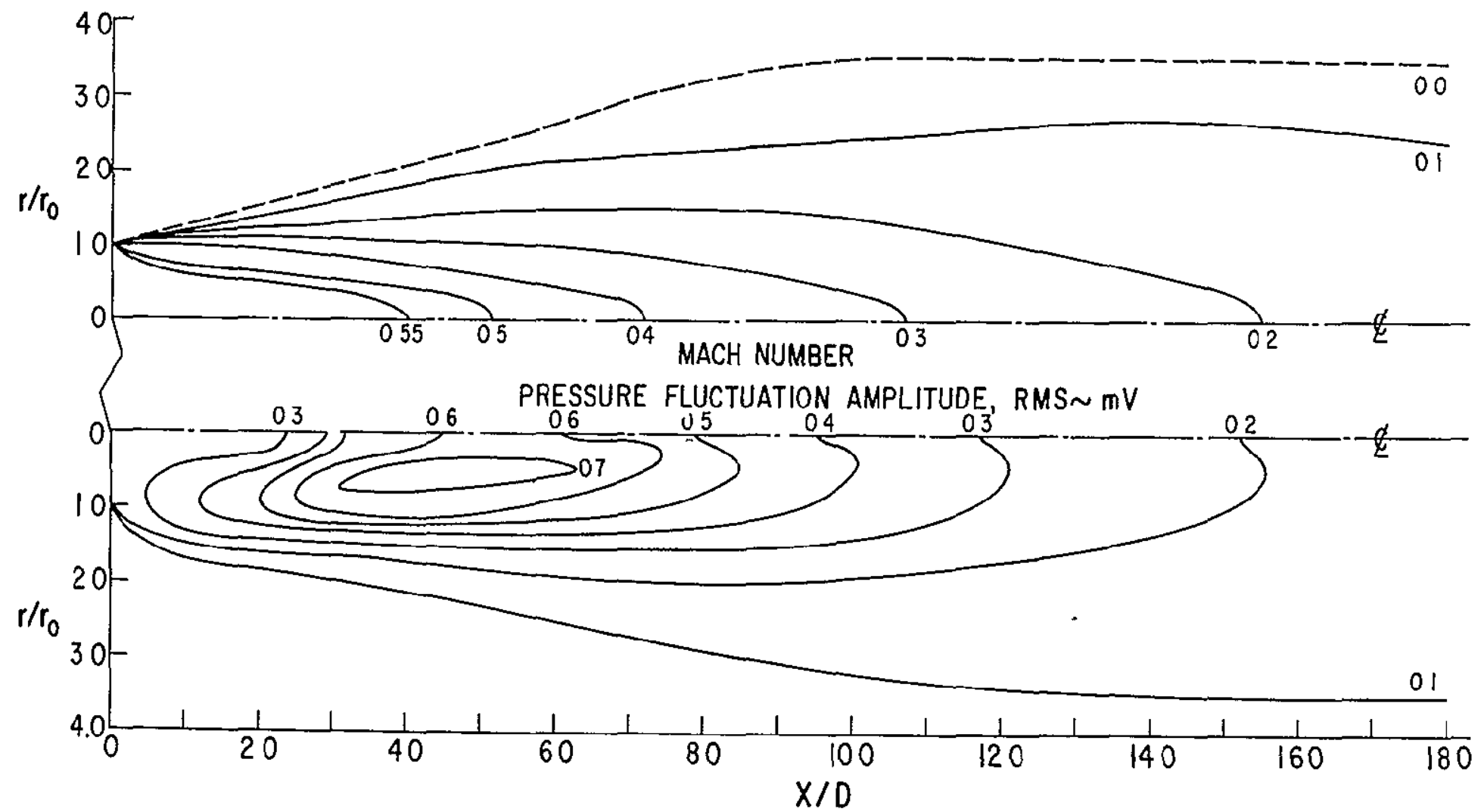

FIG 40 CONSTANT MACH NUMBER AND PIEZOELECTRIC PRESSURE FLUCTUATION CONTOURS IN THE FLOW FIELD FROM A ONE INCH CONVERGENT NOZZLE, $M_{j} \approx 0.6$ 


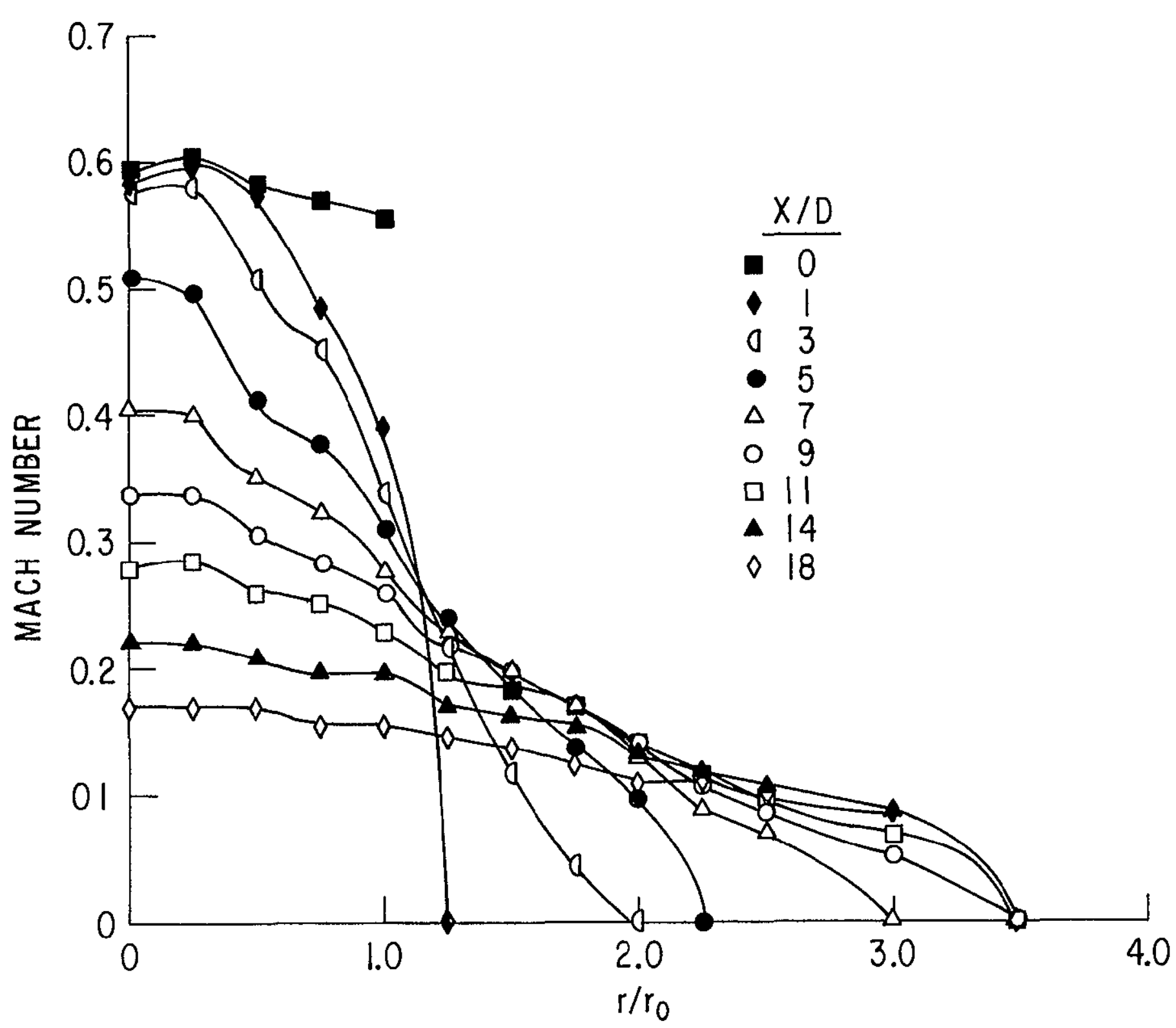

FIG.4b MACH NUMBER PROFILES ACROSS THE EXIT OF A ONE INCH DIAMETER CONVERGENT NOZZLE AT DIFFERENT DISTANCES FROM THE NOZZLE EXIT, $M_{j} \approx 0.6$ 


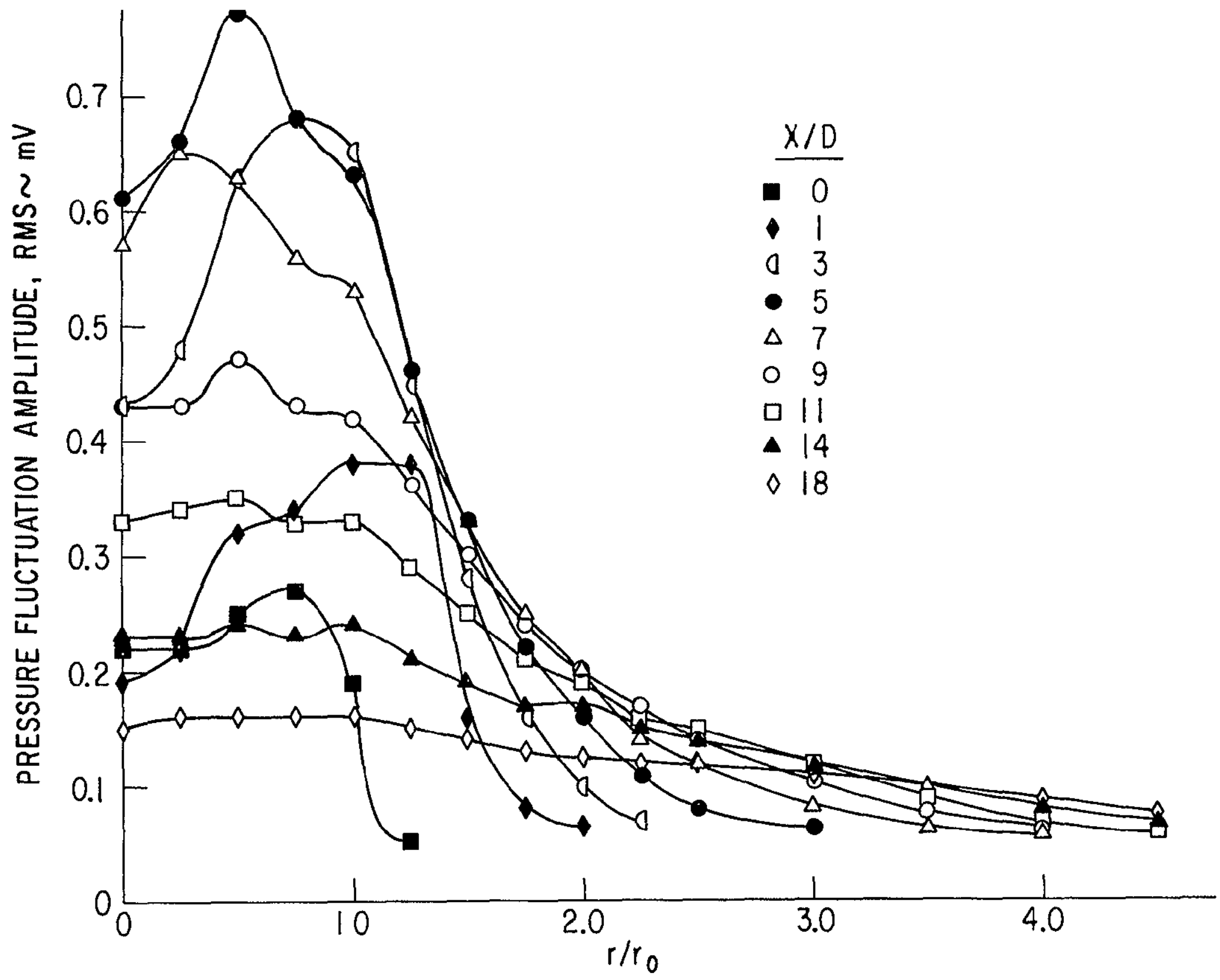

FIG 4C PIEZOELECTRIC PRESSURE FLUCTUATION PROFILES ACROSS THE EXIT OF A ONE INCH DIAMETER CONVERGENT NOZZLE AT DIFFERENT DISTANCES FROM THE NOZZLE EXIT, $M_{i} \approx 0.6$ 


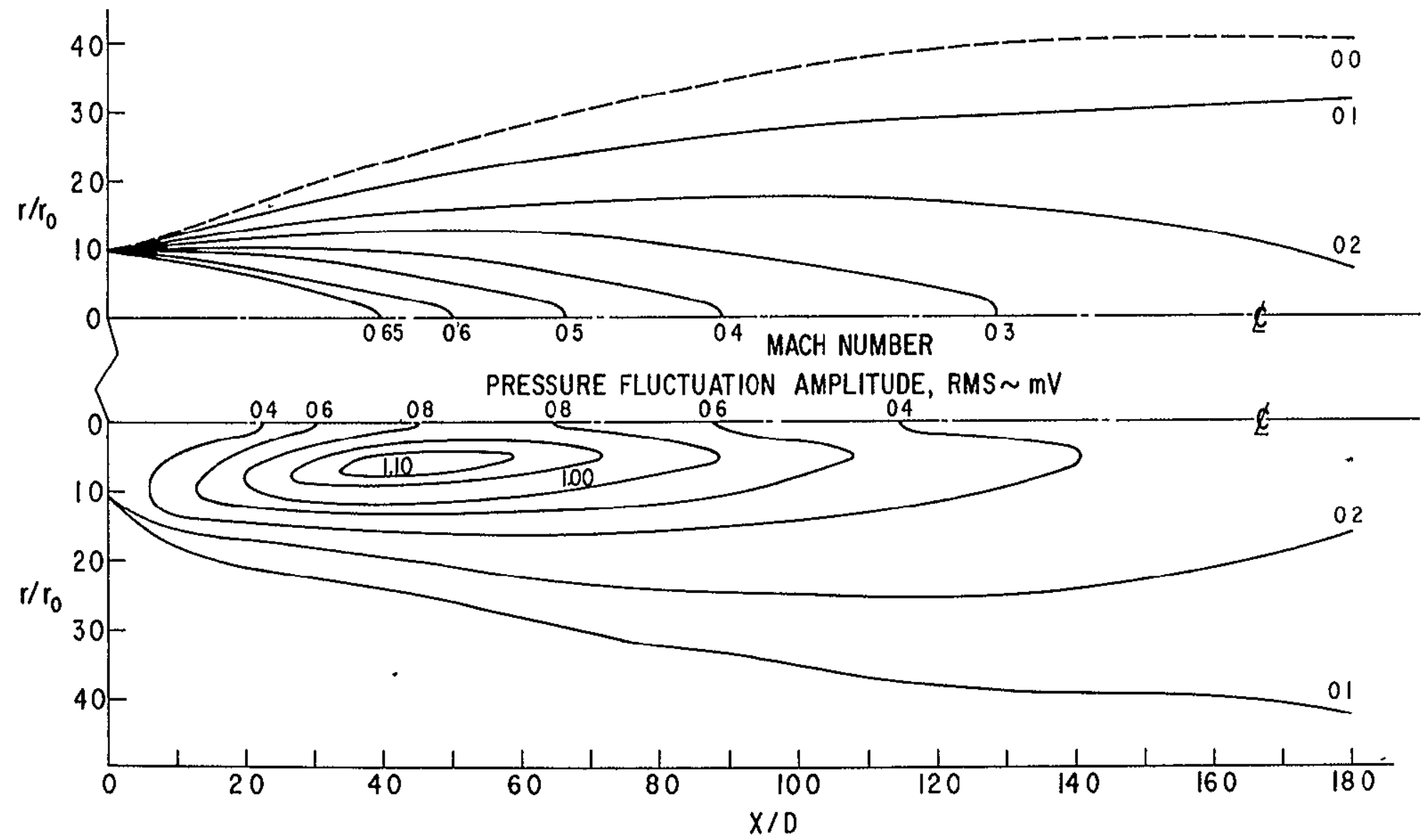

FIG 5a CONSTANT MACH NUMBER AND PIEZOELECTRIC PRESSURE FLUCTUATION CONTOURS IN THE FLOW FIELD FROM A ONE INCH CONVERGENT NOZZLE, $M_{1} \approx 07$ 


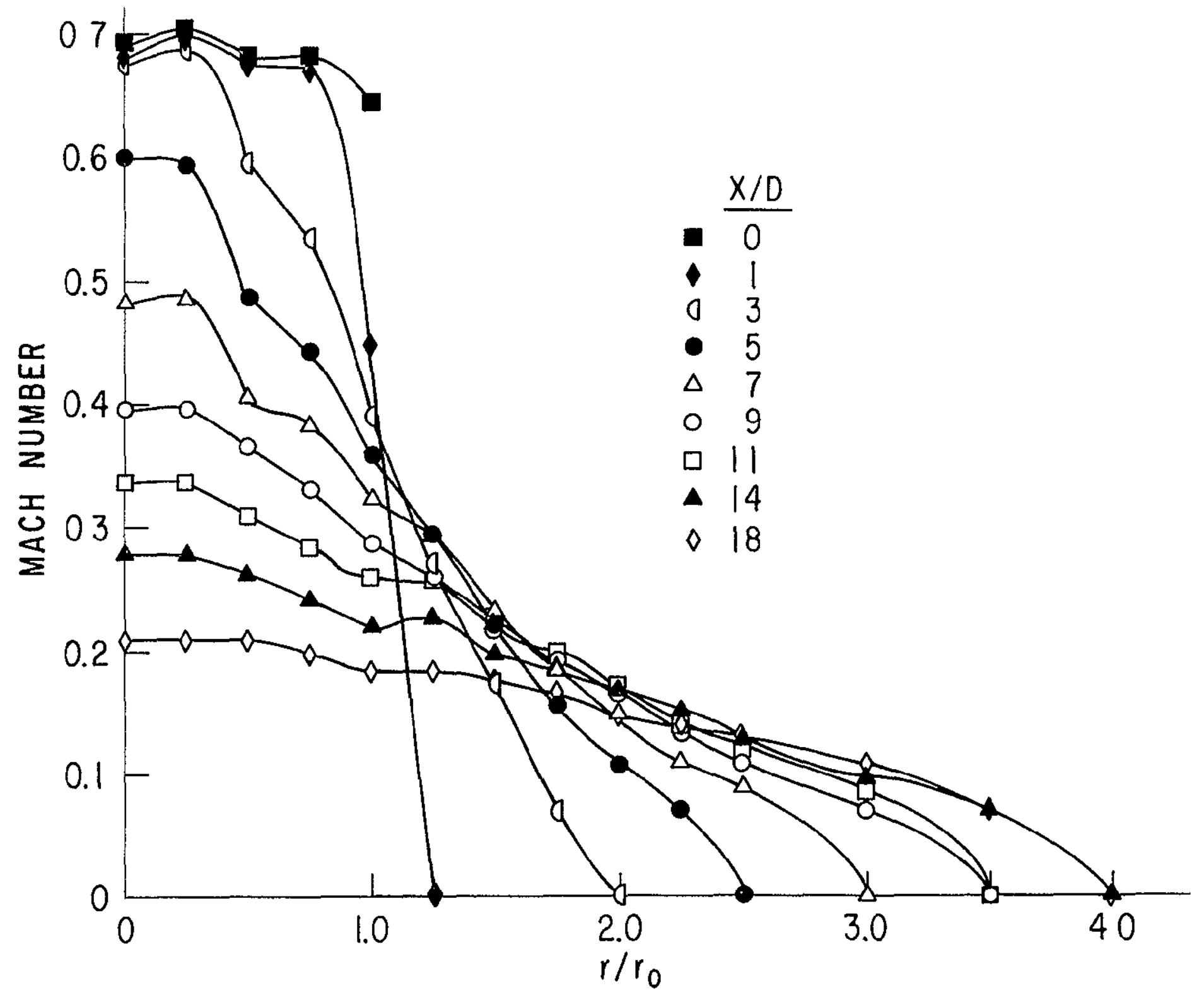

FIG. 5b MACH NUMBER PROFILES ACROSS THE EXIT OF A ONE INCH DIAMETER CONVERGENT NOZZLE AT DIFFERENT DISTANCES FROM THE NOZZLE EXIT, $M_{j} \approx 0.7$ 


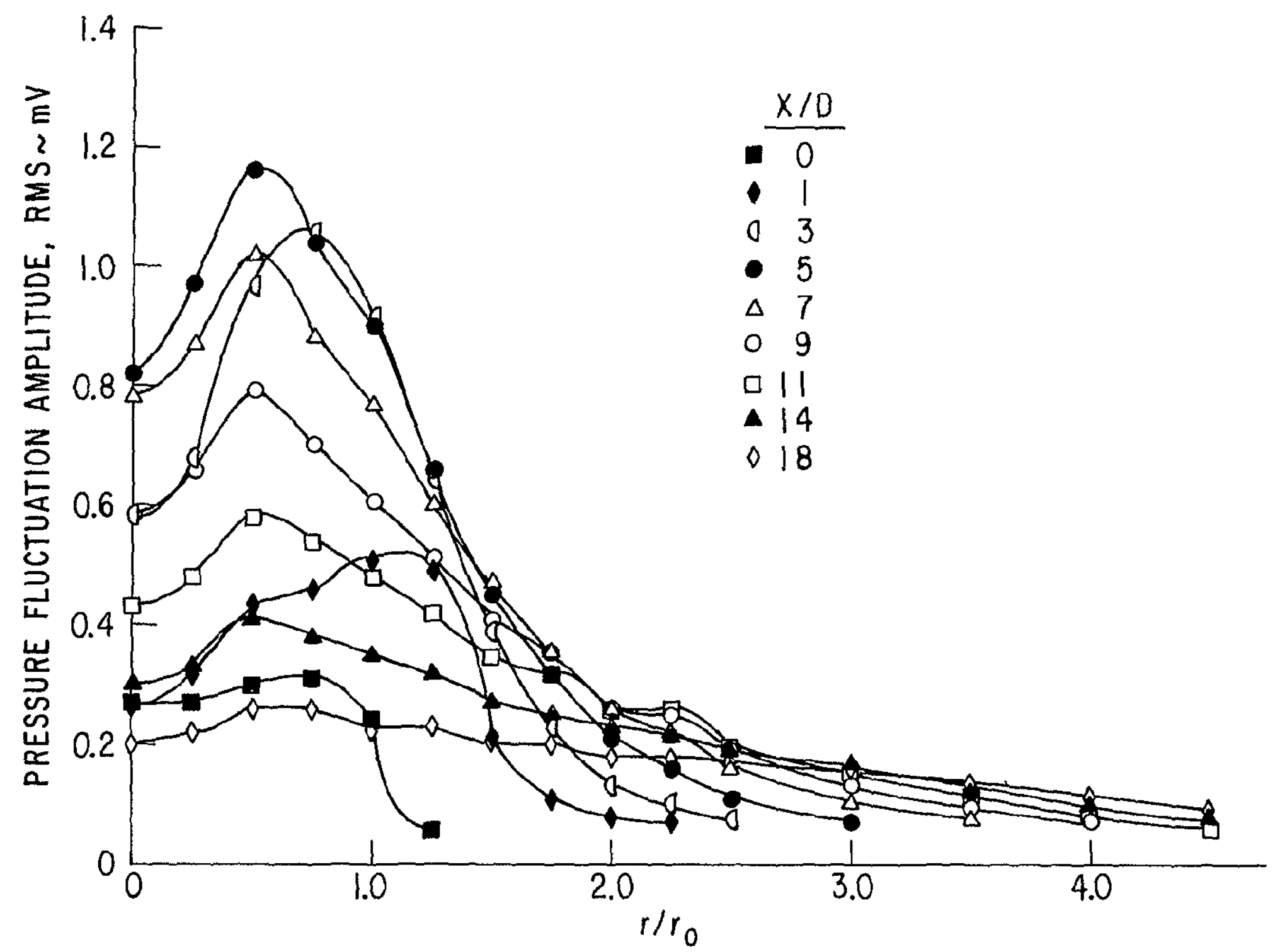

FIG.5C PIEZOELECTRIC PRESSURE FLUCTUATION PROFILES ACROSS THE EXIT OF A ONE INCH DIAMETER CONVERGENT NOZZLE AT DIFFERENT OISTANCES FROM THE NOZZLE EXIT, $M_{j} \approx 0.7$ 


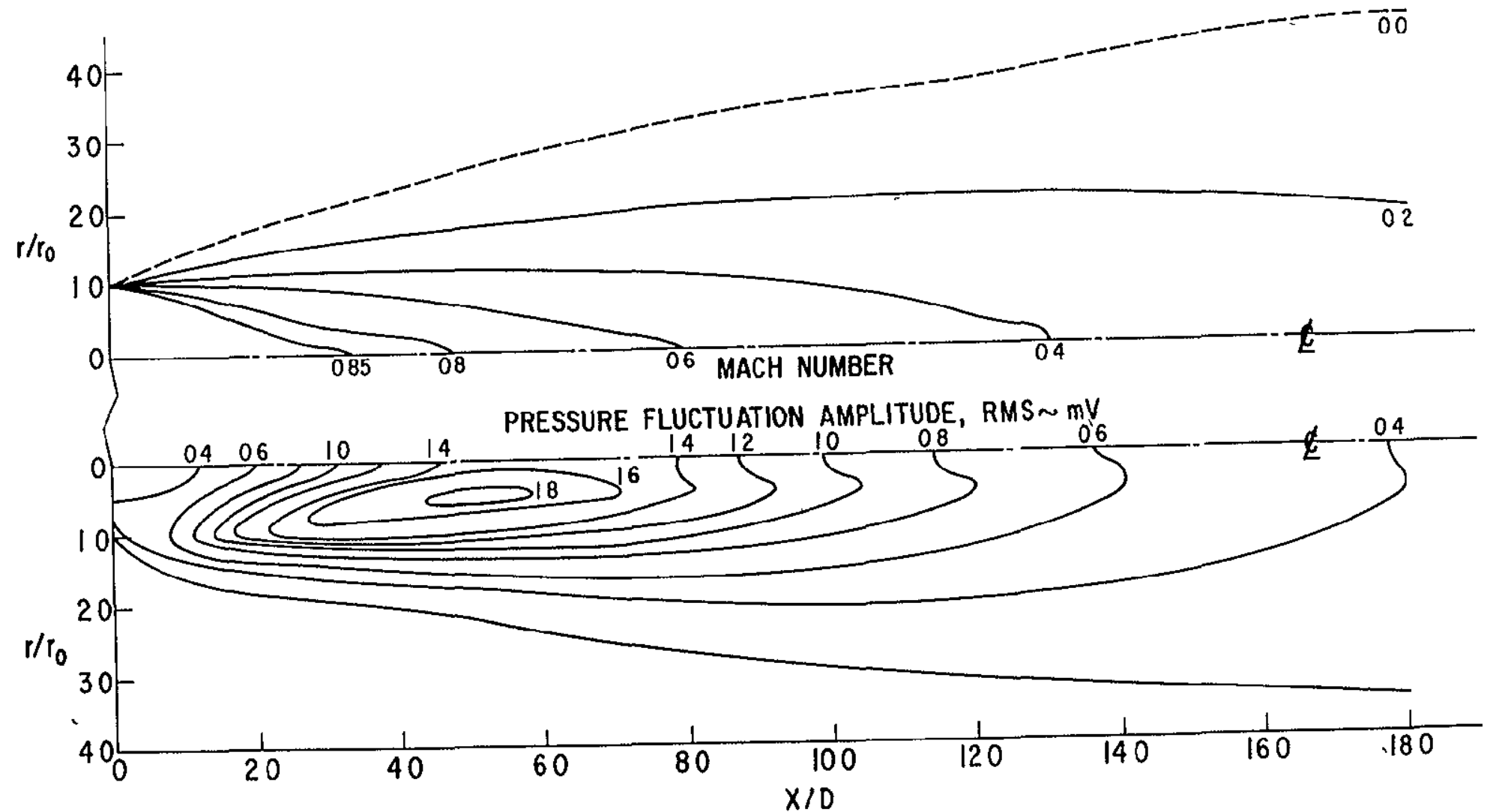

FIG 60 CONSTANT MACH NUMBER AND PIEZOELECTRIC PRESSURE FLUCTUATION CONTOURS IN THE FLOW FIELD FROM A ONE INCH CONVERGENT NOZZLE, $M_{\mathrm{j}} \approx 085$ 


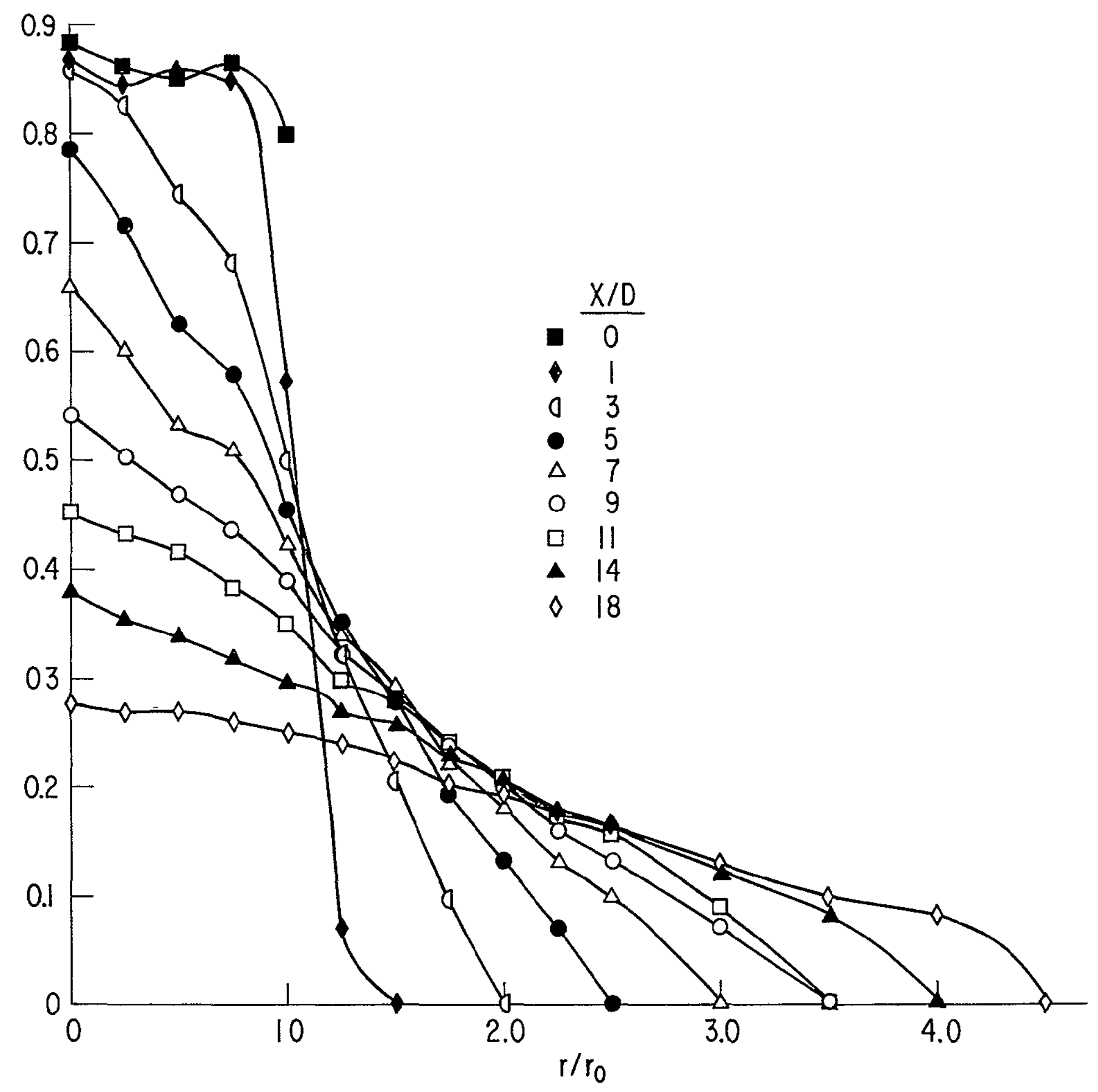

FIG.6b-MACH NUMBER PROFILES ACROSS THE EXIT OF A ONE INCH DIAMETER CONVERGENT NOZZLE AT DIFFERENT DISTANCES FROM THE NOZZLE EXIT, $M_{j} \approx 0.85$ 


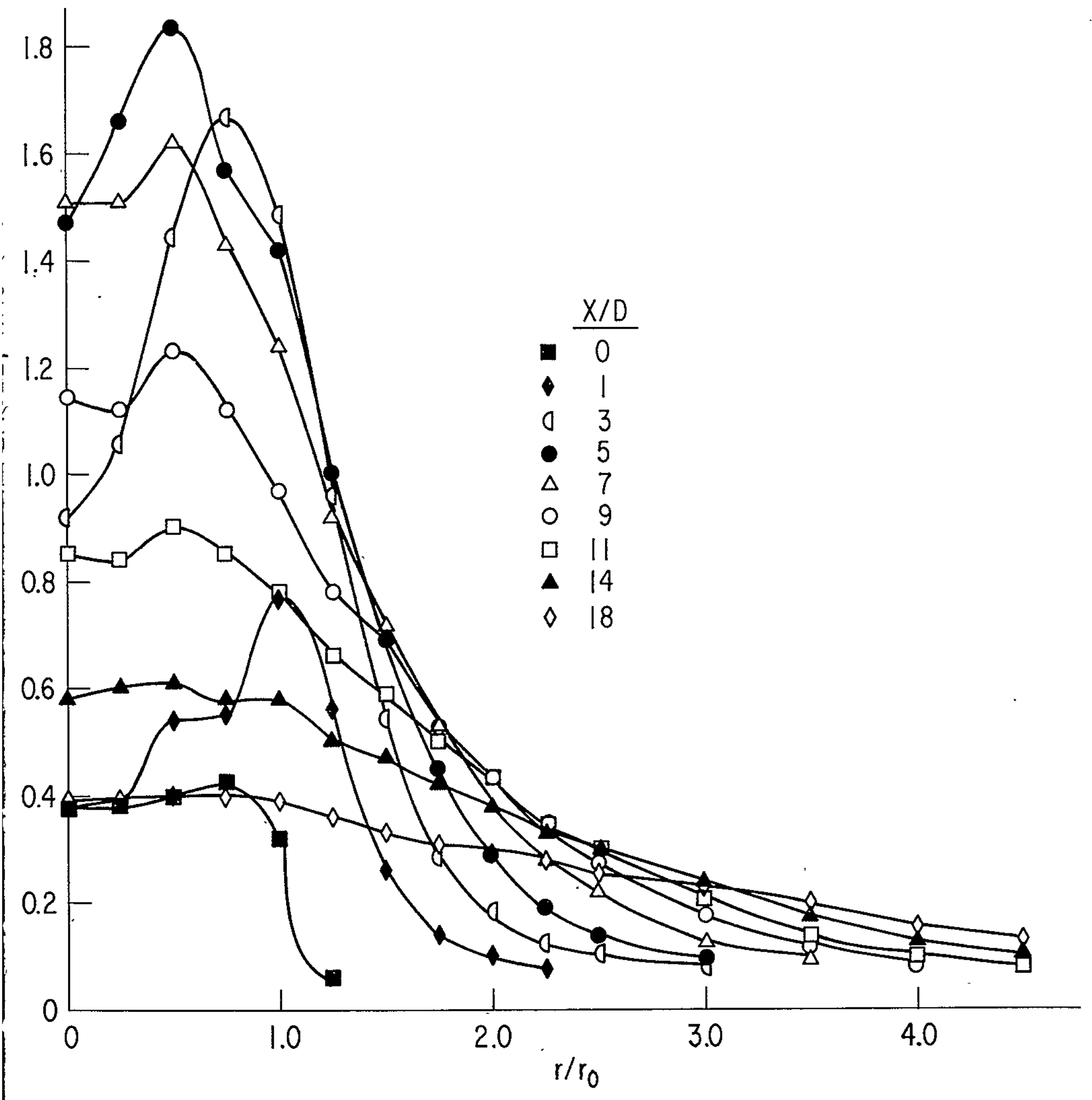

3.6C-PIEZOELECTRIC PRESSURE FLUCTUATION PROFILES ACROSS THE EXIT OF A ONE INCH DIAMETER CONVERGENT NOZZLE AT DIFFERENT DISTANCES FROM THE NOZZLE EXIT $M_{i} \approx 0.85$ 


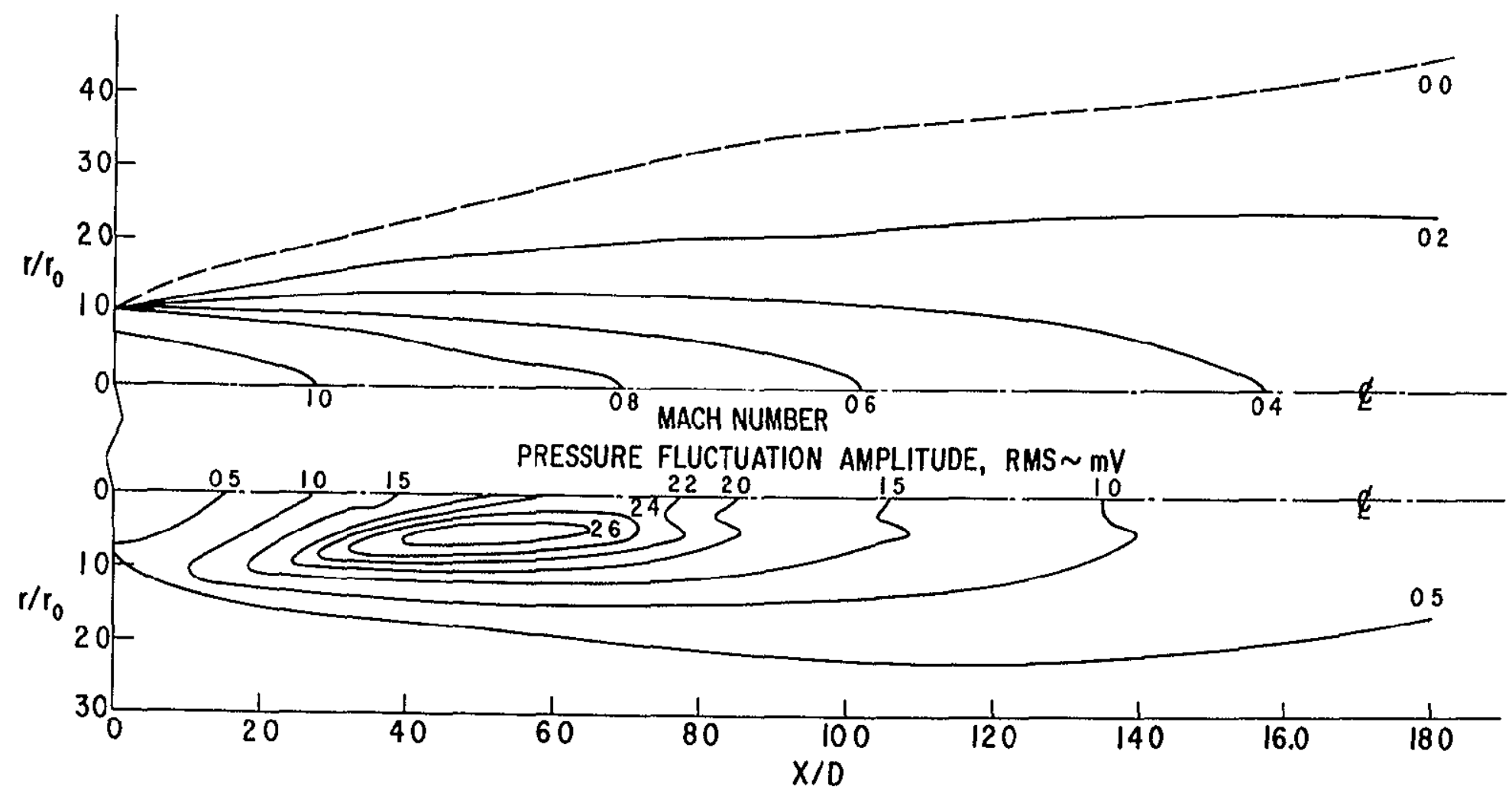

FIG TO CONSTANT MACH NUMBER AND PIEZOELECTRIC PRESSURE FLUCTUATION CONTOURS IN THE FLOW FIELD FROM A ONE INCH CONVERGENT NOZZLE, $M_{j} \approx 1.0$ 


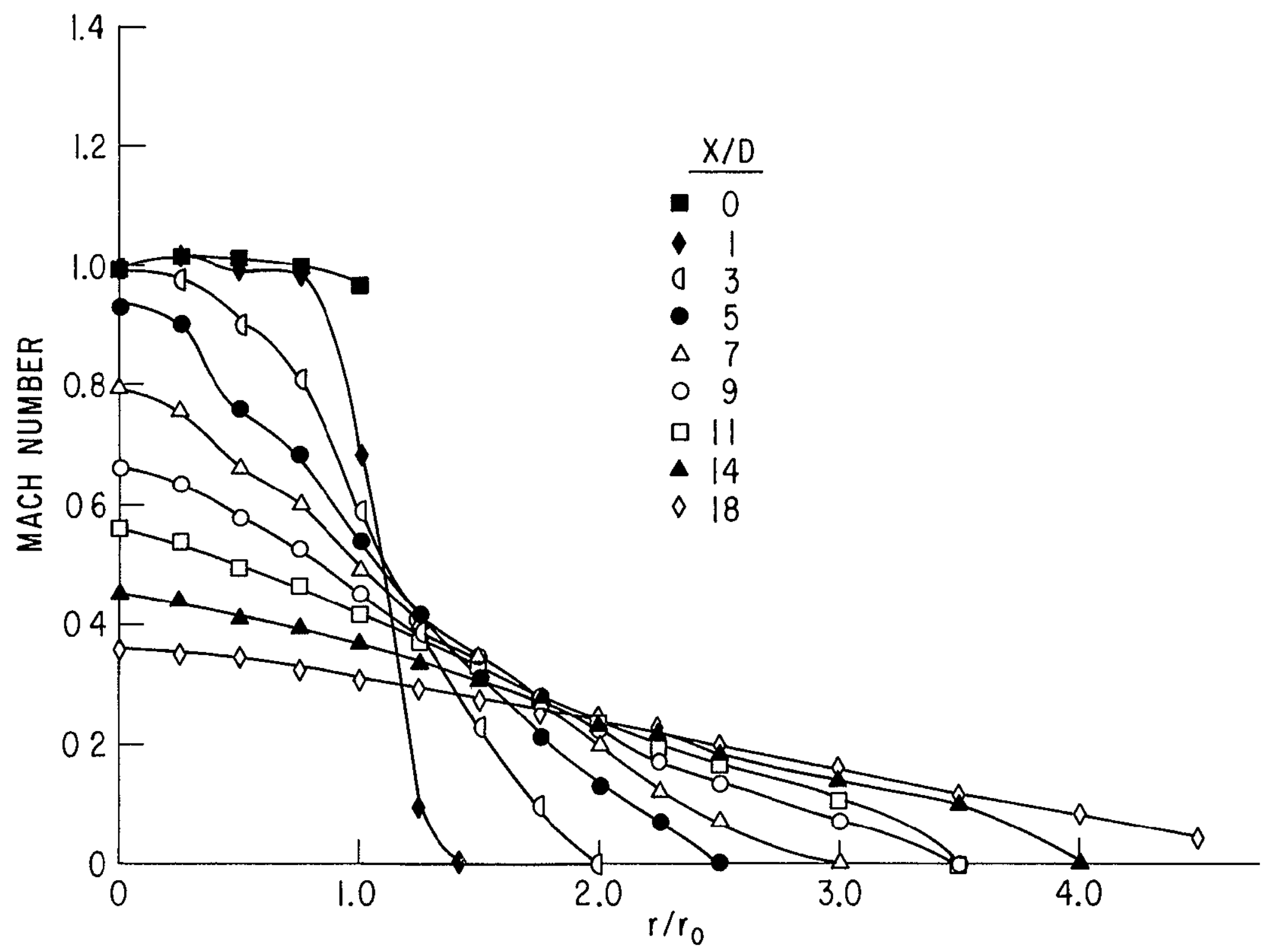

FIG.7b MACH NUMBER PROFILES ACROSS THE EXIT OF A ONE INCH DIAMETER CONVERGENT NOZZLE AT DIFFERENT DISTANCES FROM THE NOZZLE EXIT, $M_{j} \approx 1.0$ 


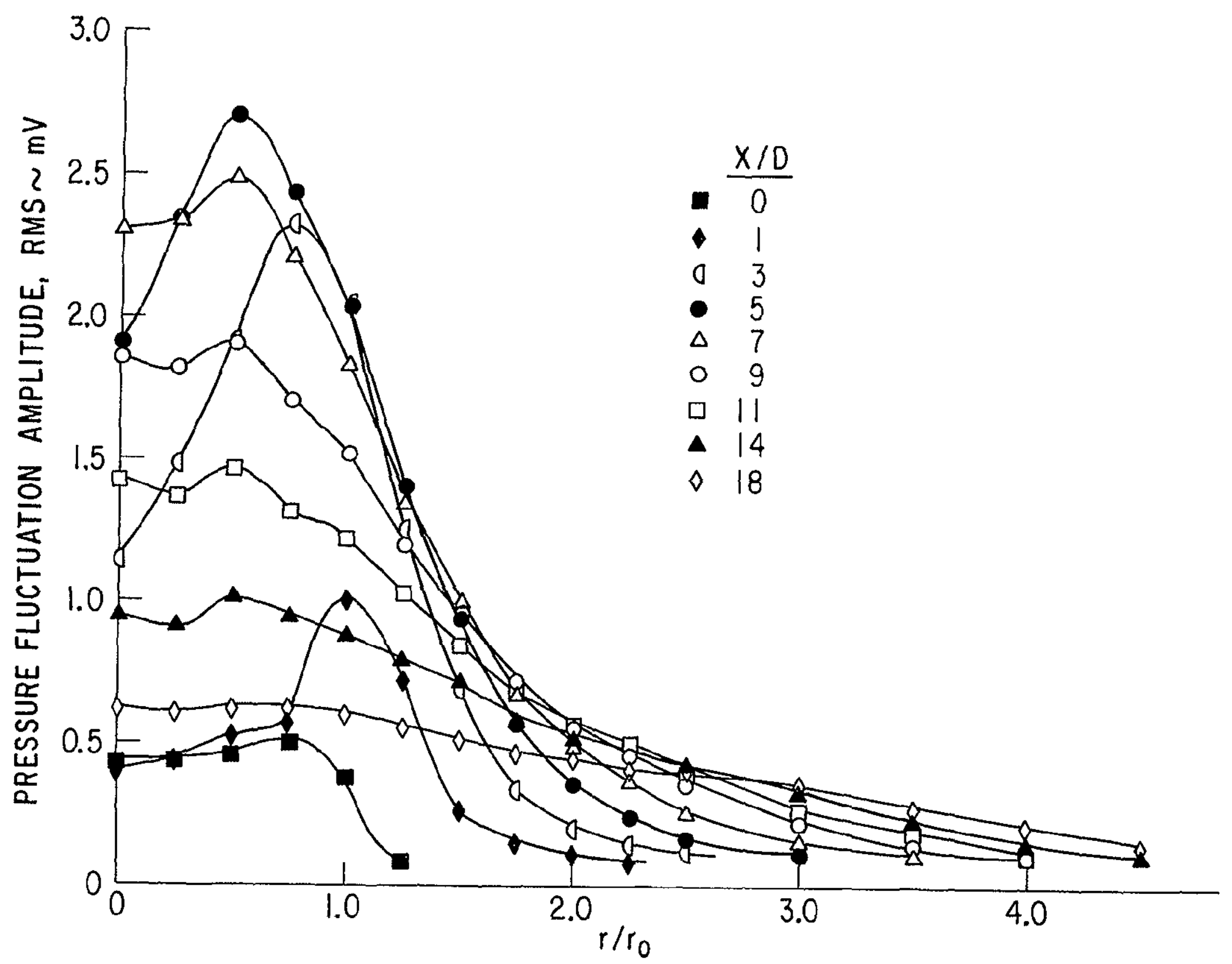

FIG.7C PIEZOELECTRIC PRESSURE FLUCTUATION PROFILES ACROSS THE EXIT OF A ONE INCH DIAMETER CONVERGENT NOZZLE AT DIFFERENT DISTANCES FROM THE NOZZLE EXIT, $M_{1} \approx 1.0$ 


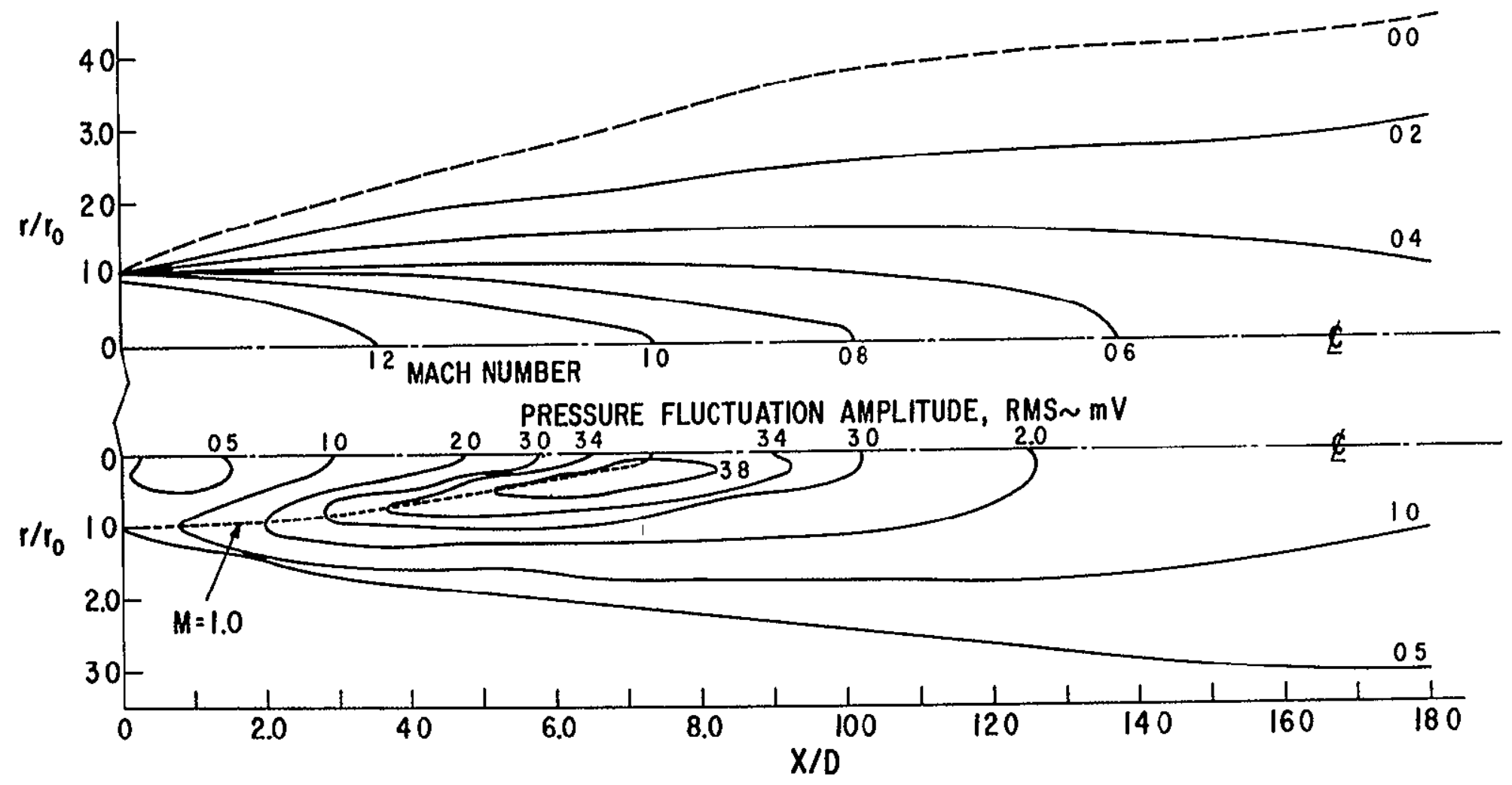

FIG. 8a CONSTANT MACH NUMBER AND PIEZOELECTRIC PRESSURE FLUCTUATION CONTOURS IN THE FLOW FIELD FROM A ONE INCH CONVERGENT NOZZLE, $M_{j} \approx 1.2$ 


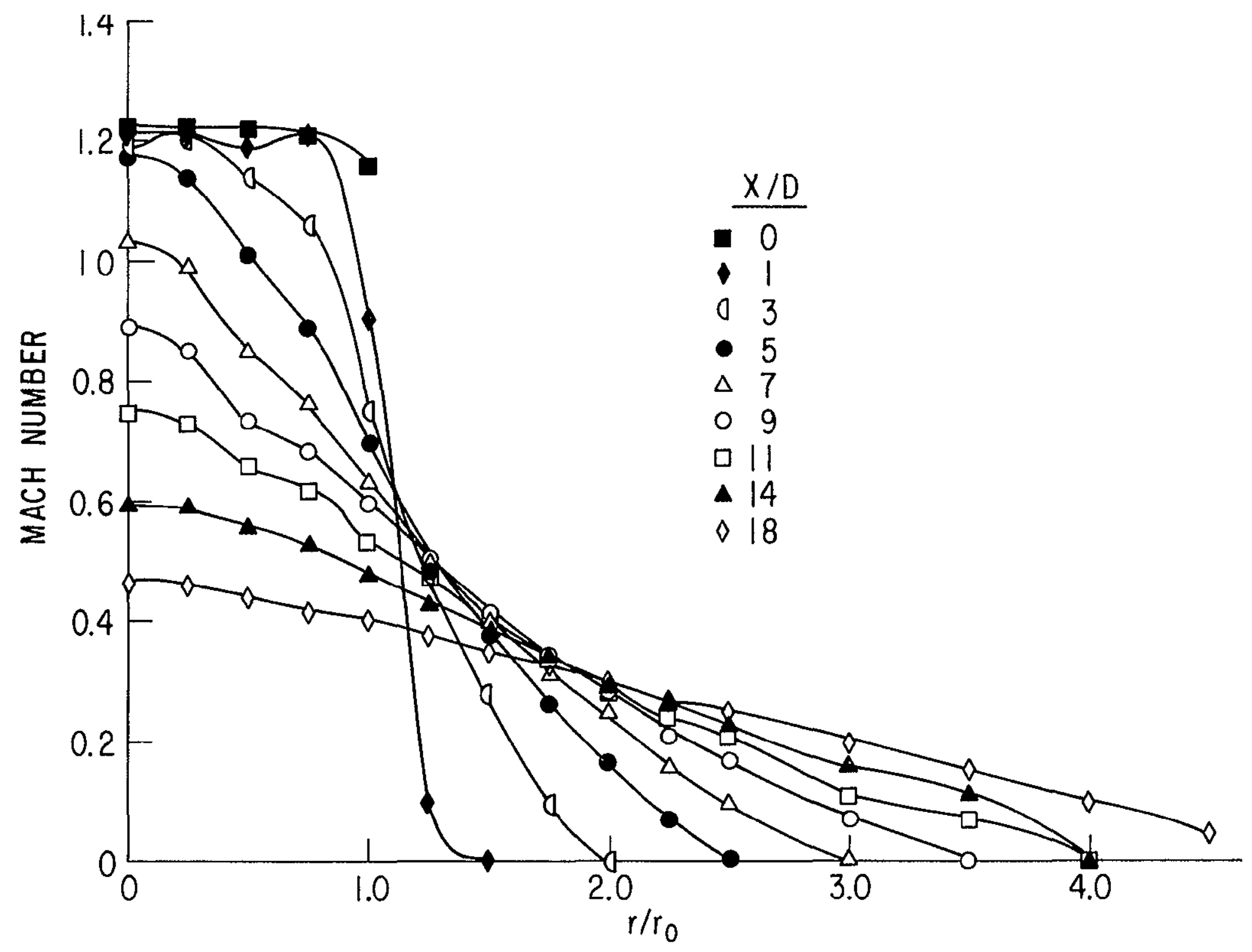

FIG. 8 b-MACH NUMBER PROFILES ACROSS THE EXIT OF A ONE INCH DIAMETER CONVERGENT NOZZLE AT DIFFERENT DISTANCES FROM THE NOZZLE EXIT, $M_{j} \approx 1.2$ 


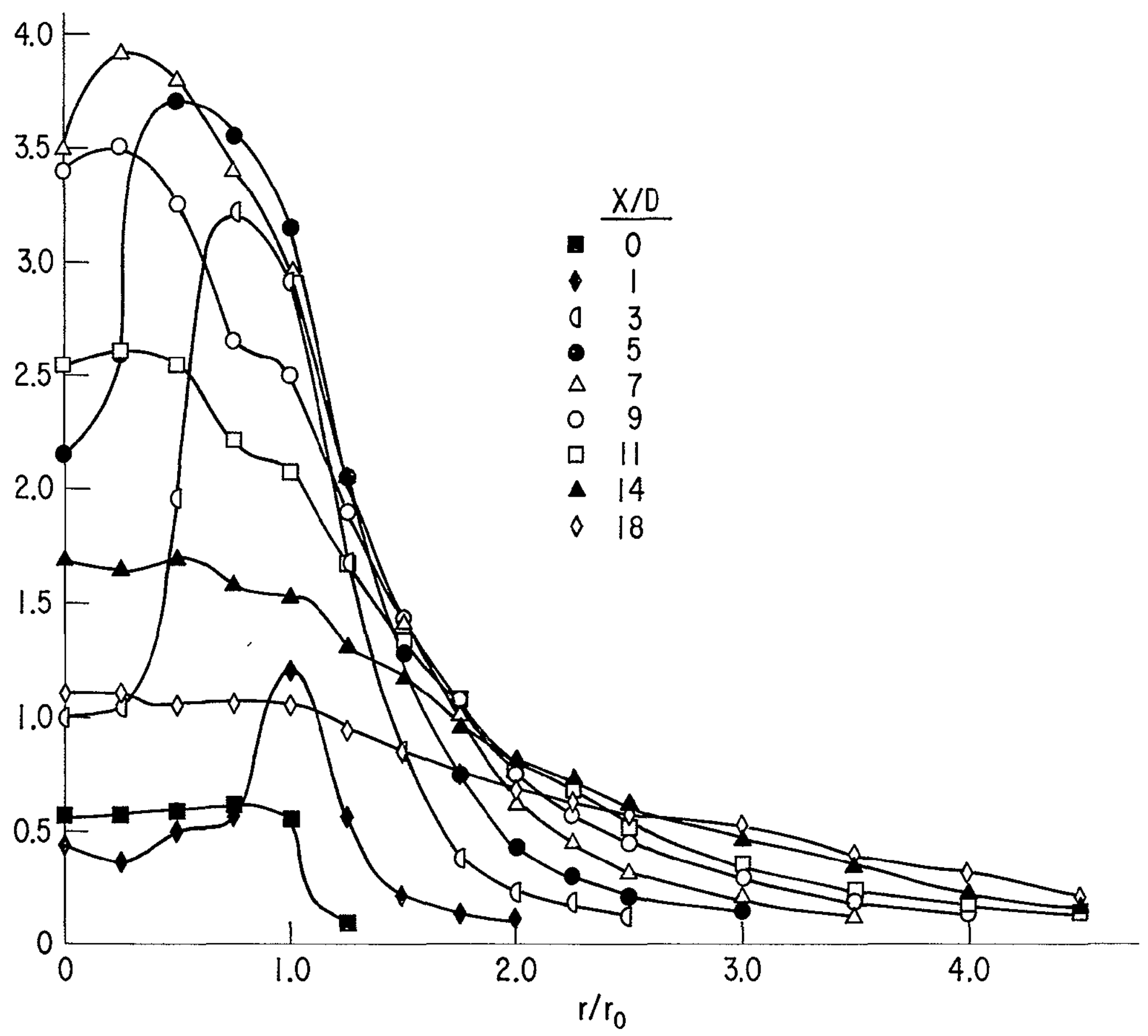

8C-PIEZOELECTRIC PRESSURE FLUCTUATION PROFILES ACROSS THE EXIT OF A ONE INCH DIAMETER CONVERGENT NOZZLE AT DIFFERENT DISTANCES FROM THE NOZZLE EXIT, $M_{j} \approx 1.2$ 


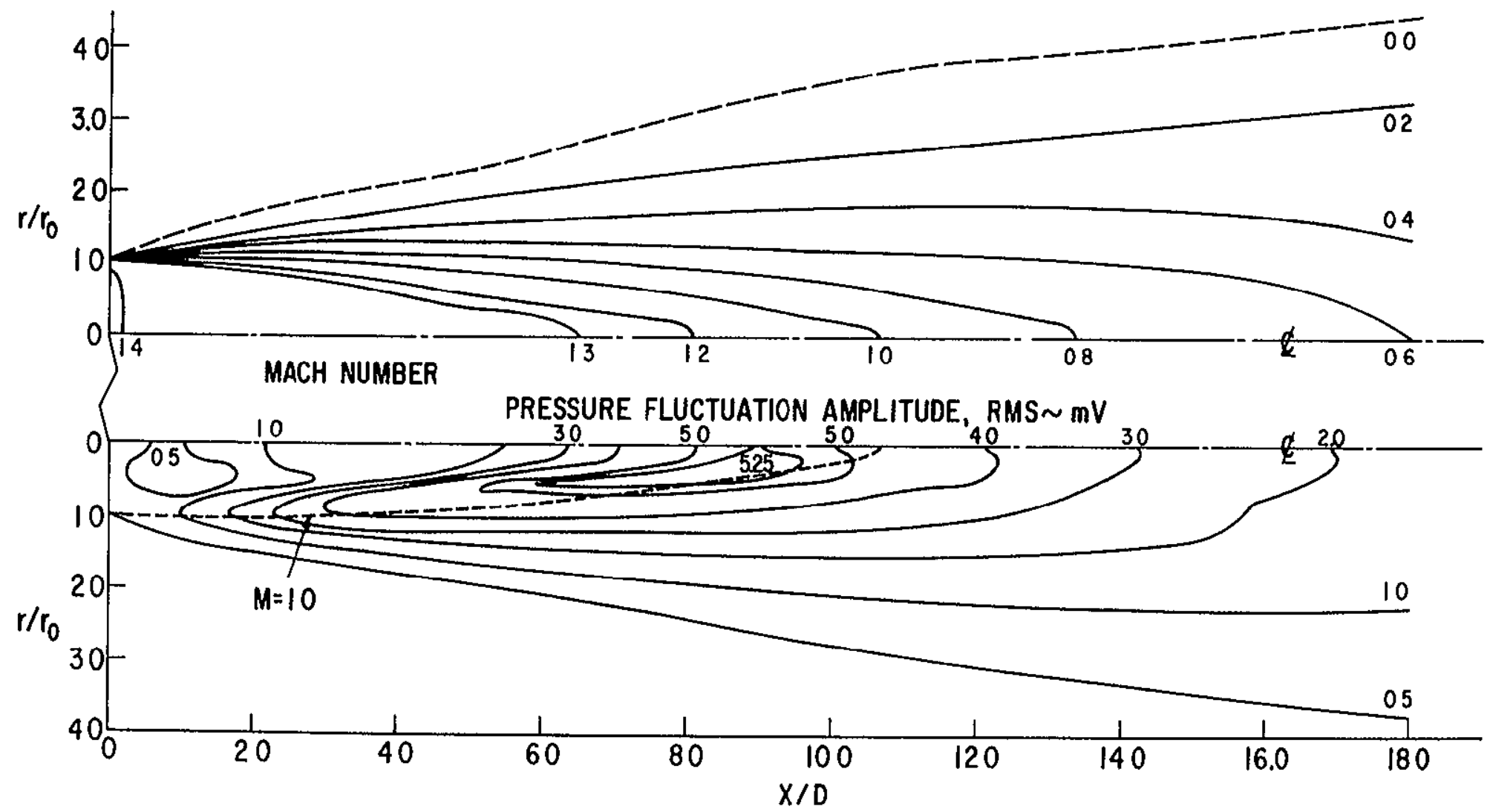

FIG.90 CONSTANT MACH NUMBER AND PIEZOELECTRIC PRESSURE FLUCTUATION CONTOURS IN THE FLOW FIELD FROM A ONE INCH CONVERGENT NOZZLE, $M_{j} \approx 14$ 


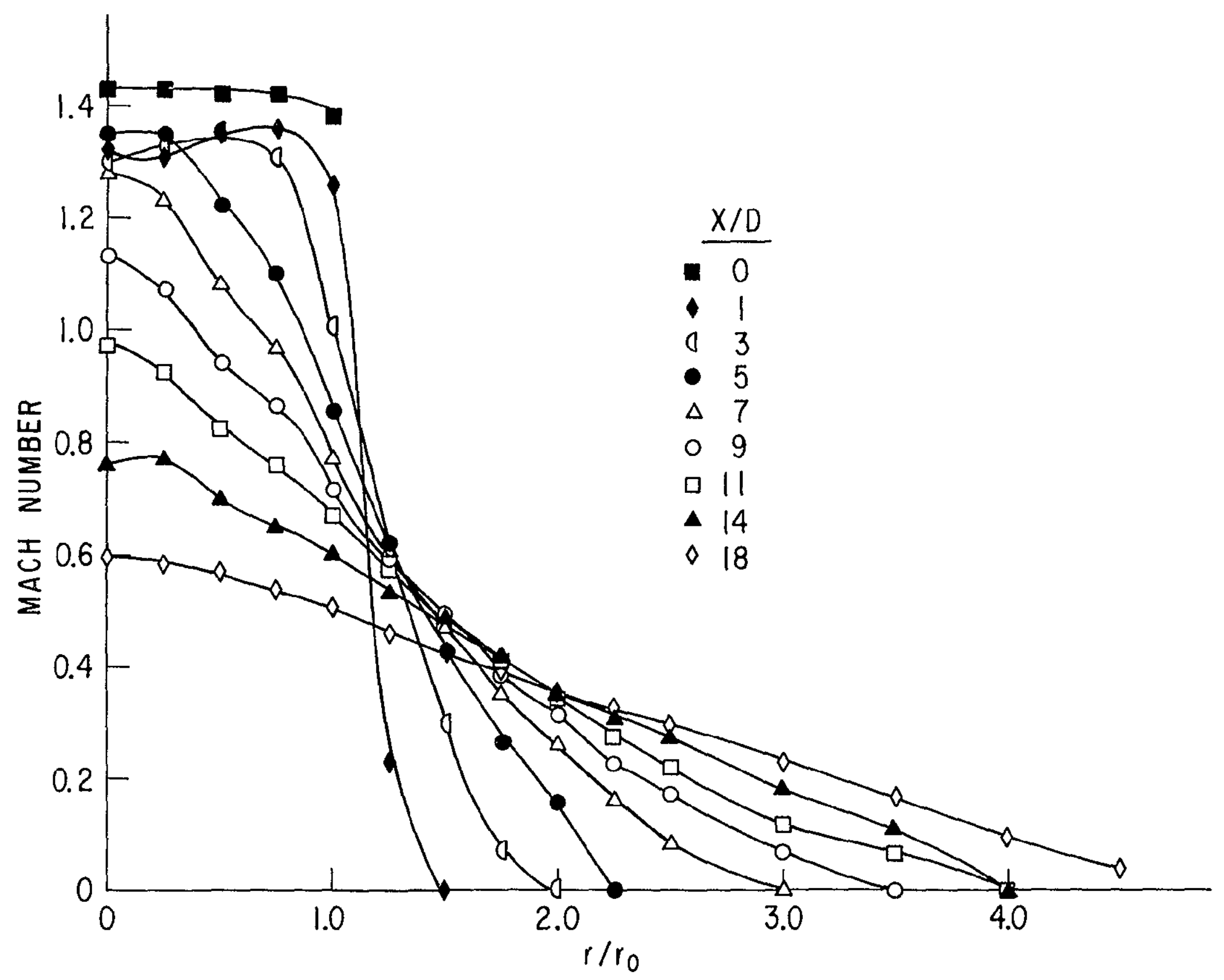

FIG.9b-MACH NUMBER PROFILES ACROSS THE EXIT OF A ONE INCH DIAMETER CONVERGENT NOZZLE AT DIFFERENT DISTANCES FROM THE NOZZLE EXIT, $M_{i} \approx 1.4$ 


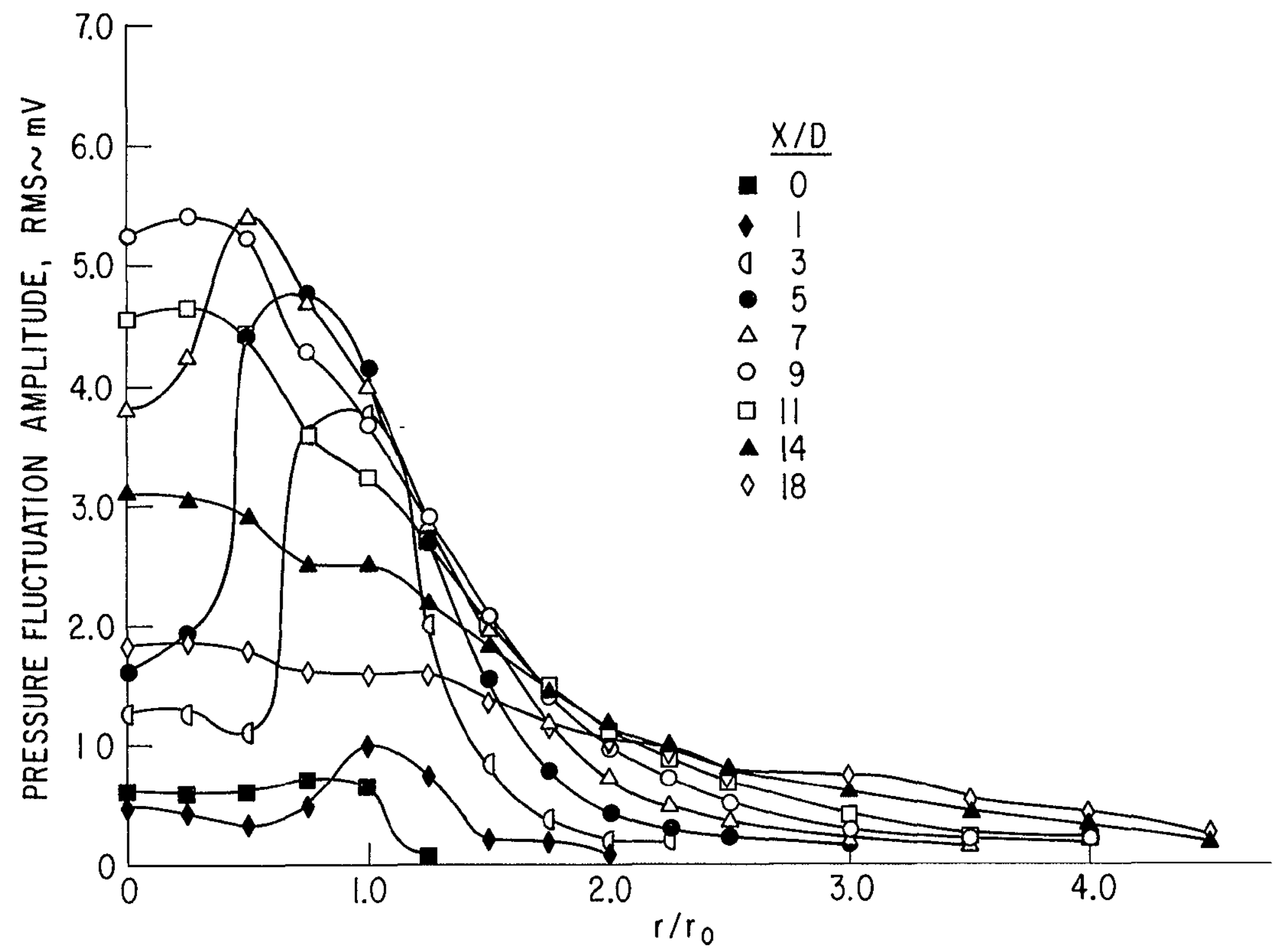

FIG. 9C PIEZO ELECTRIC PRESSURE FLUCTUATION PROFILES ACROSS THE EXIT OF A ONE INCH DIAMETER CONVERGENT NOZZLE AT DIFFERENT DISTANCES FROM THE NOZZLE EXIT, $M_{j} \approx 1.4$ 


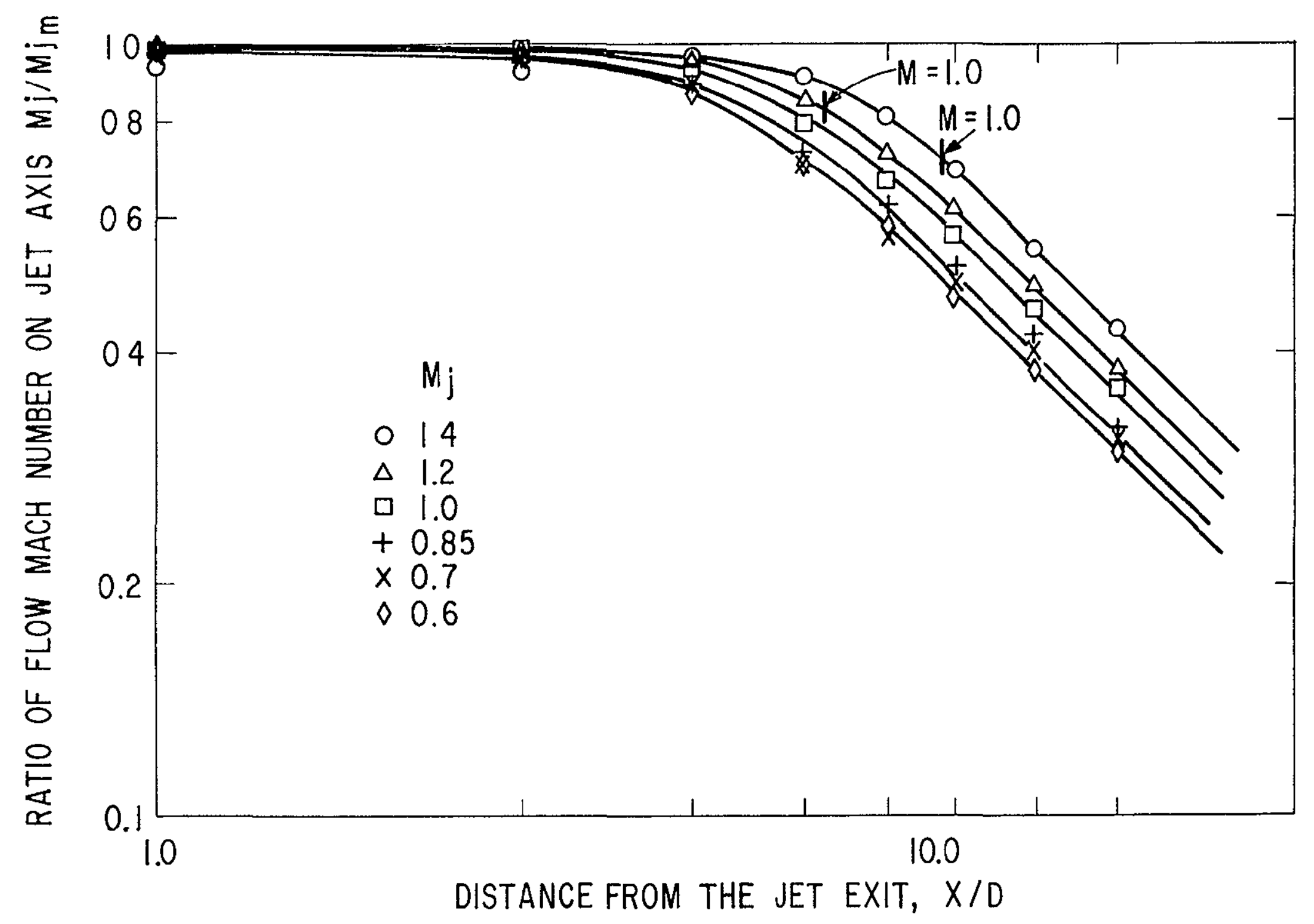

FIG. Ila FLOW MACH NUMBER RATIO ON JET AXIS FOR ONE INCH DIAMETER CONVERGENT NOZZLE. 


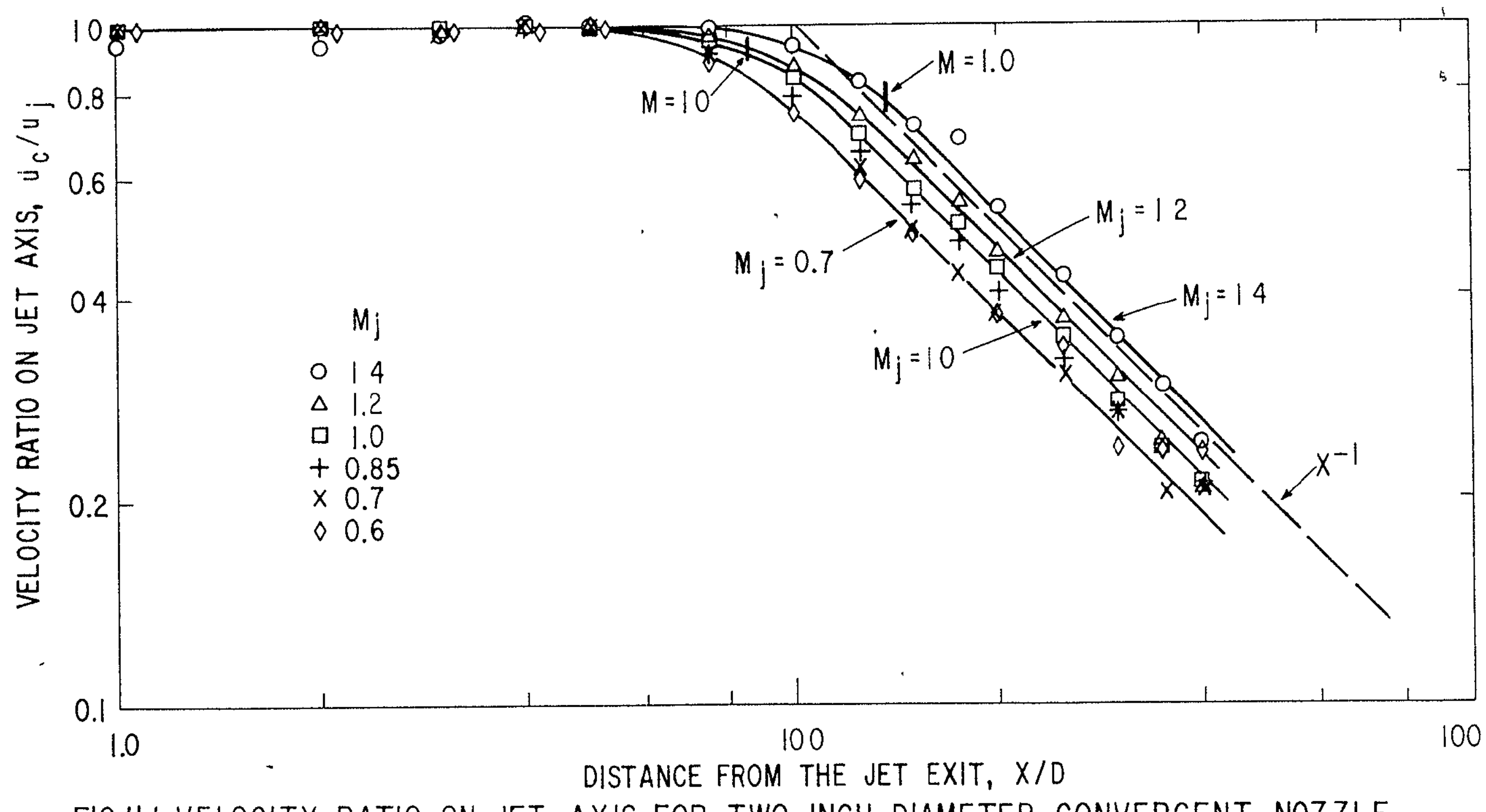

FIG.II b VELOCITY RATIO ON JET AXIS FOR TWO INCH DIAMETER CONVERGENT NOZZLE. 


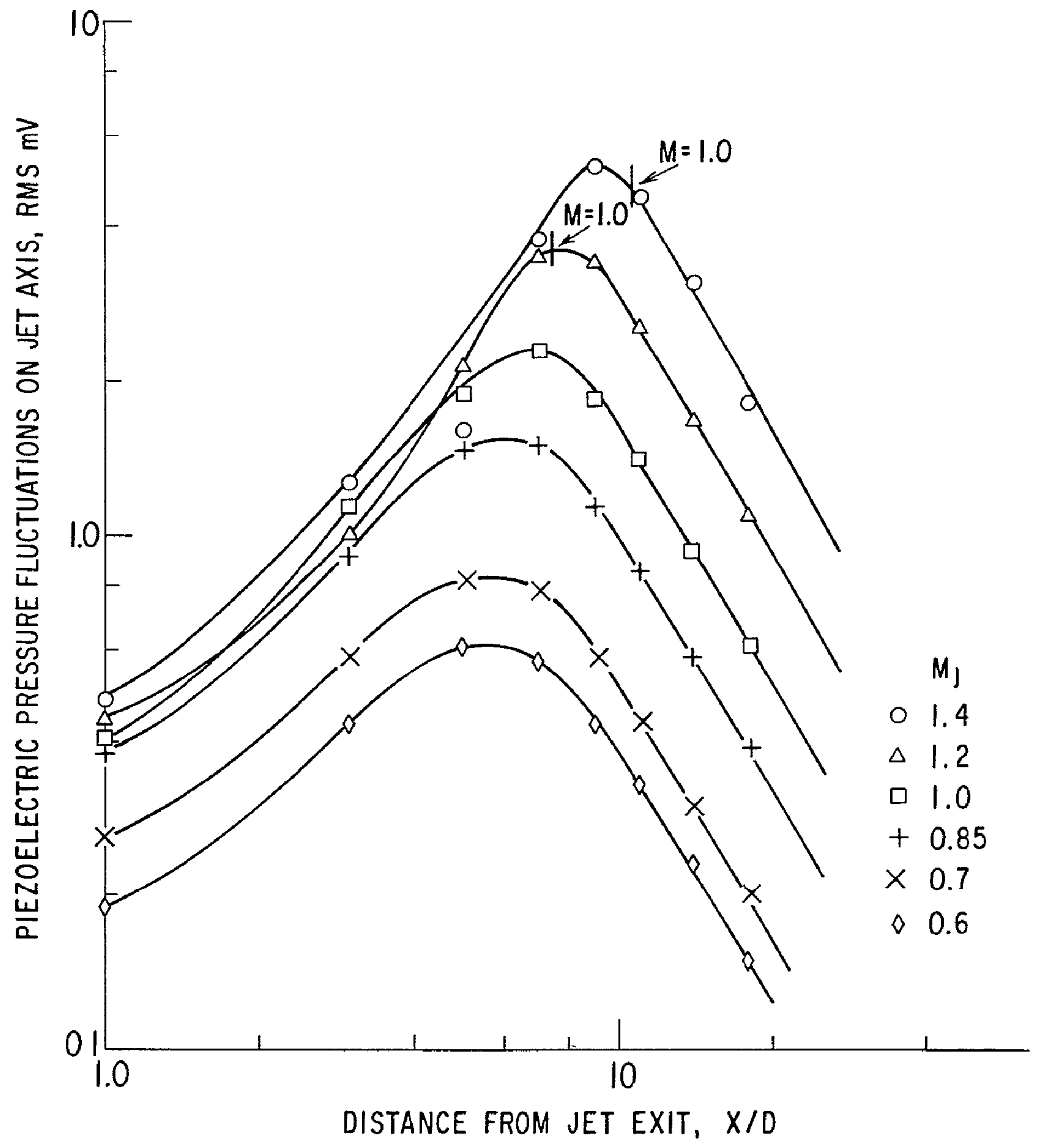

FIG I2 a VARIATION OF PIEZOELECTRIC PRESSURE FLUCTUATIONS ON JET AXIS WITH DISTANCE FROM JET EXIT FOR ONE INCH DIAMETER CONVERGENT NOZZLE 


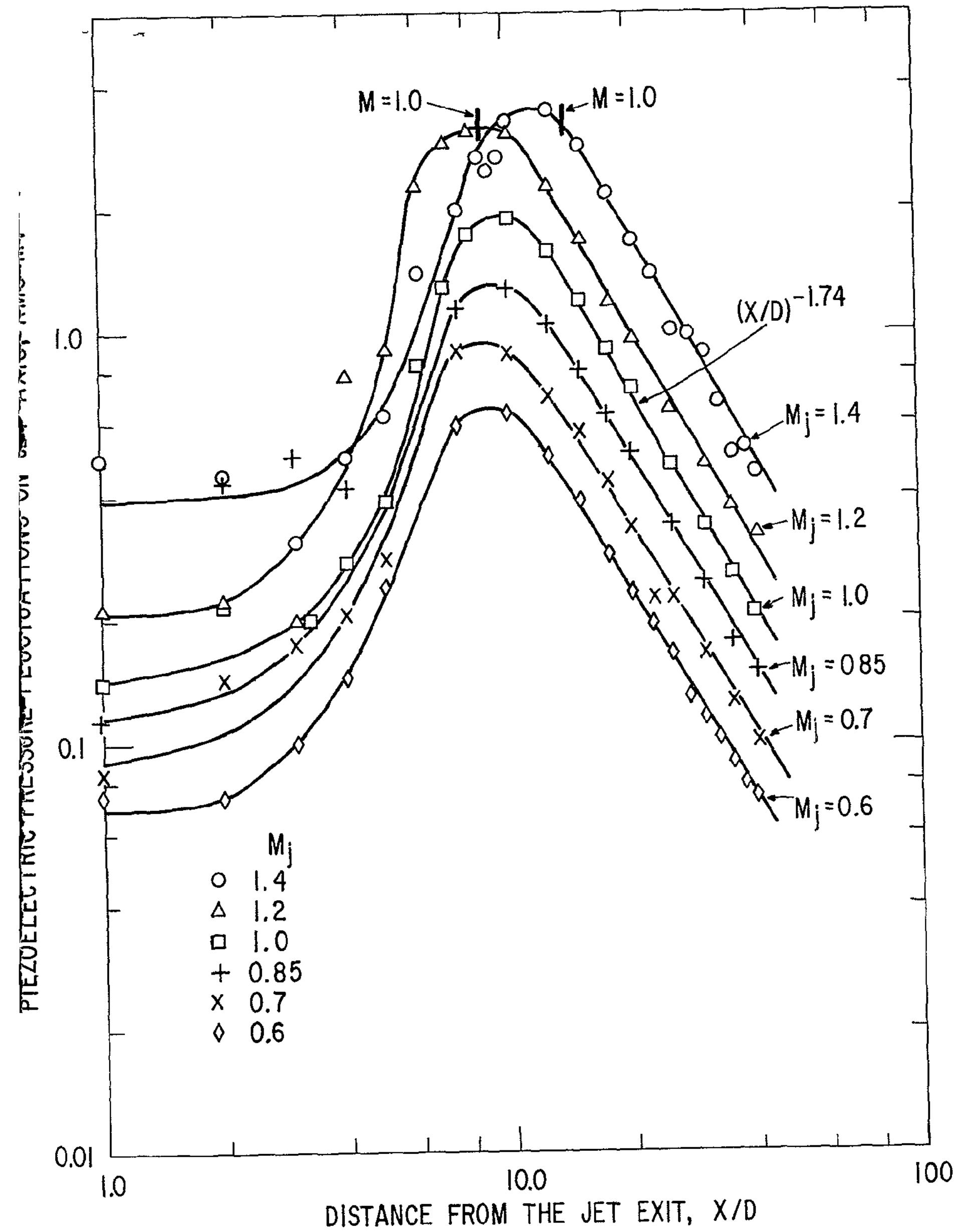

FIG. I2b VARIATION OF IMPACT PRESSURE FLUCTUATIONS ON JET AXIS WITH DISTANCE FROM JET EXIT FOR TWO INCH DIAMFTER CONVERGENT NOZZLE. 


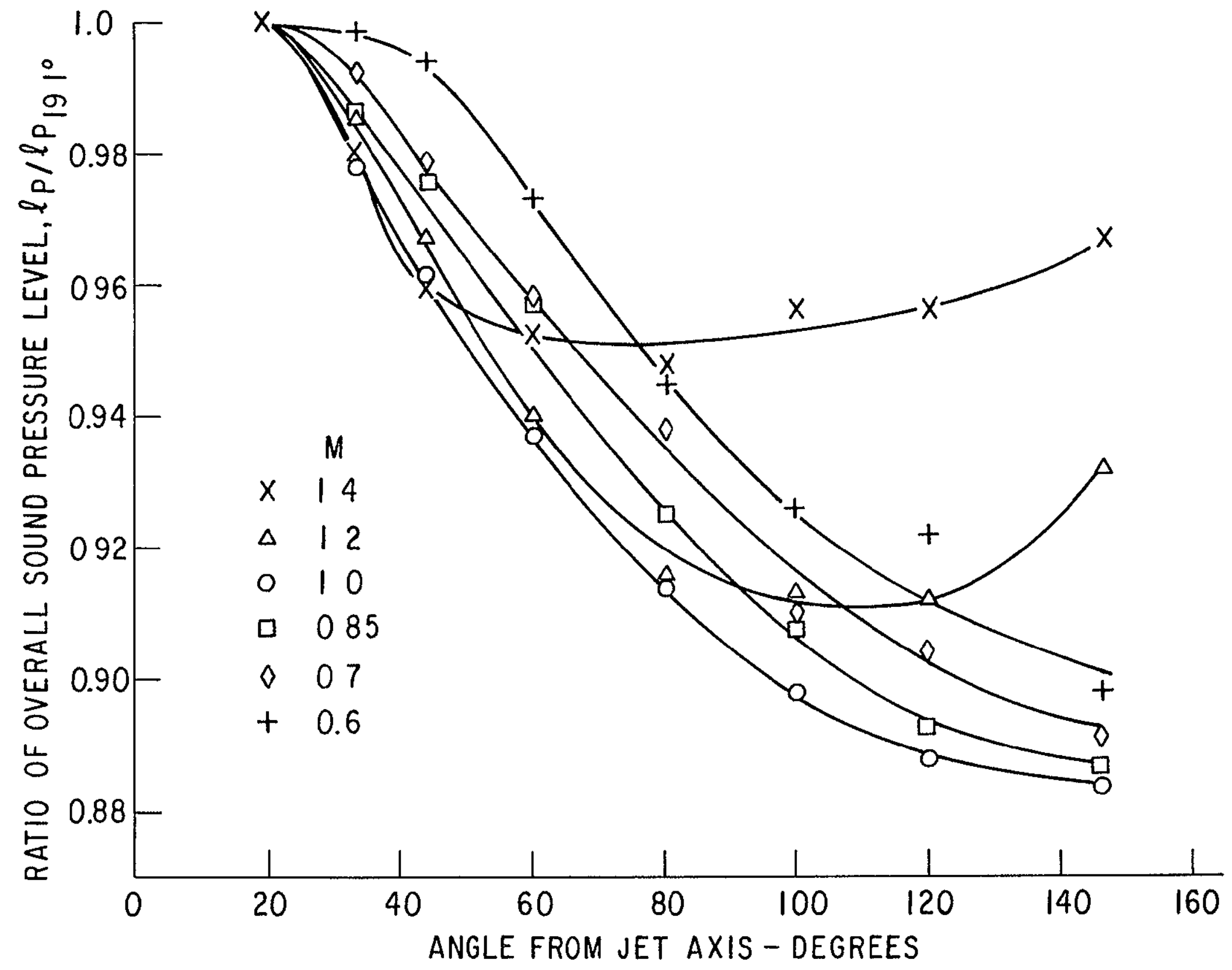

FIG I3 NORMALIZED OVERALL SOUND PRESSURE LEVEL AS A FUNCTION OF ANGULAR POSITION FROM JET AXIS FOR TWO INCH DIAMETER CONVERGENT NOZZLE 


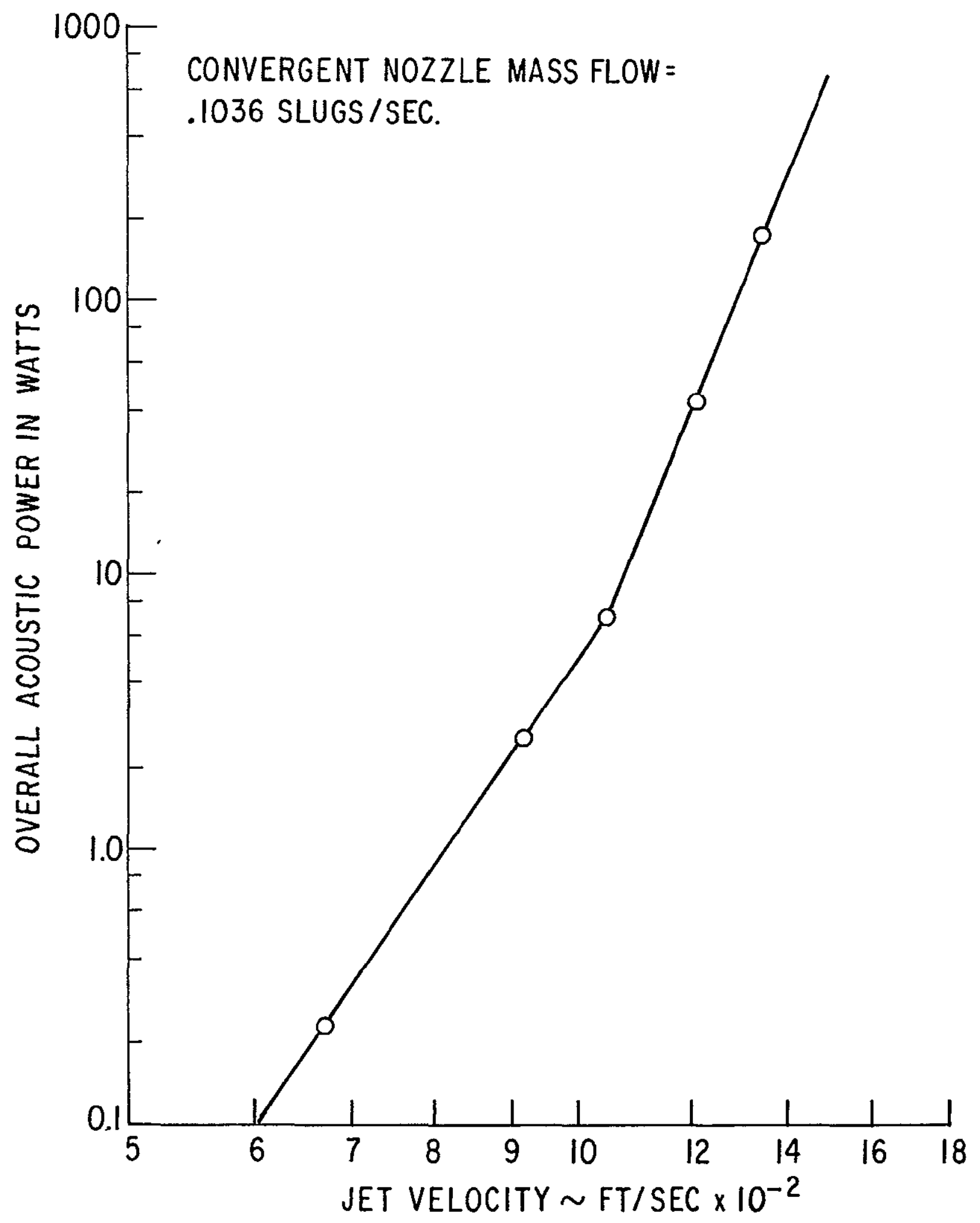

FIG I5 OVERALL SOUND POWER LEVEL IN WATTS FOR CONSTANT MASS FLOW AS FUNCTION OF JET VELOCITY. 
